\title{
EFFECT OF HYPERTENSION ON THE DEVELOPMENT OF DIABETIC CARDIOMYOPATHY
}

\author{
by \\ DAVID R. MATHIS \\ B.Sc., McMaster University, 1995 \\ A THESIS SUBMITTED IN PARTIAL FULFILLMENT OF \\ THE REQUIREMENTS FOR THE DEGREE OF \\ MASTER OF SCIENCE \\ in \\ THE FACULTY OF GRADUATE STUDIES \\ Faculty of Pharmaceutical Sciences \\ Division of Pharmacology and Toxicology
}

We accept this thesis as conforming

to the required standard

THE UNIVERSITY OF BRITISHH COLUMBIA

April, 1999

(C) Dave Mathis, 1999 
In presenting this thesis in partial fulfilment of the requirements for an advanced degree at the University of British Columbia, I agree that the Library shall make it freely available for reference and study. I further agree that permission for extensive copying of this thesis for scholarly purposes may be granted by the head of my department or by his or her representatives. It is understood that copying or publication of this thesis for financial gain shall not be allowed without my written permission.

Department of Pharmacenticul Science

The University of British Columbia

Vancouver, Canada

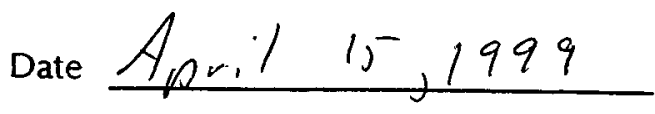




\section{ABSTRACT}

The general objective of this thesis was to examine whether or not hypertension exacerbated the development of diabetic cardiomyopathy. Previous reports in the literature support the idea that hypertension and diabetes have an additive effect and impair cardiac performance to a greater extent than does diabetes alone. However, recent evidence suggests that the rodent model of hypertension used in these studies (the Spontaneously Hypertensive Rat (SHR)) is more sensitive to the diabetogenic effects of streptozotocin (STZ) than other strains. Because the same dose of STZ was used for both hypertensive and control rats, the possibility exists that the increased cardiac dysfunction reported in the diabetic-SHR was due to a more severe diabetic condition. To study this possibility, the dose of STZ was titrated so that an equivalent level of diabetes could be induced in both SHR and Wistar control rats, thereby allowing for the examination of the influence of hypertension on the progression of diabetic cardiomyopathy.

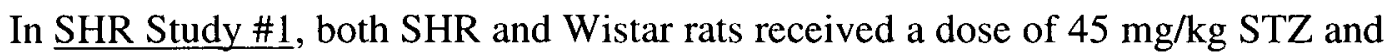
were maintained for twelve weeks of diabetes before cardiac function was studied using the isolated working heart technique. The induction of diabetes depressed weight gain in the SHR while in the Wistar-diabetic (WD) group weight gain was not significantly attenuated. Food and fluid consumption were elevated in both diabetic groups, but was significantly higher in the SHR-diabetic (SD) animals. These data, coupled with the fact that over $70 \%$ of SHR became diabetic compared to only $40 \%$ of the Wistar rats, indicated that the SHR were more sensitive to the diabetogenic effects of STZ. Cardiac contractile function was analyzed in terms of left ventricular developed pressure (LVDP), rate of contraction $(+\mathrm{dP} / \mathrm{dt})$, and rate of relaxation $(-\mathrm{dP} / \mathrm{dt})$ when the rats were twenty weeks of age. At the higher left atrial filling pressures, the SD had depressed cardiac 
function. However, the same dose of STZ in the WD group resulted in no impairment of cardiac performance. Two main conclusions were made from this study. The first was that SHR were more susceptible to the diabetogenic effects of STZ because, even at a low dose, STZ induced diabetes in the majority of SHR. In the Wistar rat, the same dose results in diabetes in only a small percentage of animals. The study also confirmed that a dose of $45 \mathrm{mg} / \mathrm{kg}$ in the SHR results in the development of cardiac dysfunction.

In SHR Study \#2 and SHR Study \#3, the objective was to examine the effect of hypertension on the progression of diabetic cardiomyopathy. To that end, SHR were injected with $45 \mathrm{mg} / \mathrm{kg} \mathrm{STZ}$ either before ( 8 weeks of age) or after (12 weeks of age) the development of hypertension and compared to normotensive Wistar rats made diabetic with $55 \mathrm{mg} / \mathrm{kg} \mathrm{STZ}$. In both studies, the induction of diabetes resulted in depressed weight gain and increased food and fluid consumption. For the rats injected at eight weeks of age, an oral glucose tolerance test (OGTT) demonstrated that the SD rats were significantly less diabetic than the WD rats, yet the degree of cardiac dysfunction was equivalent in both strains.

Injecting the SHR at twelve weeks of age increased the severity of the diabetic condition compared the rats injected at eight weeks of age. This was demonstrated by a greater glucose area under the curve (AUC), lower insulin AUC and elevated plasma lipid levels in the rats injected at the older age. Surprisingly, the heart function of the SD rats was not significantly different from the non-diabetic SHR control rats. Injecting the WD at the older age also increased the diabetic condition, but opposite to the SD animals, still impaired cardiac performance. The development of LV hypertrophy at the time of STZ injection may have prevented or compensated for the damaging effects of diabetes on the myocardium, thereby enabling the heart to perform normally. 


\section{TABLE OF CONTENTS}

\section{PAGE}

$\begin{array}{lc}\text { ABSTRACT } & \text { ii } \\ \text { TABLE OF CONTENTS } & \text { iv } \\ \text { LIST OF TABLES } & \text { vi } \\ \text { LIST OF FIGURES } & \text { vii } \\ \text { LIST OF ABBREVIATIONS } & \text { ix } \\ \text { ACKNOWLEDGEMENTS } & \mathrm{x}\end{array}$

\section{INTRODUCTION}

I. Diabetes Mellitus

A. The Pancreas and the History of Diabetes Mellitus 1

B. Classification of Diabetes Mellitus 2

1. Type 1 Diabetes

2. Type 2 Diabetes

C. Chronic Diabetes and Cardiovascular Complications

1. Clinical Presentation of Diabetic Cardiomyopathy

2. Cardiomyopathy in Experimental Diabetes

3. Subcellular Defects in the Diabetic Heart

II. Hypertension and Diabetes Mellitus

A. Clinical Presentation of Hypertension in Diabetic Patients 12

B. Animal Studies in Combined Hypertension-Diabetes 15

III. Experimental Models of Diabetes and Hypertension

A. Induction of Experimental Diabetes 18

B. The Spontaneously Hypertensive Rat 19

IV. Rationale for the Proposed Experiments 21 


\section{MATERIALS AND METHODS}

I. Materials
A. Chemicals
25
B. Assay Kits

II. Methods

A. Experimental Protocols

1. SHR Study \#1

2. SHR Study \#2

3. SHR Study \#3

B. Induction of Diabetes

C. Blood Pressure Measurement

D. Working Heart Perfusion and Analysis of

E. Oral Glucose Tolerance Test (OGTT)

F. Pancreatic Insulin Content

G. Statistical Analysis

\section{RESULTS}

I. SHR Study \#1 34

II. SHR Study \#2 and SHR Study \#3 36

$\begin{array}{ll}\text { DISCUSSION } & 65\end{array}$

$\begin{array}{ll}\text { CONCLUSIONS } & 88\end{array}$

$\begin{array}{lr}\text { REFERENCES } & 89\end{array}$ 


\section{니ST OF TABLES}

PAGE

Table 1 Classification of Diabetes Mellitus 4

Table 2. Week-Eight Fasted Plasma Glucose and Insulin Concentrations 45 in Animals in SHR Study \#1

Table 3. Percentage of SHR and Wistar Rats Remaining Diabetic 46 After Receiving $45 \mathrm{mg} / \mathrm{kg} \mathrm{STZ}$

Table 4. Termination Plasma Values for Several Indices of Diabetes 47 For the Rats in SHR Study \#1

Table 5. Physical Characteristics of the Rats in SHR Study \#1 at 48 Termination

Table 6. Comparison of Systolic blood Pressure in SHR Using Direct 52 Cannulation and Indirect Tail-Cuff Methods

Table 7. Percentage of SHR and Wistar Rats Remaining Diabetic at 58 Termination

Table 8. Termination Glucose, Insulin and Triglyceride Concentrations 59 in Rats Injected with STZ Before and After the Development of Hypertension

Table 9. Physical Characteristics at Termination of the Rats Injected with STZ Before and After the Development of Hypertension

Table 10. Summary of the Functional, Morphological, Metabolic, and Membrane Changes due to Chronic Diabetes 


\section{LIST OF FIGURES}

PAGE

Figure 1. Effect of Diabetes on: A) Weight Gain, and B) Systolic

Blood Pressure in SHR and Wistar Rats Injected with $45 \mathrm{mg} / \mathrm{kg} \mathrm{STZ}$

Figure 2. Effect of Diabetes on: A) Food, and B) Fluid Consumption in SHR and Wistar Rats Injected with $45 \mathrm{mg} / \mathrm{kg} \mathrm{STZ}$

Figure 3. Distribution of Glucose Concentrations in the WD Group After a Five-Hour Fast

Figure 4. Effect of Diabetes and Hypertension on: A) Left Ventricular

Developed Pressure (LVDP), B) Rate of Contraction (+dP/dt), and C) Rate of Relaxation (-dP/dt) of Isolated Perfused Working Hearts

Figure 5. Expression of: A) Left Ventricular Developed Pressure (LVDP),

B) Rate of Contraction (+dP/dt), and C) Rate of Relaxation $(-\mathrm{dP} / \mathrm{dt})$ in Terms of Percent Increase from the Lowest Left Atrial Filling Pressure

Figure 6. Systolic Blood Pressure of SHR and Wistar Rats Injected with

STZ: A) Before, and B) After the Development of Hypertension

Figure 7. Body Weight of SHR and Wistar Rats Injected with STZ at:

A) Eight Weeks of Age, and B) Twelve Weeks of Age

Figure 8. Food Consumption per Kilogram of Body Weight of SHR and

Wistar Rats Injected with STZ at: A) Eight Weeks of Age, and

B) Twelve Weeks of Age

Figure 9. Fluid Consumption per Kilogram of Body Weight of SHR and Wistar Rats Injected with STZ at: A) Eight Weeks of Age, and B) Twelve Weeks of Age

Figure 10. Plasma A) Glucose, and B) Insulin Levels of Overnight-Fasted SHR and Wistar Rats Injected with STZ at Eight Weeks of Age

Figure 11. Plasma A) Glucose, and B) Insulin Levels of Overnight-Fasted SHR and Wistar Rats Injected with STZ at Twelve Weeks of Age

Figure 12. Pancreatic Insulin Content of Diabetic and Hypertensive Rats Injected with STZ Before the Development of Hypertension 
PAGE

Figure 13. Effect of Hypertension and Diabetes on: A) Left Ventricular Developed Pressure (LVDP), B) Rate of Contraction (+dP/dt), and C) Rate of Relaxation (-dP/dt) of Isolated Perfused Working Hearts. SHR Received 45mg/kg STZ and Wistar Received $55 \mathrm{mg} / \mathrm{kg} \mathrm{STZ}$ at Eight Weeks of Age

Figure 14. Expression of: A) Left Ventricular Developed Pressure (LVDP),

B) Rate of Contraction (+dP/dt), and C) Rate of Relaxation $(-\mathrm{dP} / \mathrm{dt})$ in Terms of Percent Increase from the Lowest Left Atrial Filling Pressure. SHR Received $45 \mathrm{mg} / \mathrm{kg} \mathrm{STZ}$ and Wistar Received $55 \mathrm{mg} / \mathrm{kg} \mathrm{STZ}$ at Eight Weeks of Age

Figure 15. Effect of Hypertension and Diabetes on: A) Left Ventricular Developed Pressure (LVDP), B) Rate of Contraction (+dP/dt), and C) Rate of Relaxation (-dP/dt) of Isolated Perfused Working Hearts. SHR Received $45 \mathrm{mg} / \mathrm{kg} \mathrm{STZ}$ and Wistar Received $55 \mathrm{mg} / \mathrm{kg} \mathrm{STZ}$ at Twelve Weeks of Age

Figure 16. Expression of: A) Left Ventricular Developed Pressure (LVDP), 66 B) Rate of Contraction $(+\mathrm{dP} / \mathrm{dt})$, and C) Rate of Relaxation $(-\mathrm{dP} / \mathrm{dt})$ in Terms of Percent Increase from the Lowest Left Atrial Filling Pressure. SHR Received $45 \mathrm{mg} / \mathrm{kg} \mathrm{STZ} \mathrm{and} \mathrm{Wistar} \mathrm{Received}$ $55 \mathrm{mg} / \mathrm{kg} \mathrm{STZ}$ at Twelve Weeks of Age 


\section{LIST OF ABBREVIATIONS}

\begin{tabular}{|c|c|}
\hline$+\mathrm{dP} / \mathrm{dt}$ & Rate of left ventricular pressure development \\
\hline$-\mathrm{dP} / \mathrm{dt}$ & Rate of left ventricular pressure decline \\
\hline ANOVA & Analysis of variance \\
\hline $\mathrm{AUC}_{\mathrm{g}}$ & Area under the curve of plasma glucose response during an OGTT \\
\hline $\mathrm{AUC}_{\mathrm{i}}$ & Area under the curve of plasma insulin response during an OGTT \\
\hline $\mathrm{BP}$ & Blood pressure \\
\hline $\mathrm{C}-\mathrm{K}$ & Chenoweth-Koelle \\
\hline $\mathrm{H}-\mathrm{D}$ & Hypertension and Diabetes \\
\hline i.p. & Intraperitoneal \\
\hline LV & Left ventricle \\
\hline LVH & Left ventricular hypertrophy \\
\hline LVDP & Left ventricular developed pressure \\
\hline $\mathrm{mg}$ & milligrams \\
\hline $\mathrm{mmHg}$ & millimetres of mercury \\
\hline OGTT & Oral glucose tolerance test \\
\hline RIA & Radioimmunoassay \\
\hline RV & Right ventricle \\
\hline $\mathrm{SC}$ & SHR control \\
\hline $\mathrm{SD}$ & SHR diabetic \\
\hline SEM & Standard error of the mean \\
\hline SHR & Spontaneously hypertensive rat \\
\hline STZ & Streptozotocin [2-deoxy-2-(3methyl-3-nitrosourea) 1-D-glucopyranose] \\
\hline$\mu$ & micro \\
\hline WC & Wistar control \\
\hline WD & Wistar diabetic \\
\hline WKY & Wistar-Kyoto rat \\
\hline$\left[\mathrm{Ca}^{++}\right]_{\mathrm{i}}$ & Intracellular calcium concentration \\
\hline
\end{tabular}




\section{ACKNOWLEDGEMENTS}

I would like to thank Dr. John H. McNeill for all of the guidance, support, knowledge and humour he has shown me over the course of my graduate studies.

Thank you to Mary Battell for always making sure the lab was managed most efficiently, and especially to Violet Yuen and Erika Vera for all they taught me and for answering my many questions.

The members of my supervisory committee deserve a great amount of thanks for the valuable suggestions and constructive criticisms they gave.

Thanks are also given to all of the members of the McNeillian lab for their friendship throughout the years.

I would also like to express my gratitude to the Heart and Stroke Foundation of B.C. and Yukon for the financial support they provided me during my graduate studies. 


\section{INTRODUCTION}

\section{DIABETES MELLITUS}

\section{A. THE PANCREAS AND THE HISTORY OF DIABETES MELLITUS}

The pancreas, a large glandular organ located just beneath the stomach, is responsible for the secretion of several important hormones and digestive enzymes. It is composed of two major types of tissues: 1) the acini, which secrete digestive juices into the duodenum and forms approximately $98 \%$ of the organ, and 2) the islets of Langerhans, small clusters of endocrine tissue dispersed throughout the acinar tissue. In the human pancreas there are 1 to 2 million islets, each of which is composed of four major types of cells. The $\beta$-cell, making up $60 \%-80 \%$ of all islet cells, secretes insulin whereas the $\alpha$-cell, about $15 \%-25 \%$ of the total, secretes glucagon. The $\delta$-cells (10\% of the total) release somatostatin whereas the PP-cell is present in small numbers and releases pancreatic polypeptide (Guyton and Hall, 1996; Kloppel and In't Veld, 1997).

Within the last century great strides have been made in understanding the role of the pancreas and the pathophysiological consequences of diseases associated with this organ. The morphological characteristics of the pancreas were first documented in 1869 by the German medical student Paul Langerhans who noted that the pancreas was composed of two distinct groups of cells. The connection between the pancreas and diabetes was established by Minkowski and von Mering (1889) when they showed that pancreatectomized dogs exhibited characteristics similar to human diabetes mellitus (Pyke, 1997). The successful extraction of insulin from the pancreatic $\beta$-cells by Banting and Best in 1921 and the treatment of 14 year old Leonard Thompson (Banting et al, 
1922) has proven to be one of the great medical triumphs of this century. What was once a slow, agonizing death could now be controlled, so long as the patients regularly took their daily injections of insulin. Interestingly, it was not until 1965 that newly diagnosed insulin-dependent diabetic patients were shown to have specific $\beta$-cell abnormalities along with inflammatory cell infiltration (Gepts, 1965). Further investigations found that Type 1 diabetes was the result of complete and specific degradation and loss of the pancreatic $\beta$-cells (Foulis and Stewart, 1984).

The existence of a second form of clinical diabetes (Type 2 diabetes, then termed insulin-insensitive diabetes) was first documented in 1936 (Himsworth, 1936). The majority of diabetic patients are grouped into this category, which is characterized by normal or elevated levels of the circulating insulin (Yalow and Berson, 1960). It became evident that diabetes exists in several forms that have a distinct clinical presentation, etiology, and therapeutic requirement. Thus, diabetes mellitus is the name given to a group of disorders characterized by hyperglycemia and the dysregulation of carbohydrate, fat and protein metabolism due to either an absolute insulin deficiency and/or lack of insulin action.

\section{B. CLASSIFICATION OF DIABETES MELLITUS}

In early 1995, the American Diabetes Association (ADA) revised the classification scheme that was originally developed in 1979 by the National Diabetes Data Group (NDDG). The new system is soundly based on the etiology of both major forms of diabetes, and contains many of the concepts found in the original classification. The two main categories are still a) Type 1, and b) Type 2 diabetes, although the designations IDDM and NIDDM have been eliminated. The three other categories: 
gestational diabetes, other forms of diabetes, and impaired glucose tolerance (IGT) were retained from the original classification. Table 1 presents the updated classification scheme as well as the characteristics of each major group.

\section{TYPE 1 DIABETES MELLITUS}

Type 1 diabetes is characterized by absolute insulin deficiency due to pancreatic $\beta$-cell destruction, requiring the subject to depend on exogenous insulin for survival. There is a high degree of geographic variation in the incidence of this disease as well as marked variation within racial groups (LaPorte et al, 1985; Karvonen et al, 1993; Sekikawa and LaPorte, 1997). The development of Type 1 diabetes is the result of an autoimmune process that selectively targets and destroys the pancreatic $\beta$-cells while leaving the other islet cells intact (Eisenbarth, 1986). Autoantibodies directed against the B-cell (Bottazzo et al, 1980), insulin (Palmer et al, 1983) and glutamic acid decarboxylase (GAD) (Kaekkeskov et al, 1990) are found in up to $90 \%$ of Type 1 patients (DeFronzo, 1998). The autoantibodies may exist several years prior to the presentation of clinical diabetes (Ziegler et al, 1990). In addition, certain human leukocyte antigens (HLA) are associated with an increased risk of developing Type 1 diabetes (Nerup et al, 1974). The HLA are molecules whose genes are encoded within the major histocompatibility complex (MHC) on chromosome 6 (Cavan et al, 1997) and are involved with the presentation of antigens to $\mathrm{CD} 4+$ (helper) $\mathrm{T}$ cells. It has been suggested that the HLA molecules may be more effective in binding a diabetogenic antigen or interacting with the T-cell receptor, thus increasing the probability of an 
Table 1. Classification of Diabetes Mellitus

NEW

\section{CLASSIFICATION}

1) Type 1 Diabetes Mellitus

A) Autoimmune

B) Idiopathic
2) Type 2 Diabetes Mellitus

A) Nonobese

B) Obese

3) Other Specific Types of Diabetes

4) Gestational Diabetes Mellitus (GDM)

5) Impaired Glucose Tolerance (IGT) and Impaired Fasting Glucose (IFG)

- Deleted in the updated classification (Adapted from DeFronzo, 1998)

\section{FORMER \\ CLASSIFICATION}

Type I Diabetes Mellitus

or

Insulin-Dependent
Diabetes Mellitus (IDDM)*
Type II Diabetes Mellitus

or

Non-Insulin-Dependent

Diabetes Mellitus (NIDDM) *

A) Nonobese

B) Obese
Other Types of Diabetes
Impaired Glucose

Tolerance (IGT)

\section{CHARACTERISTICS}

$10 \%$ of all Diabetics

Any age but mostly young

Requires exogenous insulin injections

Ketosis prone

Autoimmune form

Genetic predispostion

HLA locus

Autoantibodies to

$\beta$-cell

Insulin

$\mathrm{GAD}_{65}$

Idiopathic form

Strongly inherited

Not HLA associated

90-95\% of Diabetics

Usually over 40 years of age

Endogenous insulin may be normal or elevated

May require insulin

Insulin resistant

Rarely ketotic

Majority are obese at diagnosis

Strong genetic predisposition

Genetic syndromes

Diseases of the pancreas

Chemical-induced diabetes

Gestational Diabetes Mellitus

Glucose intolerance during pregnancy

In most cases, tolerance normalizes after birth

Blood glucose regulation between normal and diabetic

Many patients are euglycemic with slight insulin resistance 
autoimmune response (Cavan et al, 1997; Nepom, 1990). Although the exact triggering mechanism is unknown at this time, it is obvious that both genetic and immunological factors are involved in predisposing an individual for the development of Type 1 diabetes.

\section{TYPE 2 DIABETES MELLITUS}

In Europid populations, Type 2 subjects account for $80-90 \%$ of the diabetic population (Valle et al, 1997), but in certain ethnic groups it is virtually the only form of diabetes (Zimmet et al, 1990). Obesity is prominent among 50-90\% of all Type 2 patients (Valle et al, 1997), although a portion remains non-obese while exhibiting the clinical symptoms of the disease. The primary defect is hepatic and peripheral insulin resistance offset by compensatory hyperinsulinemia. The clinical presentation of overt Type 2 diabetes occurs when the pancreatic $\beta$-cell fails to secrete sufficient quantities of insulin to overcome the existing insulin resistance (DeFronzo et al, 1997). Genetic factors play an important role in predisposing an individual to Type 2 diabetes, although environmental factors (such as nutrition and exercise) likely modulate the expression of the condition (Taylor et al, 1994; Harris and Zimmet, 1997). In select cases single gene mutations have been shown to cause Type 2 diabetes (Taylor et al, 1994), but in the majority of patients the primary causes have not been clearly established. Several cellular defects have been identified in the insulin receptor and intracellular signaling pathways which may contribute to insulin resistance and lead to overt Type 2 diabetes (see DeFronzo et al, 1997 for a comprehensive review). 


\section{CHRONIC DIABETES AND CARDIOVASCULAR COMPLICATIONS}

Long term diabetes mellitus is associated with a number of chronic complications that have a significant effect on the morbidity and mortality of the patients. The presence of diabetes increases the chance of developing cardiovascular complications by $2-3$ fold (Kannel and McGee, 1979a), and a recent study by Uusitupa et al (1993) showed that diabetics have more than an eight fold higher cardiovascular mortality rate compared to non-diabetics. In fact, it has been suggested that cardiovascular disease may account for up to $80 \%$ of all diabetic deaths (Kannel and McGee, 1979b). Clinical and epidemiological studies have illustrated the fact that diabetes is a risk factor for the development of numerous cardiovascular conditions (Stamler et al, 1993). Diabetics have an increased risk of developing cardiovascular complications such as: retinopathy (Klein and Klein, 1997), nephropathy (Sequist et al, 1989), neuropathy (Mayne, 1965), peripheral vascular disease (Walters et al, 1992), coronary artery disease (CAD) (Nathan et al, 1997), congestive heart failure (CHF) (Kannel et al, 1974), myocardial infarction (MI) (Leitersdorf et al, 1986) and ischemic stroke (Chukwuma and Tuomilehto, 1993).

\section{CLINICAL PRESENTATION OF DIABETIC CARDIOMYOPATHY}

It has been clearly established that diabetes is associated in both men and women with an increased incidence of congestive heart failure (Kannel et al, 1974). It was originally believed that the increase was due to confounding factors such as micro- and macroangiopathy (Ledet et al, 1979), but within the last twenty-five years, compelling evidence has demonstrated the existence of a cardiomyopathy distinct for the diabetic condition. The initial report published by Rubler and colleagues in 1972 was based on the postmortem findings of four adult diabetic patients with renal disease. These patients 
had advanced cardiac failure without pronounced coronary atherosclerosis and, based on the histological features of the hearts, the authors suggested the existence of a diabetic cardiomyopathy secondary to microvascular disease (Rubler et al, 1972).

Numerous studies have examined the pathological changes that occur in the diabetic myocardium (Fein and Sonnenblick, 1985; Fein, 1996). Hamby and colleagues examined the hearts of three diabetic patients with congestive heart failure (but without CAD) and found evidence of myocardial hypertrophy as well as microvascular changes including interstitial and perivascular fibrosis and endothelial proliferation (Hamby et al, 1974). The authors suggested that the microvascular changes in the myocardium might be the cause of the cardiomyopathy. In a second study of diabetic subjects with heart failure, the microvasculature was suggested to have little or no relation to the cardiac pathology (Regan et al, 1977). Instead, the authors attributed the cardiac dysfunction to decreased ventricular compliance brought about by the increased deposition of periodic acid-Schiff (PAS)-positive material in the myocardium (Regan et al, 1977). The PASpositive material was believed to be collagen, which is increased in diabetic rat hearts (Spiro and Crowley, 1993). The increase in PAS-positive material appears before the development of clinical heart failure, evidenced by the increase in PAS-positive vessels in diabetics without CHF. Endothelial proliferation has been reported among diabetic patients (Blumenthal, 1960), as well as a significant thickening of the capillary basement membrane (Fischer et al, 1979). In addition, an autopsy study by Factor and colleagues demonstrated the existence of capillary microaneurysms in diabetic hearts (Factor et al, 1980). Thus, the diabetic heart undergoes several morphological changes including atherosclerosis, hypertrophy, fibrosis (perivascular, interstitial, and replacement), glycoprotein deposition and vascular changes such as basement membrane thickening 
and microaneurysms. Importantly, it has not been clearly determined which of these changes have pathological consequences on the myocardium and are responsible for the contractile dysfunction reported in the diabetic patient.

Numerous reports are available in the literature characterizing the contractile dysfunction in diabetic patients. Both systolic and diastolic dysfunction have been reported (Tischler, 1996), and evidence of cardiomyopathy has been documented in diabetics without overt heart failure (Ahmed et al, 1975; Fisher et al, 1986). Using techniques such as systolic time interval (STI) measurement and M-mode echocardiography, several authors have documented changes in systolic function including a longer pre-ejection period (PEP) and shorter left ventricular ejection time (LVET) (Ahmed et al, 1975; Shapiro et al, 1980, 1981a, 1981b). The PEP/LVET ratio, which corresponds to the LV ejection fraction and is reflective of decreased myocardial contractility or left ventricular filling due to a higher degree of LV stiffness, is increased in diabetics compared to non-diabetics even before the development of overt heart failure (Ahmed et al, 1975). Diabetic subjects have also been shown to have a decreased left ventricular ejection fraction (LVEF) as well as an increased end-systolic volume (Friedman et al, 1982).

In addition to abnormalities in myocardial contractile function, it is evident that there are subsets of diabetic patients who have heart failure with normal systolic function (Dougherty et al, 1984). Diastolic dysfunction refers to the impairment of ventricular relaxation and/or filling, and is one of the first signs of left ventricular dysfunction in both Type 1 and Type 2 diabetics (Zarich et al, 1988; Takenaka et al, 1988). One of the characteristics of diastolic abnormalities in diabetic patients is a prolonged isovolumic 
relaxation time (Uusitupa et al, 1988; Paillole et al, 1989), which has been attributed to an increase in interstitial collagen dèposition (Regan et al, 1977).

\section{CARDIOMYOPATHY IN EXPERIMENTAL DIABETES}

Laboratory animals have been very useful in helping determine the etiology of diabetic cardiomyopathy because most of the morphological and functional abnormalities documented in human diabetic patients occur in animals with chronic diabetes. An increase in interstitial collagen deposition along with diminished diastolic compliance has been documented in several different animal species with diabetes (Regan et al, 1974; Haider et al, 1981; Bhimji et al, 1985). In rats, chronic diabetes results in both systolic and diastolic dysfunction. In insolated heart preparations, impaired left ventricular (LV) function has been characterized as depressed LV pressure development (LVDP) and rates of contraction $(+\mathrm{dP} / \mathrm{dt})$ and relaxation $(-\mathrm{dP} / \mathrm{dt})$ compared to non-diabetic controls (Penpargkul et al, 1980; Vadlamudi et al, 1982; Tahiliani et al, 1983). Isolated papillary muscles and cardiomyocytes from diabetic rats also have impaired contraction and relaxation (Fein et al, 1980; Ren and Davidoff, 1997), suggesting that intracellular changes are involved in the contractile dysfunction. Thus, the development of diabetic cardiomyopathy is likely multi-factorial in origin and results from both morphological changes to the heart along with intracellular defects within the myocyte.

\section{SUBCELLULAR DEFECTS IN THE DIABETIC HEART}

Several subcellular defects, which may be causally related to the progression of cardiac dysfunction, have been reported in the diabetic heart. These include changes to the contractile proteins, sarcoplasmic reticulum (SR), mitochondria and sarcolemma, as well as to several enzymes involved in the metabolism of glucose and fatty acids (Dhalla 
et al, 1996). Dillmann (1980) was the first to report contractile protein defects in the diabetic heart. In this study, the $\mathrm{Ca}^{++}$-ATPase activity of both actomyosin and myosin were found to be depressed in diabetic hearts. This enzyme is responsible for the cleavage of ATP into ADP and $\mathrm{P}_{i}$ and provides the energy required for cross-bridge formation and contractile force development. This change in $\mathrm{Ca}^{++}-\mathrm{ATPase}$ activity was associated with changes in the myosin isoenzyme composition from $\mathrm{V}_{1}$ (which has the highest $\mathrm{Ca}^{++}$-ATPase activity) to $\mathrm{V}_{3}$ (lowest $\mathrm{Ca}^{++}$-ATPase activity) (Dillmann, 1980). The regulatory protein Troponin $T$ also undergoes an isoform shift from $T_{1}$ to $T_{3}$ during diabetes (Akella et al, 1995); this isoform shift is related to altered length-dependent $\mathrm{Ca}^{+}$ sensitivity (Akella et al, 1995; Hoffman et al, 1995).

The regulation of intracellular $\mathrm{Ca}^{++}$is critically important for the precise control of myocardial contractile performance, and alterations in $\mathrm{Ca}^{++}$release and/or sequestration have been implicated in the development of cardiac dysfunction (Yu et al, 1997). The SR membrane system releases and sequesters $\mathrm{Ca}^{++}$on a beat-by-beat basis to support the contraction and relaxation of the myocardium. The SR $\mathrm{Ca}^{++}$-ATPase is the pump responsible for the sequestration of calcium into the SR and its activity has been shown to be depressed in the hearts of diabetic rats (Lopaschuk et al, 1983). These alterations in calcium regulation are correlated with a slower rate of relaxation and may account for the diastolic dysfunction described earlier (Penpargkul et al, 1981). In addition, insufficient replenishment of the $\mathrm{Ca}^{++}$stores limits the amount of $\mathrm{Ca}^{++}$released from the SR for the next contraction, thereby limiting force development and consequently systolic function.

The sarcolemma contains several important pumps and transporters that are either directly or indirectly involved in intracellular $\mathrm{Ca}^{++}$regulation. Proteins such as the sarcolemmal $\mathrm{Ca}^{++}$-stimulated ATPase (Heyliger et al, 1987), the $\mathrm{Na}^{+} / \mathrm{Ca}^{++}$exchanger 
(Makino et al, 1987), $\mathrm{Na}^{+} / \mathrm{K}^{+}$ATPase (Pierce and Dhalla, 1983) and $\mathrm{Na}^{+}-\mathrm{H}^{+}$exchanger (Pierce et al, 1990) have all been reported to be depressed in the diabetic heart. In addition, there appears to be a decreased receptor density of L-type calcium channels in the sarcolemma (Lee et al, 1992). These proteins transport ions across the sarcolemmal membrane to establish and maintain the electrochemical gradient between extra- and intracellular compartments. When combined with altered SR function, decreased activity of these pumps and exchangers may ultimately result in the inability to adequately remove intracellular $\mathrm{Ca}^{++}$from the cell, and thus lead to elevated intracellular $\mathrm{Ca}^{++}\left[\mathrm{Ca}^{++}\right]_{i}$ levels. These alterations in $\left[\mathrm{Ca}^{+1}\right]_{i}$ regulation may result in a slower rate of relaxation due to depressed removal of $\left[\mathrm{Ca}^{++}\right]_{i}$ and provide an attenuated $\mathrm{Ca}^{++}$release for subsequent contractions (Pierce and Russell, 1997). Thus, both systolic and diastolic function may be affected by impaired $\left[\mathrm{Ca}^{++}\right]_{i}$ regulation. In addition, sustained elevation of $\left[\mathrm{Ca}^{++}\right]_{i}$ could result in $\mathrm{Ca}^{++}$overload and activation of $\mathrm{Ca}^{++}$-sensitive proteases and enzyme cascades that mediate the destruction of the cellular components (Orrenius et al, 1989).

Preceding the morphological, functional and subcellular changes described in the above sections are alterations in myocardial fuel supply and utilization brought about by the lack of insulin action on the heart. In uncontrolled diabetes, cardiac metabolism shifts from a combination of glucose and fatty acid (FA) metabolism to the almost exclusive use of FA as the fuel source (Lopaschuk, 1996). It appears that this alteration in myocardial energy metabolism may be an important contributing factor to the depression in contractile function seen in diabetics. High concentrations of FA have been associated with a depression of cardiac contractile function (Opie, 1970), while interventions which correct the hyperlipidemia improve cardiac function (Rodrigues et al, 1986; Rodrigues et $a l, 1988)$. Elevated fatty acid oxidation can have a detrimental effect on the heart by 
increasing the oxygen requirement for catabolism (compared to glucose oxidation), and by producing fatty acid intermediates (such as acylcarnitine and long chain acyl-CoA) which are toxic to the cell (Rodrigues et al, 1995). These intermediates may have multiple effects on the heart, including: alteration of membrane structure, inhibition of SR and sarcolemmal pumps and exchangers important in $\left[\mathrm{Ca}^{++}\right]_{\mathrm{i}}$ regulation (described above), and inhibition of glucose transport and metabolism (Rodrigues et al, 1995). Increased fatty acid oxidation results in the inhibition of glycolytic enzymes such as phosphofructokinase and the pyruvate dehydrogenase complex that are important in glucose metabolism (Rodrigues et al, 1995). Recently, compounds that either enhance glucose oxidation or inhibit fatty acid oxidation have been shown to improve diabetic heart function (Wall and Lopaschuk, 1989; Nichol et al, 1991). This suggests that improving glucose utilization, and therefore limiting the toxic effects of elevated fatty acid metabolism, may be a viable option in preventing the development of diabetic cardiomyopathy.

\section{HYPERTENSION AND DIABETES MELLITUS}

\section{A. CLINICAL PRESENTATION OF HYPERTENSION IN DIABETIC PATIENTS}

High blood pressure is one of the most common diseases in developed countries and exists in $15-25 \%$ of the adult population (WHO/ISH $\left.{ }^{1}, 1993\right)$. Elevated blood pressure is associated with an increased risk of cardiovascular disease such as stroke and coronary heart disease. This risk increases progressively throughout the entire range of blood pressure values (WHO/ISH, 1993). Hypertension is also one of the leading causes

\footnotetext{
' Guidelines Subcommittee of the WHO/ISH Mild Hypertension Liaison Committee
} 
of CHF in humans. The Framingham study showed that $75 \%$ of all patients with $\mathrm{CHF}$ had a history of hypertension independent of CAD (McGee et al, 1971).

It has been well established in both clinical and population-based studies that hypertension is more prevalent in diabetic subjects than in the non-diabetic population (Fuller, 1985). A recent study re-examined the prevalence of hypertension in diabetics using the updated blood pressure criteria proposed by the JNC- $\mathrm{V}^{2}$ and showed that, on average, $51 \%$ of the Type 1 diabetics and $80 \%$ of the Type 2 diabetics were hypertensive (Tarnow et al, 1994). The risk of cardiovascular disease (CVD)-related death is 2-3 fold greater in patients with both hypertension and diabetes than subjects with either isolated hypertension (at all levels of elevated systolic blood pressure) or diabetes (Fuller et al, 1983; Stamler et al, 1993). All of the CVD subclasses, which includes coronary heart disease (CHD) (angina, CAD, MI, CHF, sudden death), cerebrovascular disease (stroke) and peripheral vascular disease, contribute to the increase risk of CVD morbidity and mortality in diabetic hypertensive patients (Christlieb, 1982; Assmann and Schulte, 1988; Mahler, 1990; $\mathrm{HDSG}^{3}$, 1993; Hoy et al, 1995; Rossing et al, 1996). Microvascular complications such as end-stage renal disease and retinopathy are also accelerated and more frequently observed when diabetic patients are hypertensive (Knowler et al, 1980; Krolewski et al, 1988). Conversely, in long-term diabetic patients free of any chronic complications there is a low prevalence of hypertension (Oakley et al, 1974).

Early pathological studies on the hearts of diabetic patients showed that the coexistence of both hypertension and diabetes resulted in morphological and pathological changes that were more severe than when either condition existed in isolation (Factor $e t$

\footnotetext{
${ }^{2}$ Joint National Committee on the Detection, Evaluation, and Treatment of High Blood Pressure - Fifth Report, 1993.

${ }^{3}$ Hypertension in Diabetes Study Group, 1993
} 
$a l, 1996)$. The initial report by Factor and colleagues was an autopsy study describing the cardiac morphology of nine diabetic patients with congestive heart failure and hypertension (Factor et al, 1980). The hearts of these patients were compared to those of normal individuals and to those with either diabetes or hypertension. Of the four groups, patients with both hypertension and diabetes (H-D) had the greatest left ventricular wall thickness and the heaviest hearts. These hearts also had the greatest degree of myocytolysis and focal scarring as well as areas of microscopic fibrosis. The most prominent feature of the H-D hearts was the diffuse distribution of dense interstitial connective tissue throughout the myocardium. A second autopsy study using a larger number of patients confirmed and extended the observations described above and implicated hypertension as an important factor in the progression of diabetic cardiomyopathy (van Hoeven and Factor, 1990).

Left ventricular anatomy and function have been studied in surviving patients with hypertension and diabetes through the use of noninvasive techniques such as $\mathrm{M}$ mode echocardiography. Using this technique, it has been found that H-D patients have an increased septal wall thickness and posterior wall thickness compared to patients with either isolated hypertension or diabetes (Shapiro et al, 1981; Venco et al, 1987; Grossman et al, 1992). Interestingly, the increase in left ventricular hypertrophy in the H-D group has been reported to occur prior to clinical signs of ischemic heart disease or congestive heart failure (Grossman et al, 1992).

Paralleling the changes in LV thickness and mass in the H-D group is impaired cardiac function. Decreased LV contractility (reflected by the ratio of end-systolic wall stress to end-systolic volume index) was found in H-D patients compared to nondiabetic hypertensive individuals (Grossman et al, 1992). In a study by Shapiro and coworkers 
(1981), left ventricular function was also significantly impaired in diabetic patients with hypertension compared to diabetics with normal blood pressure. Venco and colleagues (1987) reported impaired diastolic function in H-D characterized by a depressed velocity of increase of the LV dimension in early diastole and reduced velocity of thinning of the LV posterior wall. These abnormalities were present in all of the $H-D$ patients monitored in the study, whereas only nine of twenty patients with hypertension alone had abnormal diastolic function (Venco et al, 1987). In a group of Type 1 diabetics with a wide range of systolic blood pressures, there was a positive correlation between diastolic dysfunction, blood pressure and LV mass compared to normotensive, nondiabetic subjects (Danielsen, 1988). The impairment of diastolic function was attributed to the increased stiffness of the left ventricle brought about from the increase in LV mass, fibrotic tissue and deposition of connective tissue. Thus, the development of hypertension in the diabetic individual is associated with an increased severity of morphological and functional changes.

\section{B. ANIMAL STUDIES IN COMBINED HYPERTENSION-DIABETES}

Animal models of hypertension-diabetes have been very useful in helping confirm these observations and in characterizing the effects of hypertension on the diabetic heart under experimental conditions. Using a model of renovascular hypertension (RVH) superimposed with STZ-induced diabetes, Factor and colleagues found that the H-D animals developed cardiac pathology very similar to that previously documented in their human autopsy studies. The diabetic and hypertensive rats had cardiomegaly, extensive interstitial and replacement fibrosis, and myocytolysis significantly greater than what occurred with either isolated condition (Factor et al, 1981). Interestingly, these 
pathological changes occurred in both the left and right ventricle of rats with combined hypertension and diabetes (Fein et al, 1989). Similar morphological changes have also been reported when alloxan was injected into spontaneously hypertensive rats (Hashimoto, 1969). It had been hypothesized that the microvascular changes previously documented in the hearts of diabetic patients (Factor et al, 1980) were intensified in the hearts of H-D subjects and may be the underlying lesion responsible for increased myocardial damage. Injecting a silicone rubber solution into the beating heart of H-D rats revealed numerous areas of microvascular tortuosity, microaneurysms and focal areas of luminal narrowing believed to be microvessels in spasm (Factor et al, 1984). The frequency of these microvascular lesions was much greater in rats with combined $\mathrm{H}$ D compared to rats with either hypertension or diabetes. Ultrastructural analysis of the heart showed that the effect of combined hypertension and diabetes was not limited to histopathological changes. Using the RVH-diabetic rat model, Mall and colleagues (1991) found in the hearts of H-D rats an acceleration of abnormalities such as the occurrence of small mitochondria and an increase in the volume ratio of mitochondria to myofibrils. An ultrastructural study by Factor and coworkers (1983) also reported much more extensive myofibrillar damage in the H-D group.

Along with the increased severity of myocardial pathology in the hearts of H-D rats is an impairment of contractile function. Analysis of cardiac function using the isolated working heart technique has shown that inducing diabetes in SHR results in more severe cardiac dysfunction than that which occurs in a diabetic-normotensive rat (Rodrigues and McNeill, 1986; Rodgers, 1986). At the higher LV filling pressures, SHR-diabetic rat hearts exhibited depressed LVDP and rate of contraction as well as a depressed rate of relaxation. Interestingly, depressed cardiac function has also been 
reported in renovascular hypertensive Wistar-Kyoto (WKY) rats made diabetic with STZ (Rodgers et al, 1991). This finding is significant because WKY rats are relatively resistant to the cardiodepressive effects of chronic diabetes even though they develop hyperglycemia and hypoinsulinemia (Rodrigues and McNeill, 1986; Rodgers, 1986). Superimposing hypertension in diabetic WKY rats impaired cardiac performance whereas either hypertension or diabetes alone had no detrimental effect (Rodgers $e t$ al, 1991). The depressed cardiac performance in rats with combined H-D has been linked to the hypothyroid state of these animals and to a lower rate of intracellular calcium uptake by the sarcoplasmic reticulum (Davidoff et al, 1990a; Davidoff et al, 1990b).

In vivo assessment of cardiac performance has shown a similar cardiac dysfunction in H-D rats. Yamamoto and Nakai (1988) tested cardiac function during rapid blood infusion in moderately diabetic SHR (40mg/kg STZ) and found an attenuated LVDP and $\mathrm{dP} / \mathrm{dt}_{\max }$ response compared to the nondiabetic SHR control. These results were confirmed in a later study using $55 \mathrm{mg} / \mathrm{kg} \mathrm{STZ}$ (Dai et al, 1994). When taken together, there is strong evidence that the addition of hypertension has an additive or synergistic effect on the development of diabetic cardiac dysfunction.

However, not all of the studies examining cardiac function in models of combined H-D have reported a synergistic effect of these two conditions. A study of papillary muscle mechanics from rats with renovascular hypertension and diabetes showed no additional dysfunction in H-D rats compared to the diabetic, normotensive group (Fein et $a l, 1990)$. Indices such as the duration of contraction and relaxation were prolonged in both diabetic and H-D groups compared to their respective controls, but no statistical difference was found between the two diabetic groups. Using the isolated working heart technique, diabetic SHR have been shown to have depressed cardiac function that was of 
the same magnitude as the diabetic, normotensive group (Pijl et al, 1994; van Zwieten et $a l, 1996)$. In male Sprague-Dawley rats made hypertensive with deoxycorticosterone acetate (DOCA), injection of STZ did not result in depressed cardiac function at the higher atrial filling pressures (Dai and McNeill, 1992). There were also no significant differences between the H-D group and diabetic groups.

Thus, although there is strong evidence supporting the additive effect of hypertension on the development of diabetic cardiomyopathy, the results are equivocal at this time.

\section{EXPERIMENTAL MODELS OF DIABETES AND HYPERTENSION}

\section{A. Induction of Experimental Diabetes}

Induction of Type 1 diabetes is most commonly performed using one of two compounds: alloxan or streptozotocin (STZ). Both compounds selectively destroy the pancreatic $\beta$-cell and produce a state of hypoinsulinemia and hyperglycemia, the severity of which can be controlled by the dose of the compound. Alloxan was the first agent reported to have a toxic $\beta$-cell effect (Dunn et al, 1943). However, STZ has replaced it as the agent of choice due to its greater selectivity to the $\beta$-cells (Hoftiezer and Carpenter, 1973) and the lower mortality rate found in STZ-diabetic animals (Junod et al, 1969). STZ is comprised of a glucose molecule connected to a highly reactive nitrosourea side chain. The nitrosourea moiety is responsible for $\beta$-cell toxicity, while the glucose moiety facilitates transport across the cell membrane by binding to a membrane receptor, possibly GLUT2 (Schnedl et al, 1994). STZ's $\beta$-cell toxicity is believed to be the result 
of two related processes: i) methylation of DNA, and ii) free radical production. When inside the $\beta$-cell, the nitrosourea side chain decomposes to form carbonium ions $\left(\mathrm{CH}_{3}^{+}\right)$ that alkylate DNA bases and cause DNA strand breaks (Uchigata et al, 1982). In addition, DNA stand breaks may be initiated by free radicals such as the hydroxyl radical $\left(\mathrm{OH}^{*}\right)$. The process of DNA repair requires activation of poly (ADP-ribose) synthase, an enzyme that excises damaged DNA segments and which uses NAD as a substrate. The depletion of cellular NAD due to the sudden increase in poly (ADP-ribose) synthase activity results in the cessation of all NAD-dependent cellular functions and death of the $\beta$-cell (Okamoto, 1987). Recent evidence implicates nitric oxide (NO) production in the diabetogenic effects of STZ but at this time the precise mechanism of action is unclear (Tanaka et al, 1995).

Rats injected with STZ exhibit similar acute and chronic symptoms as human diabetic patients. These include polydypsia, polyphagia, polyuria, decreased weight gain, hyperglycemia, hypoinsulinemia and cardiovascular complications. At an i.v. dose of 55 $\mathrm{mg} / \mathrm{kg} \mathrm{STZ}$, cardiac contractile function has been reported to be depressed within 6-8 weeks of STZ injection (Tahiliani et al, 1983).

\section{B. THE SPONTANEOUSLY HYPERTENSIVE RAT}

The spontaneously hypertensive rat (SHR) is a genetic animal model of hypertension commonly used to study the pathogenesis of essential hypertension and to test the effectiveness of potential therapeutic treatments. The strain was derived by Okamoto and Aoki in 1963 by the selective inbreeding of Wistar rats and requires no surgical or pharmacological interventions to initiate a rise in blood pressure. SHR begin to develop hypertension between five to eight weeks of age and by fifteen weeks of age 
systolic blood pressure plateaus around $200 \mathrm{mmHg}$. The most commonly used normotensive control strain is the Wistar-Kyoto (WKY) rat originally bred from the same Wistar colony as the SHR. However, the SHR and WKY have a significant degree of genetic divergence and differ in several physiological and biochemical characteristics which must be kept in mind when comparing the two strains (Yamori, 1983; Kurtz and Morris, 1987; St. Lezin et al, 1992).

Although there is a substantial base of knowledge, the physiological mechanisms by which blood pressure is elevated in the SHR are not completely understood. It is believed that the development of hypertension in the SHR is multifactorial in origin and that several systems are involved. The sympathetic nervous system (SNS) has garnered much attention and appears to be one of the main contributors to the development of hypertension in this model. Direct examination of the SNS has shown that SHR have increased sympathetic activity at rest (Judy et al, 1979) and neonatal sympathectomy attenuated the blood pressure increase (Lee et al, 1987). In addition, there is an exaggerated vasoconstrictor response to SNS stimulation (Lais and Brody, 1978) that may be due to several alterations, including an elevated catecholamine release (Ekas and Lokhandwala, 1981) and changes in adrenergic receptor density and intracellular signaling cascades on the responsive tissues (Takata and Kato, 1996).

The vasculature also plays a role in the development and maintenance of hypertension in the SHR. The increase in sympathetic activity (via $\beta$-adrenergic stimulation), along with the direct effect of elevated blood pressure, accelerates vascular protein synthesis (Yamori, 1984). In addition, cultured vascular smooth muscle cells (VSMC) from SHR show elevated rates of growth and proliferation compared to those from WKY rats (Yamori et al, 1981). The blood vessels that hypertrophy become 
irreversibly constricted and thus maintain the elevation in blood pressure. Changes in function of the $\mathrm{Na}^{+}-\mathrm{K}^{+}$cotransport, $\mathrm{Na}^{+}-\mathrm{H}^{+}$exchanger and $\mathrm{Ca}^{++}$pump have all been documented (Ferrari and Bianchi, 1995) but whether these alterations are an underlying cause of the blood pressure increase or merely a secondary effect has not been clearly established.

The role of the kidney in the development and maintenance of hypertension was illustrated when the transplantation of a kidney from an SHR into a normotensive strain produced sustained hypertension (Rettig et al, 1989). The mechanisms by which the kidney exerts the pressor response are not exactly known, but may be related to increased tone of the preglomerular vessels (Ferrari and Bianchi, 1995). Thus, the role of the kidney may be at least partly dependent on changes brought about by elevated SNS activity. Sodium and water retention is exaggerated in the SHR during the early phase of hypertension (Beierwaltes et al, 1982), but these changes are believed to be a consequence of elevated blood pressure and not the underlying factor responsible for the development of hypertension (Dietz et al, 1984).

\section{RATIONALE OF THE PROPOSED EXPERIMENTS}

Several recent studies using the STZ-injected SHR have shown that the addition of hypertension exacerbates the development of diabetic cardiomyopathy. In these studies, the same dose of STZ was used for both SHR and normotensive strains. The validity of these results can be questioned because there is uncertainty about whether or not the SHR are more sensitive to the diabetogenic effects of STZ (Somani et al, 1979; 
Voss et al, 1989; Dai et al, 1994). Recently, Jian and colleagues (1996) examined this by injecting Wistar and SHR with $55 \mathrm{mg} / \mathrm{kg} \mathrm{STZ}$ and then determined the severity of diabetes one week later in terms of plasma glucose, insulin, pancreatic insulin and the ability to handle a glucose load (OGTT). The results showed that the same dose of STZ resulted in lower pancreatic and plasma insulin levels as well as higher plasma glucose levels in the SHR than Wistar rat. By titrating the level of STZ, they showed that 45 $\mathrm{mg} / \mathrm{kg} \mathrm{STZ}$ in the SHR produced a similar level of diabetes as $55 \mathrm{mg} / \mathrm{kg}$ in the Wistar rat (Jian et al, 1996). Since most of the literature has used the same dose of STZ to induce diabetes in both hypertensive and normotensive groups of animals, the severity of diabetes might have been different in the H-D group compared to the normotensive diabetic group. The question that arises is whether the increased cardiac dysfunction reported in the diabetic-SHR was due to the increased diabetogenic effect of STZ (increased sensitivity), or whether it was due to the additive effect of hypertension on the diabetic condition. In order to compare accurately the effect of hypertension on the diabetic heart, the level of diabetes should be equivalent for both SHR and control rats. By controlling the severity of diabetes, we would now be able to study the effect of hypertension on the progression of diabetic cardiomyopathy.

Three separate studies were performed to determine the role of hypertension on the development of diabetic heart disease. In SHR Study \#1 both SHR and Wistar rats received a dose of $45 \mathrm{mg} / \mathrm{kg} \mathrm{STZ}$ and were maintained for twelve weeks before cardiac function was studied using the isolated working heart technique. The objective of this study was to confirm that the SHR were more susceptible than the Wistar rat to the diabetogenic effect of STZ, as was suggested by several investigators (Somani et al, 
1979; Voss et al, 1989; Dai et al, 1994; Jian et al, 1996). Also important was to show that the development of diabetes in the SHR resulted in cardiac dysfunction. Previous reports comparing the cardiac function of diabetic SHR and Wistar rats have used a dose of at least $55 \mathrm{mg} / \mathrm{kg} \mathrm{STZ}$ in both strains (Rodrigues and McNeill, 1986; Rodgers, 1986). At this dose, a high mortality rate was reported in the diabetic-SHR group. Using a lower dose of STZ in both strains eliminated the risk of mortality while allowing for the analysis of diabetic state and cardiac function.

Although the WKY is usually used as the normotensive control for the SHR, for these studies the Wistar rat was used. There are several reasons for this, including: $i$ ) high degree of genetic variation between WKY and SHR, ii) the WKY are slightly hypertensive compared to other strains, iii) the WKY require higher concentrations of STZ to induce cardiomyopathy, and $i v$ ) the Wistar is the predominant strain of rat used in our laboratory and the effects of STZ in this strain have been well established.

In the next two studies, the concentration of STZ given to the rats was adjusted to produce an equivalent level of diabetes in both SHR and Wistar. In SHR Study \#2, the SHR were injected with $45 \mathrm{mg} / \mathrm{kg} \mathrm{STZ}$ and the Wistar with $55 \mathrm{mg} / \mathrm{kg} \mathrm{STZ} \mathrm{before} \mathrm{the}$ development of significant hypertension in the SHR. The diabetic state was maintained

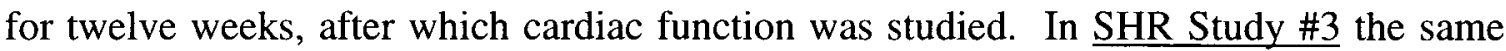
doses of STZ were injected at twelve weeks of age, after hypertension had been established. By creating a similar degree of diabetes in both SHR and Wistar rats, the effect of hypertension on diabetic cardiomyopathy could then be determined. 


\section{SPECIFIC GOALS OF THE PRESENT INVESTIGATION}

1. To study the role of hypertension on the development of diabetic cardiomyopathy using a model of genetic hypertension and experimental diabetes mellitus.

2. To determine if the SHR are more susceptible than the Wistar rat to the diabetogenic effect of STZ.

3. To determine whether hypertension or diabetes is the driving force behind the increased myocardial contractile dysfunction reported in combined hypertensivediabetic animals.

4. To examine the effect of pre-existing hypertension on the progression of diabetic cardiomyopathy.

5. To determine whether or not the use of a moderate doses of STZ in the SHR produced a stable model for studying the effects of combined hypertension and diabetes. 


\section{MATERIALS AND METHODS}

\section{MATERIALS}

\section{A. CHEMICALS}

The following chemicals were purchased from Sigma Chemicals Co. (St. Louis, Mo.): sodium chloride, calcium chloride, potassium chloride, magnesium chloride, Dglucose, sodium bicarbonate, and streptozotocin. Halothane was purchased from Halocarbon Laboratories (North Augusta, S.C.) and heparin (heparin sodium) was acquired from Organon Teknika (Toronto, Ont). Sodium pentobarbital was purchased from MTC Pharmaceuticals (Cambridge, Ont).

\section{B. ASSAY KITS}

Plasma glucose levels were analyzed using the glucose oxidase method (Boehringer Mannheim GmbH Diagnostica, Germany) while plasma and pancreatic insulin levels were quantified using RIA kits purchased from Linco Research Inc. (St. Charles, Mo.). Plasma triglyceride and cholesterol levels were measured using colourimetric kits from Boehringer Mannheim GmbH Diagnostica. 


\section{METHODS}

\section{A. EXPERIMENTAL PROTOCOLS}

\section{SHR STUDY \#1: INJECTION OF $45 \mathrm{mg} / \mathrm{kg} \mathrm{STZ} \mathrm{IN} \mathrm{BOTH}$ SHR AND WISTAR RATS BEFORE THE DEVELOPMENT OF HYPERTENSION}

The goal of the first study was to confirm that the SHR were more susceptible to STZ and that the increased level of diabetes resulted in more severe cardiac dysfunction. Male SHR and Wistar rats were acquired at five weeks of age from Charles River (Montreal, Canada) and randomly assigned to four experimental groups: Wistar Control (WC, $n=10$ ), SHR Control (SC, n=10), Wistar Diabetic (WD, $n=13$ ), and SHR Diabetic

$(\mathrm{SD}, \mathrm{n}=14)$. At seven weeks of age, systolic blood pressure was measured using the indirect tail cuff technique to verify the pre-hypertensive state of the SHR groups. Experimental diabetes was induced via a single tail vein injection of $45 \mathrm{mg} / \mathrm{kg}$ STZ to both SD and WD groups, while the control groups received an equivalent volume of isotonic saline. Rats from each group were housed two per cage and given food and water ad libitum. Body weight and food and fluid consumption was measured on a weekly basis throughout the study while systolic blood pressure was measured at four, eight and eleven weeks post-STZ. At week eight, the rats were five-hour fasted and a blood sample collected for plasma insulin and glucose analysis. After twelve weeks of diabetes, the rat was anesthetized with an overdose of sodium pentobarbital and tail bled for a termination blood sample. Once the rat was unconscious, the heart was quickly excised and mounted on the working heart apparatus for the study of contractile function. 
Upon the completion of these measurements, the whole heart, right ventricle (RV) and left ventricle (LV) (including the septum) were weighed to give an index of cardiac hypertrophy.

\section{SHR STUDY \#2: INJECTION OF $45 \mathrm{mg} / \mathrm{kg} \mathrm{STZ} \mathrm{IN} \mathrm{SHR} \mathrm{AND}$ $55 \mathrm{mg} / \mathrm{kg}$ STZ IN WISTAR RATS PRIOR TO THE DEVELOPMENT OF HYPERTENSION}

The objective of this study was to examine the influence of hypertension on the development of diabetic cardiomyopathy by producing a similar diabetic state in both hypertensive and normotensive animals. Male SHR and Wistar rats were procured at 5 weeks of age from Charles River, Montreal, Canada and randomly assigned to four experimental groups: Wistar Control (WC, $n=10)$, SHR Control (SC, $n=10)$, Wistar Diabetic (WD, $n=10$ ), and SHR Diabetic (SD, $n=13$ ). At eight weeks of age the SD group was injected with $45 \mathrm{mg} / \mathrm{kg} \mathrm{STZ}$ while the WD group received $55 \mathrm{mg} / \mathrm{kg} \mathrm{STZ} \mathrm{in}$ order to induce an equivalent degree of diabetes. Both WC and SC groups received an equivalent volume of the saline vehicle. The rats in each of the four groups were housed two per cage and given water and food ad libitum. Food and fluid consumption as well as changes in body weight were measured biweekly. At six weeks post-STZ injection, the animals were fasted for five hours and tail bled to acquire a plasma sample for glucose and insulin analysis. At week eleven, the rats were fasted overnight (14 hours) and an oral glucose tolerance test (OGTT) performed to accurately determine the severity of diabetes. Systolic blood pressure was measured using the indirect tail cuff method before the injection of STZ and at week six and eleven to ensure the development of hypertension in the SHR groups. At termination, the rat was anesthetized with an overdose of sodium pentobarbital and the heart quickly excised for the study of 
contractile function. In addition, whole blood was immediately collected from the chest cavity for the measurement of termination (non-fasted) plasma glucose, insulin, cholesterol, and triglyceride levels. The pancreas was also dissected from the carcass for the measurement of pancreatic insulin content. Cardiac contractile function was measured using the isolated working heart technique and upon the completion of these measurements the whole heart, right ventricle (RV) and left ventricle (LV) (including the septum) were weighed.

\section{SHR STUDY \#3: INJECTION OF $45 \mathrm{mg} / \mathrm{kg}$ STZ IN SHR AND $55 \mathrm{mg} / \mathrm{kg}$ STZ IN WISTAR RATS AFTER THE DEVELOPMENT OF HYPERTENSION}

In the final study, the goal was to examine cardiac function in diabetic and diabetic-hypertensive rats after the development of hypertension. For this study, SHR and Wistar rats were acquired at nine weeks of age from Charles River (Montreal, Canada) and randomly assigned to four experimental groups: Wistar Control (WC, $\mathrm{n}=10$ ), SHR Control (SC, $\mathrm{n}=10$ ), Wistar Diabetic (WD, $\mathrm{n}=11$ ), and SHR Diabetic (SD, $\mathrm{n}=14$ ). At twelve weeks of age, systolic blood pressure was measured using the indirect tail cuff method to ensure the hypertensive state of the SHR groups. Experimental diabetes was induced via a single tail vein injection of STZ dissolved in isotonic saline. In a similar fashion to SHR STUDY \#2, the SD group received $45 \mathrm{mg} / \mathrm{kg}$ STZ whereas the WD group received $55 \mathrm{mg} / \mathrm{kg} \mathrm{STZ}$ and the control groups were injected with an equivalent volume of isotonic saline. Rats from each group were housed two per cage and given food and water ad libitum. Body weight and food and fluid consumption was measured on a weekly basis throughout the study while systolic blood pressure was 
measured at three and six weeks post-STZ injection. At week 1, an OGTT was performed on each rat in the study and at week six, a second OGTT performed on six rats from each group. Left ventricular function was studied using the isolated working heart technique after eight weeks of diabetes. A termination blood sample was acquired by tail bleed for plasma measurements and the ventricular weights were documented.

\section{B. INDUCTION OF DIABETES}

Experimental diabetes was induced by a single tail vein injection of STZ dissolved in isotonic saline $(0.9 \% \mathrm{NaCl})$. Control rats were injected with the saline vehicle alone. Prior to the injection, each animal was lightly anesthetized by halothane inhalation. Rats with blood glucose levels greater than $13 \mathrm{mM}$ were considered diabetic.

\section{BLOOD PRESSURE MEASUREMENT}

Systolic blood pressure was measured in conscious rats using the indirect tail cuff method without external preheating (Bunag, 1973; Bunag and Butterfield, 1982). This method has been shown to record systolic blood pressures within $5 \mathrm{mmHg}$ compared to direct intra-arterial cannulation and thus provides an accurate but non-invasive pressure measurement (Bunag and Butterfield, 1982; Hwang et al, 1989). Prior to the actual blood pressure measurements, the rats were acclimatized to the plexiglass animal holders for 30 minutes on three consecutive days. The equipment used included a tail sensor/cuff, an automatic cuff pump (Model 20NW), a multi-sensor manual scanner (Model 65-120 and blood pressure amplifier with an analog/digital recorder/printer (Model 179) from IITC Inc. (Woodland Hills Ca., USA). Using this setup the various parameters, such as 
maximal inflation pressure, deflation rate and cycling interval were kept constant. As the inflated cuff gradually deflated, the reappearance of pulsations in the tail were detected by the photoelectric sensor and amplified and digitally recorded as the systolic BP. The systolic BP value for each animal was the mean of 3 or 4 separate tracings.

In order to verify that the systolic blood pressure measurement acquired using the indirect tail cuff method was a close approximation of the actual blood pressure, direct blood pressure was measured in two SC rats and one SD rat each from SHR Exp's 2, 3 and 4. All rats were twenty-one weeks of age at the time of the direct blood pressure measurement. The rats were anesthetized with sodium pentobarbital at a dose of $60 \mathrm{mg} / \mathrm{kg}$ of body weight, given intraperitoneally. When the rat became unconscious, a medial incision was made in the ventral surface of the neck and the left carotid artery was isolated and catheterized with a polyethylene cannula (PE-50). The catheter was secured in place with suture thread and the free end was tunneled subcutaneously and externalized at the interscapular region. Patency was maintained by periodic flushing of small volumes of a heparinized saline solution. The incision was closed with surgical staples and the rat was allowed to recover from the procedure for five hours. The arterial cannula was connected to a pressure transducer (Model DT-XX, Viggo-Spectramed, Oxnard, Ca.) and a pressure processor amplifier (Gould 13-4615-52). Direct systolic and diastolic pressure tracings were obtained with a chart recorder (Gould TA2000).

\section{WORKING HEART PERFUSION AND ANALYSIS OF CARDIAC CONTRACTILE FUNCTION}

Animals were weighed and deeply anesthetized by an i.p. injection of $100 \mathrm{mg} / \mathrm{kg}$ sodium pentobarbital. Once unconscious, the heart was quickly removed and placed in cold, oxygenated Chenoweth-Koelle $(\mathrm{C}-\mathrm{K})$ buffer. The millimolar concentrations of 
solutes in the buffer were as follows: $\mathrm{NaCl} 120 ; \mathrm{KCl} 5.6 ; \mathrm{CaCl}_{2} 2.18 ; \mathrm{MgCl}_{2} .2 .1$; $\mathrm{NaHCO}_{3}$ 19.2; glucose $10 \mathrm{mM}$. Once aerated, the buffer had a pH of 7.4. The aortic stump was located and tied to a 16 gauge stainless steel perfusion cannula connected to the working heart apparatus. At this point the heart was perfused in the Langendorff (retrograde) manner with aerated $\left(95: 5 \mathrm{O}_{2}: \mathrm{CO}_{2}\right)$ buffer warmed to $38^{\circ} \mathrm{C}$. The heart was cleaned of any extraneous tissue and a second perfusion cannula was inserted into the pulmonary vein and tightly secured with suture thread. Perfusion of the isolated heart was then switched from Langendorff mode to working heart mode so that buffer passed through the pulmonary cannula and required contraction of the left ventricle to perfuse the cardiac tissue. In SHR Experiments 1 and 3, a slight modification was made to the working heart procedure in order to collect the lipoprotein lipase (LPL) enzyme from the endothelial cell surface of the myocardial blood vessels. Briefly, when the isolated heart had been cleaned and mounted in Langendorff mode, the perfusion medium was switched from $\mathrm{C}-\mathrm{K}$ buffer to $\mathrm{C}-\mathrm{K}$ buffer containing $0.1 \%$ bovine serum albumin (BSA) (Fraction V) and heparin $(5 \mathrm{U} / \mathrm{mL})$. The flow rate of perfusate from the apex of the heart was maintained at $9-10 \mathrm{~mL}$ per minute. After four minutes of perfusion, during which time the perfusate was collected from the apex of the heart, the retrograde perfusion was switched back to the original $\mathrm{C}-\mathrm{K}$ buffer so that the analysis of cardiac function could be performed. The analysis of LPL enzyme activity is not discussed in this thesis. Once the pulmonary cannula was inserted and secured into the pulmonary vein heart perfusion was switched to working heart mode.

After a brief equilibration period at a preload of $6.3 \mathrm{mmHg}$, the heart was maximally stimulated at 300 beats/minute at twice threshold voltage by square wave pulses of $5 \mathrm{msec}$ duration using a Grass SD9. Intraventricular pressure was measured by 
inserting a 20 gauge needle connected to a Statham pressure into the apex of the heart. Aortic outflow was subjected to a constant afterload of a $13 \mathrm{~cm}$ water column (PE 160 tubing) and arterial compliance was mimicked by a sealed chamber containing air and a fixed height of buffer. When the heart was stable, left ventricular function was analyzed by varying the pump speed (and therefore the preload) in a range of 3-11 $\mathrm{mmHg}$ using a peristaltic pump (Masterflex pump with a Model 7016 pump head). Changes in ventricular pressure were recorded by a Grass Model 79D polygraph and by computer which analyzed left ventricular function in terms of $+\mathrm{dP} / \mathrm{dt}$ (rate of pressure increase), $-\mathrm{dP} / \mathrm{dt}$ (rate of pressure decrease) and LVDP (maximum ventricular pressure). When the experiment was completed, the heart was blotted dry and weighed along with the isolated right ventricle (RV) and left ventricle (including septum) (LV) to give an index of cardiac hypertrophy. The working heart procedure was originally described by Neely (1967, 1975) and further modified by investigators in our laboratory (Vadlamudi et al, 1982; Verma and McNeill, 1994).

\section{E. ORAL GLUCOSE TOLERANCE TEST (OGTT)}

In order to verify the severity of diabetes, an oral glucose tolerance test was conducted on overnight (14 hour) fasted rats. All blood samples were acquired from the nicked tail vein and collected in heparinized capillary tubes. Following a basal blood sample, each rat was given a $1 \mathrm{~g} / \mathrm{kg}$ glucose solution by oral gavage and blood samples acquired at 10,20,30 and 60 minutes post-gavage. The blood samples were spun at $15,000 \mathrm{rpm}$ for 15 minutes at $4^{\circ} \mathrm{C}$ and the plasma removed and stored at $-70^{\circ} \mathrm{C}$ until assayed for insulin and glucose. The area under the curve (AUC) was calculated for both 
insulin $\left(\mathrm{AUC}_{\mathrm{i}}\right)$ and glucose $\left(\mathrm{AUC}_{\mathrm{g}}\right)$ and included the basal $(\mathrm{t}=0)$ time point. The AUC value was calculated based on the trapezoid method using the formula:

$$
\mathrm{T}_{0}+\left(\mathrm{T}_{10} * 10\right)+\left(\mathrm{T}_{20} * 10\right)+\left(\mathrm{T}_{30} * 10\right)+\left(\mathrm{T}_{60} * 30\right)
$$

\section{F. PANCREATIC INSULIN CONTENT}

During the termination procedure, the pancreas was dissected from the rat intestine and cleaned of fat and any lymph nodes. The pancreas was blotted and weighed before being placed in $5 \mathrm{~mL}$ of chilled $5 \mathrm{M}$ acetic acid and homogenized using a polytron (position 5) for 5 seconds. The homogenate was boiled for 10 minutes and centrifuged at $15,000 \mathrm{rpm}$ for 10 minutes at $4^{\circ} \mathrm{C}$. The supernatant was aliquoted into microcentrifuge tubes and frozen at $-70^{\circ} \mathrm{C}$ until assayed for insulin content.

\section{G. STATISTICAL ANALYSIS}

All data are reported as mean \pm SEM unless otherwise noted. Two-way analysis of variance (ANOVA), followed by a Newman-Keuls multiple-comparison test was used to determine differences between multiple group mean values. Comparing the means of two samples was performed by Student's t-test. Changes in contractile function between groups over time were analyzed by General Linear Model (GLM) ANOVA followed by a Newman-Keuls test using the Number Cruncher Statistical System (NCSS). The level of statistical significance was set at $\mathrm{p}<0.05$. 


\section{RESULTS}

\section{SHR STUDY \#1: INJECTION OF $45 \mathrm{mg} / \mathrm{kg} \mathrm{STZ} \mathrm{IN} \mathrm{BOTH}$ SHR AND WISTAR RATS BEFORE THE DEVELOPMENT OF HYPERTENSION}

Injecting $45 \mathrm{mg} / \mathrm{kg} \mathrm{STZ}$ into the SHR and Wistar rats had differing effects on the development of diabetes. In the SHR, inducing diabetes resulted in depressed weight gain, whereas in the diabetic Wistar rats there was no significant difference in body weight compared to their control group (Figure 1). Food and fluid consumption was significantly elevated in both diabetic groups versus the control animals (Figure 2). However, the diabetic SHR (SD) animals consumed significantly more food and fluid compared to the Wistar diabetic group (WD). There was no mortality in either of the diabetic groups during the twelve-week study period.

Figure 1 illustrates the changes in systolic blood pressure that occurred during the study. Prior to STZ injection, the SHR had a slight elevation in blood pressure compared to the Wistar rats, and this dramatically increased in the weeks following the induction of diabetes to a plateau close to $200 \mathrm{mmHg}$. Systolic blood pressure did not increase significantly as the Wistar rats aged. The induction of diabetes did not have any effect on blood pressure in the Wistar rats, but in the SD group the development of hypertension was significantly attenuated.

Eight weeks after the STZ injection, a five-hour fasted plasma sample was analyzed to determine the severity of diabetes in each group. The diabetic rats were hyperglycemic compared to the controls, but the plasma insulin levels were significantly lower only in the SD group (Table 2). The plasma insulin levels of the SC were two-fold 
higher than the WC group, suggesting that the SHR required more insulin to maintain euglycemia.

Based on a fasted plasma glucose value greater than $13 \mathrm{mM}$, only $40 \%$ of the WD rats remained diabetic whereas ten of fourteen $(70 \%)$ SHR animals developed diabetes (Table 3). Figure 3 is the distribution of plasma glucose concentrations of the WD animals and clearly illustrates the dichotomy within the group. Taken together with the general characteristics described earlier, these results show that the SHR were more sensitive to STZ than the Wistar strain.

At termination, a plasma sample was acquired to measure the concentrations of glucose, insulin and plasma lipids (Table 4). Similar to the five-hour fasted samples, the WD rats were hyperglycemic even though there was not a significant decrease in plasma insulin levels. In the SD animals, the hyperglycemia was associated with a decrease in the plasma insulin concentration $(\mathrm{SC}, 3.14 \pm 0.3 \mathrm{ng} / \mathrm{mL}$ vs. $\mathrm{SD}, 2.1 \pm 0.2 \mathrm{ng} / \mathrm{mL} ; \mathrm{P}<0.05$ by t-test). Surprisingly, the insulin concentrations were not significantly different when all four treatment groups were compared by ANOVA. Plasma triglycerides and cholesterol were elevated in both diabetic SHR and Wistar groups compared to their respective controls. However, the difference in triglyceride levels between control and diabetic SHR rats was only significant by t-test, even though there was a three fold increase in the SD group (SC, $0.3 \pm 0.0 \mathrm{mM}$ vs. $\mathrm{SD}, 0.9 \pm 0.1 \mathrm{mM}$ ).

The physical characteristics of the diabetic and control rats at termination are described in Table 5. In the SHR, diabetes resulted in lower body and heart weights compared to their controls, whereas in the WD there was no significant decrease. The ratio of heart weight (or ventricular weight) to body weight corrects for differences in body mass and is thus a measure of relative cardiac hypertrophy. In both SHR groups the 
heart:body and LV:body ratios were significantly greater than in the Wistar groups. The induction of diabetes did not affect the ratios in either SD or WD groups, indicating that the lower weight of cardiac tissue in the SD rats was due to an overall decrease in body weight.

After twelve weeks of diabetes, cardiac performance was examined in terms of left ventricular developed pressure (LVDP), rate of contraction $(+\mathrm{dP} / \mathrm{dt})$, and rate of relaxation $(-\mathrm{dP} / \mathrm{dt})$ using the isolated working heart technique. For all three parameters, cardiac function in the SD rats was depressed at the higher left atrial filling pressures (Figure 4). However, in the WD group cardiac performance was not significantly different than the WC controls. At any given filling pressure, the SHR had a higher developed pressure and rate of contraction, which can be explained by the presence of left ventricular hypertrophy. Expressing the data in terms of percent increase (from the lowest left atrial filling pressure) showed that the magnitude of pressure development in both SHR and Wistar strains was equivalent (Figure 5). It also supported the idea that SD heart function was depressed while the WD hearts was not.

\section{SHR STUDY \#2 INJECTION OF $45 \mathrm{mg} / \mathrm{kg} \mathrm{STZ} \mathrm{IN} \mathrm{SHR}$ and SHR STUDY \#3: $\quad$ AND $55 \mathrm{mg} / \mathrm{kg}$ STZ IN WISTAR RATS}

In the following two studies diabetes was induced in SHR and Wistar rats before and after the development of hypertension in the SHR. In both cases, the SHR received $45 \mathrm{mg} / \mathrm{kg} \mathrm{STZ}$ while the Wistar received $55 \mathrm{mg} / \mathrm{kg} \mathrm{STZ}$. To clarify the terminology used in the text, SD and WD rats injected after the development of hypertension (in the SHR) are also described as: the older rats, or rats injected at twelve weeks of age. 
Measurement of systolic blood pressure at eight weeks of age confirmed that the SHR were normotensive compared to the Wistar rats (Figure 6). The SHR became hypertensive over the following weeks and maintained a systolic blood pressure close to $200 \mathrm{mmHg}$. At twelve weeks of age, the SHR had statistically higher blood pressure than the Wistars, and it was at this age that the second group of animals was injected with STZ to induce diabetes. The induction of diabetes did not have any significant effect on blood pressure in either strain of rat.

To confirm that the systolic blood pressure measurements acquired by the indirect tail-cuff method were an accurate representation of the real blood pressure value, two SHR control and two diabetic SHR were examined using both indirect tail-cuff and direct cannulation techniques. Comparison of the two techniques showed that the indirect tailcuff method does not measure systolic blood pressure exactly (Table 6). However, with the exception of the SHR Control \#1 values, the indirect tail-cuff values were a close representation of the blood pressure and were accurate enough to detect the trends in blood pressure. The SHR control rats had a systolic blood pressure of about $200 \mathrm{mmHg}$, whereas the induction of diabetes attenuated the development of hypertension to about $160 \mathrm{mmHg}$.

Diabetes depressed weight gain, in both SHR and WD groups, compared to their respective controls (Figure 7). Furthermore, inducing diabetes at a later age (after the development of hypertension) resulted in a greater degree of weight loss, especially in the diabetic Wistars. Food and fluid consumption was significantly elevated in both diabetic groups versus the control rats and injecting the rats with STZ at different ages did not substantially alter the amount of food and fluid consumed for either strain (Figures 8 and 9). 
One week before the termination of the rats, an oral glucose tolerance test (OGTT) was performed to assess the diabetic state of the animals. In the rats injected before the development of hypertension, $45 \mathrm{mg} / \mathrm{kg} \mathrm{STZ}$ in the SHR produced a diabetic state that was less severe than $55 \mathrm{mg} / \mathrm{kg} \mathrm{STZ}$ produced in the Wistars (Figure 10). This was shown by the significantly higher plasma glucose concentrations of the WD group throughout the time course of the OGTT, as well as glucose area under the curve (AUC $)$ value. Both diabetic groups had lower plasma insulin levels versus the control groups and were unable to release any insulin reserves in response to the glucose challenge. However, the SD animals had significantly higher insulin AUC value than the WD rats, supporting the idea that the WD rats were more diabetic than the SD group.

Injecting the rats after the development of hypertension increased the severity of diabetes in both groups of animals. In the SHR, injecting the rats with STZ at twelve weeks of age compared to eight resulted in significantly decreased plasma insulin concentration and higher plasma glucose level ( $\mathrm{P}<0.05$, t-test, comparing AUC's) (Figure 11). A similar drop in the plasma insulin levels (based on the OGTT AUC, by 2-sample t-test) was measured in the older WD animals. Although the plasma glucose concentration was not significantly different from those injected at the earlier age, the WD rats injected at the older age continually lost weight and were very emaciated. Thus, the drop in the plasma insulin levels could explain the increased severity of the diabetic symptoms. There was no significant difference in glucose or insulin OGTT values between the older WD and SD rats, indicating that the severity of diabetes was equivalent.

The age of the rat at the time of STZ injection affected the number of rats that developed diabetes. In the SHR, injection of $45 \mathrm{mg} / \mathrm{kg} \mathrm{STZ}$ at eight weeks of age 
induced diabetes in nine of thirteen animals $(69 \%)$, while the same dose injected at twelve weeks of age induced diabetes in $93 \%$ of the animals (thirteen of fourteen) (Table 7). A dose of $55 \mathrm{mg} / \mathrm{kg} \mathrm{STZ}$ in the Wistar resulted in diabetes in $90 \%$ of the animals at eight weeks and $100 \%$ of the rats at twelve weeks of age.

Table 8 describes the non-fasted plasma insulin, glucose and lipid levels of the animals at termination. For SHR and Wistar animals, the induction of diabetes in both younger and older rats resulted in a significant decrease in plasma insulin concentration and increase in plasma glucose levels. In the rats injected before hypertension, the WD group had a significantly greater degree of hyperglycemia than the SD rats, which correlated with a lower plasma insulin concentration. There was no difference in either plasma glucose or insulin levels for the WD and SD groups injected after the development of hypertension. For plasma triglycerides, there was a dramatic increase in both SD and WD groups injected at the older age compared to both SC and WC controls and the diabetic groups injected before the development of hypertension.

For the rats injected with STZ before hypertension development in the SHR, the pancreatic insulin content was measured at termination. As expected, the injection of STZ severely decreased the pancreatic insulin content of both SHR and Wistar groups (Figure 12). However, there was no difference in insulin content between the SD and WD groups. Comparison between the SHR and Wistar strains showed that the pancreatic insulin content of the SHR was lower than the Wistar when expressed in terms of per gram of pancreatic tissue (2-sample t-test).

The induction of diabetes resulted in lower heart and left ventricular weights in both Wistar and SHR diabetic animals compared to the control groups (Table 9). There was no significant difference between the heart:body, RV:body, and LV:body ratios 
between the SC and SD groups, indicating that the lower heart weights in the SD group was not due to a specific loss of heart mass. The heart ratios of both control and diabetic SHR animals were significantly higher than the comparable Wistar groups, suggesting that the hearts of the SHR were hypertrophied. Unlike the SHR, the induction of diabetes in the Wistar rats increased the heart:body and LV:body ratios.

At twenty weeks of age, the effect of increasing left atrial filling pressures on cardiac contractile function was studied in terms of left ventricular developed pressure (LVDP), rate of contraction $(+\mathrm{dP} / \mathrm{dt})$ and rate of relaxation $(-\mathrm{dP} / \mathrm{dt})$. In the rats injected with STZ at the earlier age (before hypertension), left ventricular function of both WD and SD groups failed at the higher filling pressures compared to their respective controls (Figure 13). Of the two diabetic groups, the WD rats had significantly depressed left ventricular pressure development and rate of relaxation. However, when the contractile curves were expressed in terms of percent increase, there was no difference between WD and SD groups (Figure 14). Thus, the magnitude of dysfunction was similar in both diabetic groups, even though the actual contractile curves of the SD were higher.

Figure 15 shows the contractile curves of the rats injected after the development of hypertension. The hearts of WD rats showed lower LVDP and $+\mathrm{dP} / \mathrm{dt}$ values compared to the Wistar control group at filling pressures greater than $8 \mathrm{mmHg}$. However, in the SD rats there was no depression of LVDP or rate of contraction. The rate of relaxation was significantly lower than the SHR controls at the highest filling pressure and was confirmed when the curves were expressed in terms of percent increase (Figure 16). 

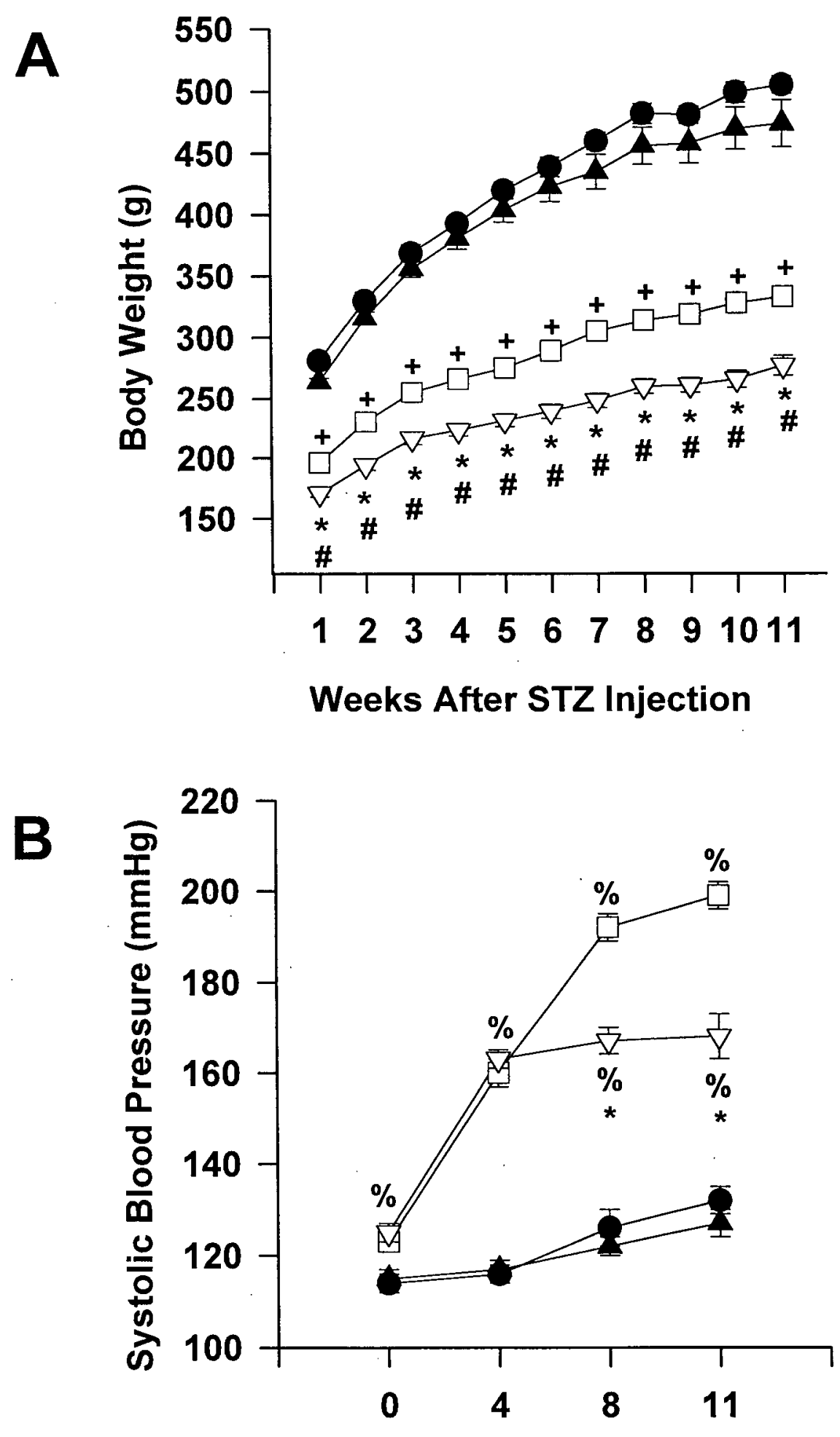

Weeks After STZ Injection

Figure 1. Effect of diabetes on A) weight gain, and B) systolic blood pressure in SHR and Wistar rats injected with $45 \mathrm{mg} / \mathrm{kg}$ STZ. Wistar Control $(n=10)$, SHR Control $(n=10), \quad \Delta \quad$ Wistar Diabetic $(n=13), \quad \nabla \quad$ SHR Diabetic $(n=14)$.

" $n$ " denotes the number of rats in each group. Values are expressed as mean $+/$ - SEM.

${ }^{*} P<0.05$ vs. same strain control. \# $P<0.05$ vs. WD group. $+P<0.05$ vs. WC group. $\% \mathrm{P}<0.05$ vs. both Wistar groups. 

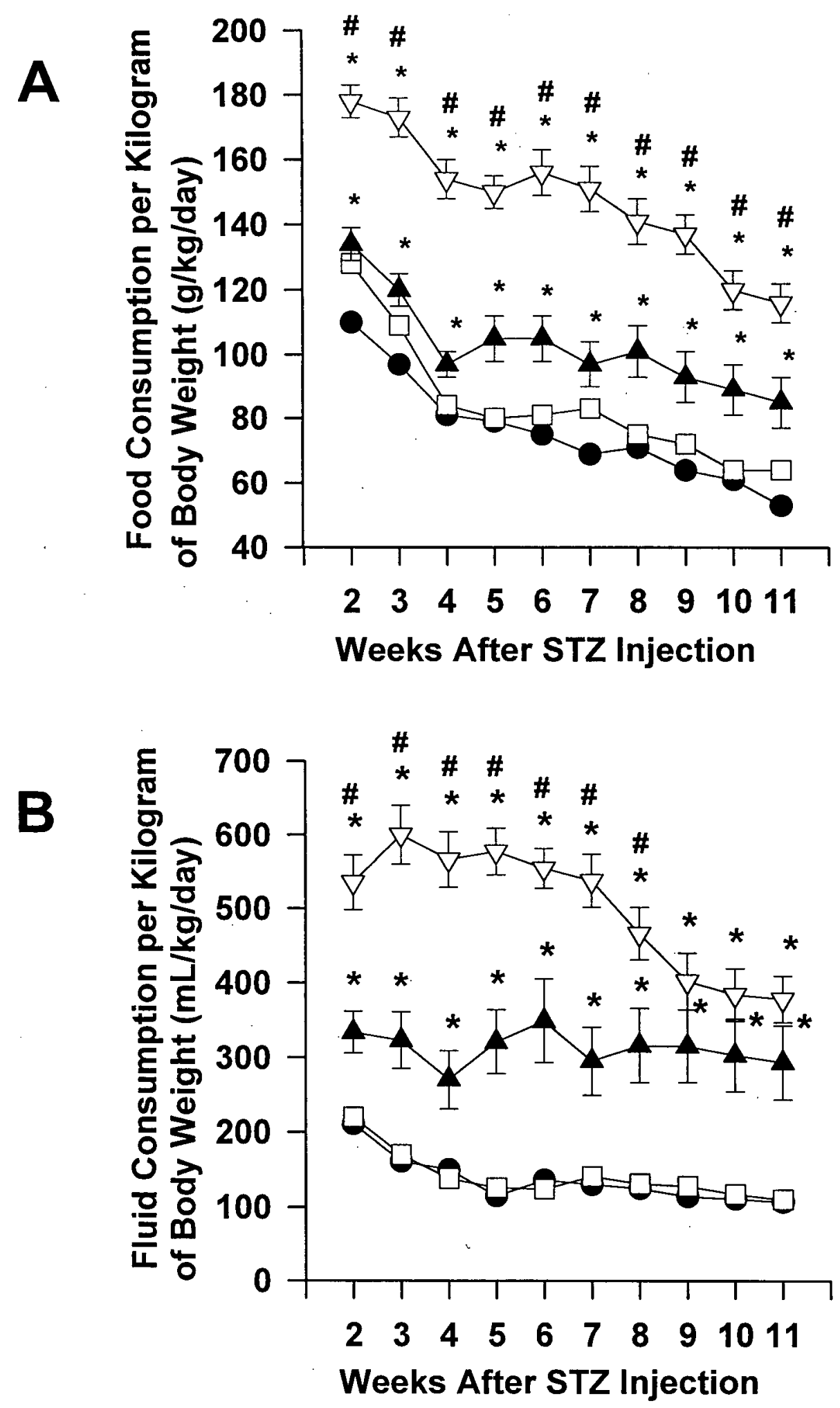

Figure 2. Effect of diabetes on: A) food, and B) fluid consumption in SHR and Wistar rats injected with $45 \mathrm{mg} / \mathrm{kg} \mathrm{STZ}$.

Wistar Control $(n=10)$,

SHR Control $(n=10)$,

$\Delta$ Wistar Diabetic $(n=13), \quad \nabla \quad$ SHR Diabetic $(n=14)$. " $n$ " denotes the number of rats in each group. Values are expressed as mean $+/$ - SEM. ${ }^{*} \mathrm{P}<0.05$ vs. same strain control. \# $P<0.05$ vs. WD group. 
Table 2. Week-Eight Fasted Plasma Glucose and Insulin Concentrations in Animals in SHR Study \#1

\begin{tabular}{lcccc}
\hline & $\begin{array}{c}\text { WC } \\
(n=10)\end{array}$ & $\begin{array}{c}\text { SC } \\
(n=10)\end{array}$ & $\begin{array}{c}\text { WD } \\
(n=13)\end{array}$ & $\begin{array}{c}\text { SD } \\
(n=14)\end{array}$ \\
\hline $\begin{array}{l}\text { Plasma Glucose } \\
(\mathrm{mM})\end{array}$ & $7.5 \pm 0.2$ & $7.6 \pm 0.3$ & $13.4 \pm 1.8^{*}$ & $13.8 \pm 1.4^{*}$ \\
$\begin{array}{l}\text { Plasma Insulin } \\
(\mathrm{ng} / \mathrm{mL})\end{array}$ & $1.9 \pm 0.1$ & $4.3 \pm 0.4^{+}$ & $1.7 \pm 0.2$ & $1.4 \pm 0.1^{*}$ \\
\hline
\end{tabular}

Both SHR and Wistar rats were injected with $45 \mathrm{mg} / \mathrm{kg} \mathrm{STZ}$ before the development of hypertension. Rats were fasted for five hours before the blood was collected by tail bleed into heparinized capillary tubes. WC $=$ Wistar Control, $\mathrm{SC}=\mathrm{SHR}$ Control, WD = Wistar Diabetic, SD = SHR Diabetic. " $n$ " indicates the number of rats in each group. Values are expressed as mean \pm SEM.

$\begin{array}{ll}* \quad & P<0.05 \text { vs. Same Strain Control } \\ \dagger & P<0.05 \text { vs. WC Group }\end{array}$ 


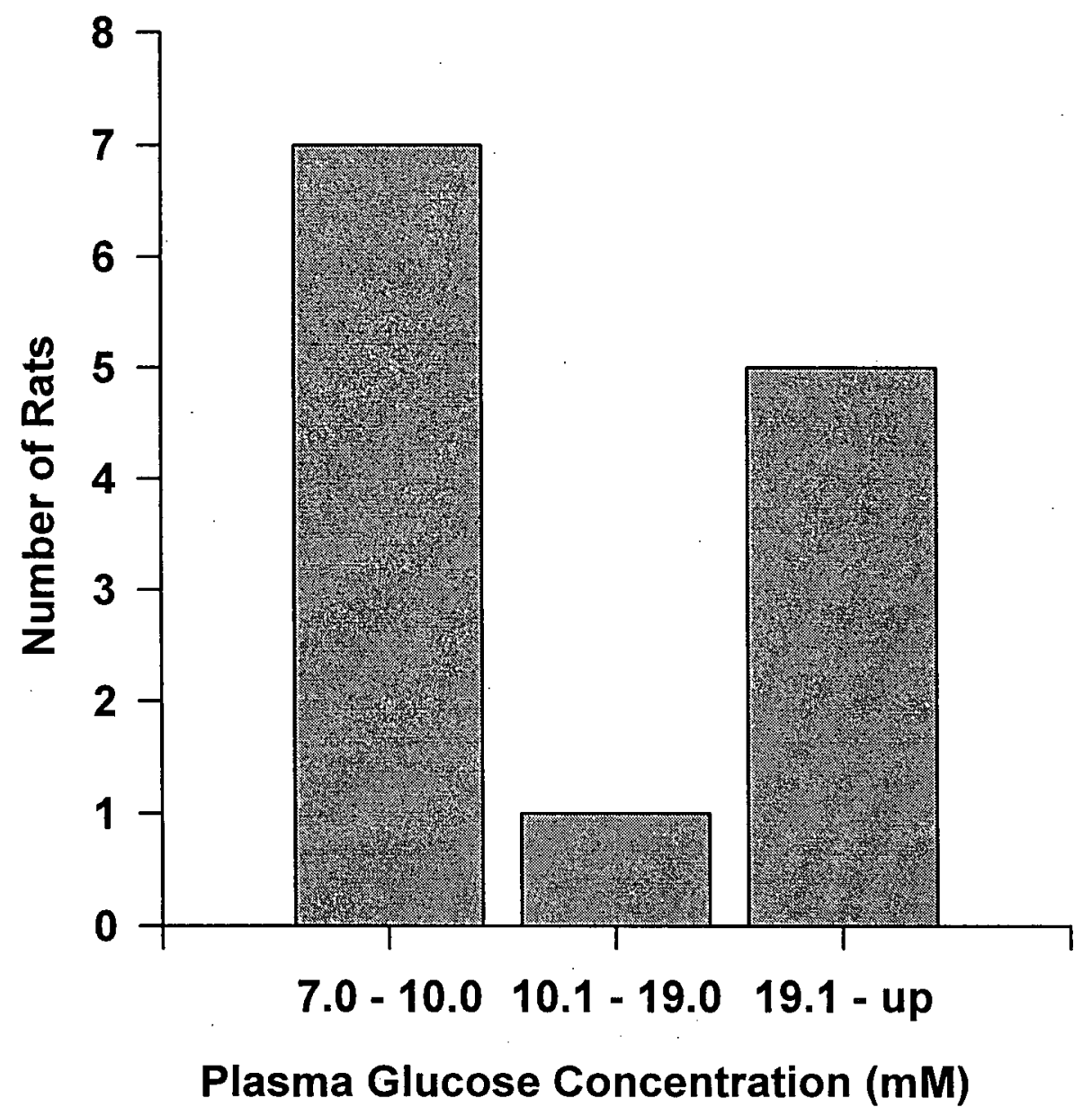

Figure 3. Distribution of glucose concentrations in the WD group after a five-hour fast. The blood was collected via the tail vein into heparinized capillary tubes. The plasma glucose concentration was determined by the glucose oxidase method and is expressed as millimoles per litre. 
Table 3. Percentage of SHR and Wistar Rats Diabetic after Receiving $45 \mathrm{mg} / \mathrm{kg} \mathrm{STZ}$

\begin{tabular}{lccc}
\hline & $\begin{array}{c}\text { Number } \\
\text { Injected }\end{array}$ & $\begin{array}{c}\text { Number } \\
\text { Remaining } \\
\text { Diabetic }\end{array}$ & $\begin{array}{c}\text { Percentage } \\
\text { Diabetic }\end{array}$ \\
\hline SHR Diabetic & 14 & 10 & $71 \%$ \\
Wistar Diabetic & 13 & 5 & $38 \%$ \\
\hline
\end{tabular}

Both SHR and Wistar rats were injected with $45 \mathrm{mg} / \mathrm{kg} \mathrm{STZ}$ before the development of hypertension. Rats were maintained for twelve weeks before termination. 
Table 4. Termination Plasma Values for the Rats in SHR Study \#1

\begin{tabular}{lcccc}
\hline & $\begin{array}{c}\text { WC } \\
(n=10)\end{array}$ & $\begin{array}{c}\text { SC } \\
(n=10)\end{array}$ & $\begin{array}{c}\text { WD } \\
(n=10)\end{array}$ & $\begin{array}{c}\text { SD } \\
(n=10)\end{array}$ \\
\hline $\begin{array}{l}\text { Plasma Glucose } \\
(\mathrm{mM})\end{array}$ & $7.3 \pm 0.2$ & $7.4 \pm 0.4$ & $16.4 \pm 2.5^{*}$ & $17.4 \pm 1.9^{*}$ \\
$\begin{array}{l}\text { Plasma Insulin } \\
(\mathrm{ng} / \mathrm{mL})\end{array}$ & $2.3 \pm 0.3$ & $3.1 \pm 0.3^{+}$ & $1.5 \pm 0.7^{*}$ & $2.1 \pm 0.2^{\$}$ \\
$\begin{array}{l}\text { Plasma Triglycerides } \\
(\mathrm{mM})\end{array}$ & $0.8 \pm 0.1$ & $0.3 \pm 0.04^{+}$ & $2.2 \pm 0.6^{*}$ & $0.9 \pm 0.1^{\$}$ \\
$\begin{array}{l}\text { Plasma Cholesterol } \\
(\mathrm{mM})\end{array}$ & $1.0 \pm 0.1$ & $0.7 \pm 0.1^{+}$ & $1.4 \pm 0.1^{*}$ & $0.9 \pm 0.03^{*}$ \\
\hline
\end{tabular}

Both SHR and Wistar rats were injected with $45 \mathrm{mg} / \mathrm{kg} \mathrm{STZ}$ before the development of hypertension. Rats were maintained for twelve weeks before termination. Plasma was acquired by tail bleed immediately prior to sacrifice. WC $=$ Wistar Control, SC $=$ SHR Control, WD $=$ Wistar Diabetic, SD $=$ SHR Diabetic. " $n$ " indicates the number of rats in each group. Values are expressed as mean \pm SEM.

$\begin{array}{ll}* & P<0.05 \text { vs. Same Strain Control } \\ \dagger & P<0.05 \text { vs. WC Group } \\ \# & P<0.05 \text { vs. WD Group } \\ \$ & P<0.05 \text { vs. SC Group, by t-test }\end{array}$ 
Table 5. Physical Characteristics of the Rats in SHR Study \#1 at Termination

\begin{tabular}{lcccc}
\hline & $\begin{array}{c}\text { WC } \\
(n=10)\end{array}$ & $\begin{array}{c}\text { SC } \\
(n=10)\end{array}$ & $\begin{array}{c}\text { WD } \\
(n=10)\end{array}$ & $\begin{array}{c}\text { SD } \\
(n=10)\end{array}$ \\
\hline Body Wt (g) & $521 \pm 11$ & $353 \pm 8^{\dagger}$ & $475 \pm 26$ & $285 \pm 10^{* \#}$ \\
Heart Wt (mg) & $1494 \pm 32$ & $1408 \pm 25$ & $1423 \pm 40$ & $1172 \pm 44^{* \#}$ \\
RV Wt (mg) & $246 \pm 7$ & $193 \pm 5^{\dagger}$ & $241 \pm 10$ & $170 \pm 8^{* \#}$ \\
LV+Septum Wt (mg) & $1041 \pm 21$ & $1067 \pm 23$ & $981 \pm 26$ & $869 \pm 33^{* \#}$ \\
Heart : Body (mg:g) & $2.9 \pm 0.04$ & $4.0 \pm 0.1^{\dagger}$ & $3.0 \pm 0.1$ & $4.1 \pm 0.1^{\#}$ \\
RV : Body (mg:g) & $0.5 \pm 0.01$ & $0.5 \pm 0.01^{\dagger}$ & $0.5 \pm 0.02$ & $0.6 \pm 0.02^{\#}$ \\
LV : Body (mg:g) & $2.0 \pm 0.02$ & $3.0 \pm 0.1^{\dagger}$ & $2.1 \pm 0.1$ & $3.0 \pm 0.1^{\#}$ \\
LV : RV (mg:g) & $4.2 \pm 0.1$ & $5.5 \pm 0.2^{\dagger}$ & $4.1 \pm 0.1$ & $5.2 \pm 0.2^{\#}$ \\
\hline
\end{tabular}

Both SHR and Wistar rats were injected with $45 \mathrm{mg} / \mathrm{kg}$ STZ before the development of hypertension. Rats were maintained for twelve weeks before termination. $W C=$ Wistar Control, $S C=$ SHR Control, WD $=$ Wistar Diabetic, SD $=$ SHR Diabetic. " $n$ " indicates the number of rats in each group. Values are expressed as mean \pm SEM.

$\begin{array}{ll}* & P<0.05 \text { vs. Same Strain Control } \\ t & P<0.05 \text { vs. WC Group } \\ \# & P<0.05 \text { vs. WD Group }\end{array}$ 


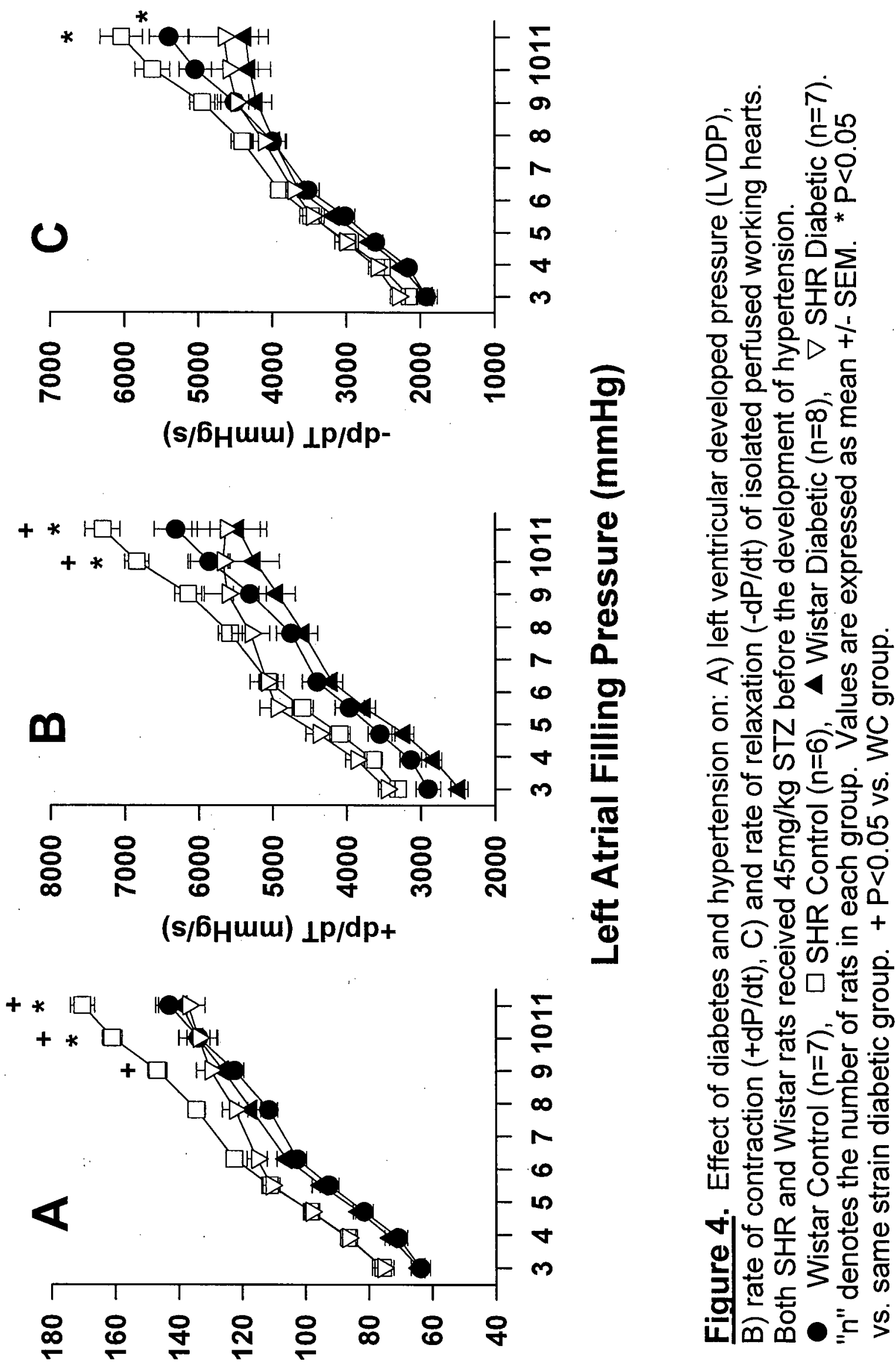

(6Нmس) da^า 


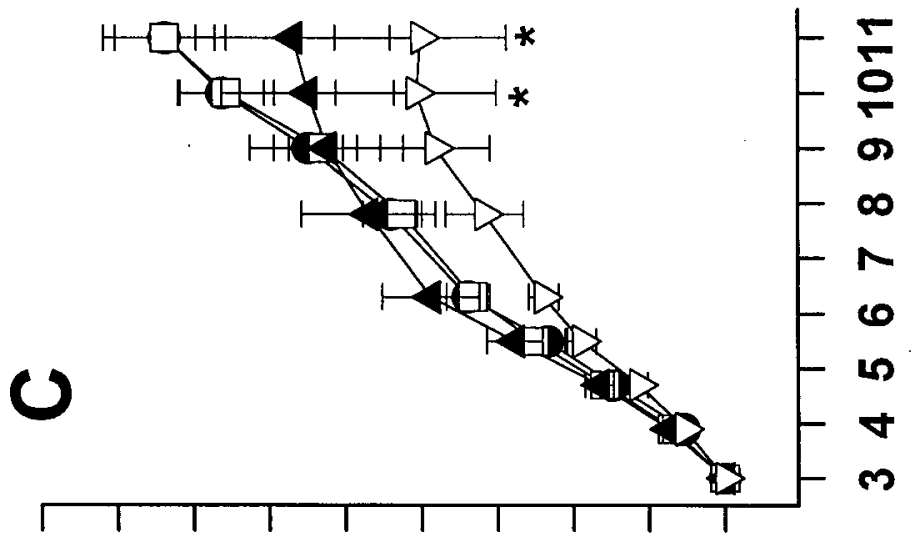

숭

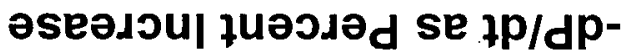

$\boldsymbol{m}$

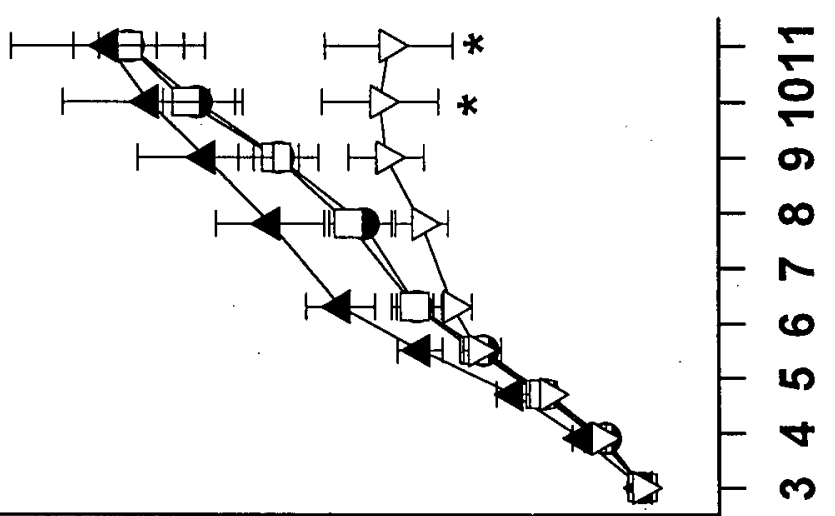

아융

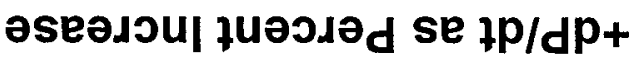

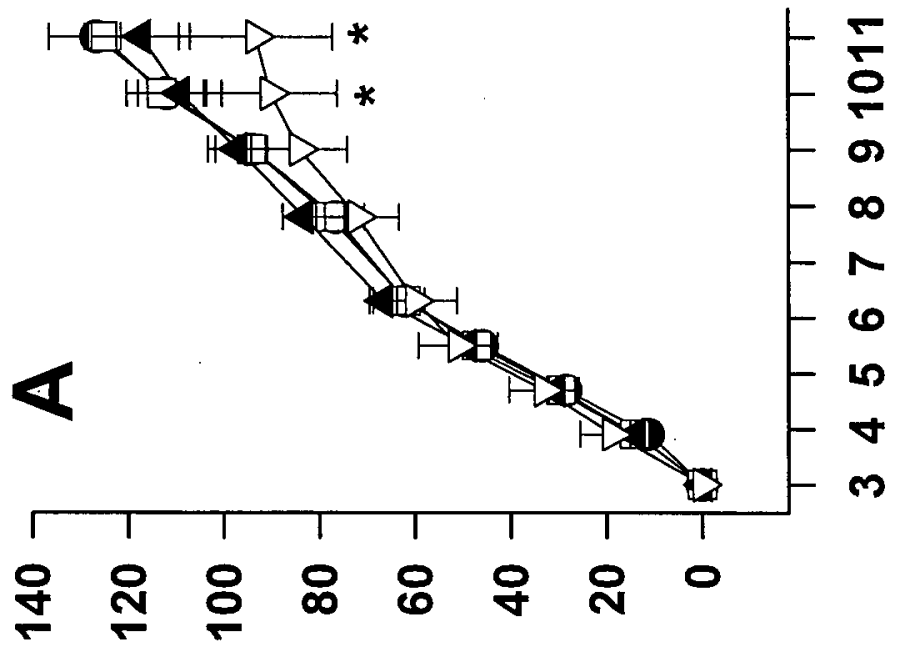

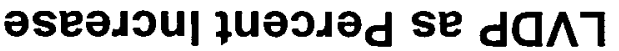

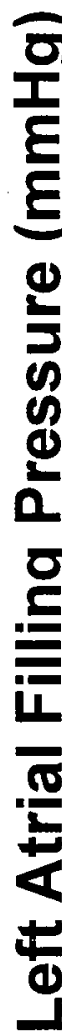

을 을

ᄃ.

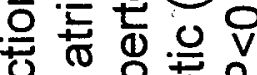

0 잉

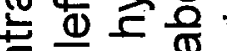

엉 苾范之

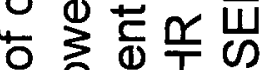

d 으로

닌 음

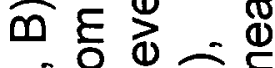

iิㄴㅇㅇ

吕离至

$>\underset{0}{\mathbb{0}} \stackrel{0}{0}$

(1) 잉

气. .5 造

की

d

文的需田

므잋

$\Phi 4$

ㄴㅇㅇ

ญ

व

\%

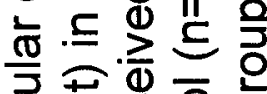

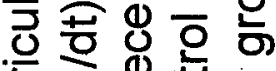

든 응 능

$\gg \pm+\frac{1}{\mathbb{0}} \circlearrowleft$

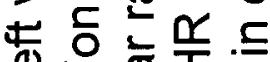

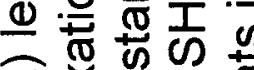

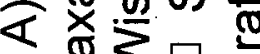

拧 $\frac{0}{0} \square$

ᄃ范宁市

음 또슬 은

\&

○吅

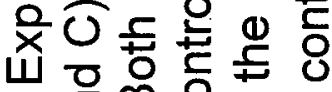

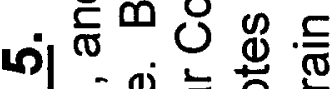

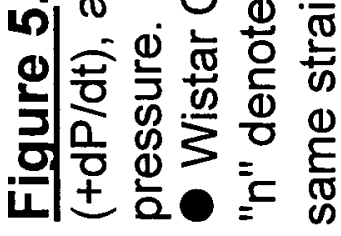



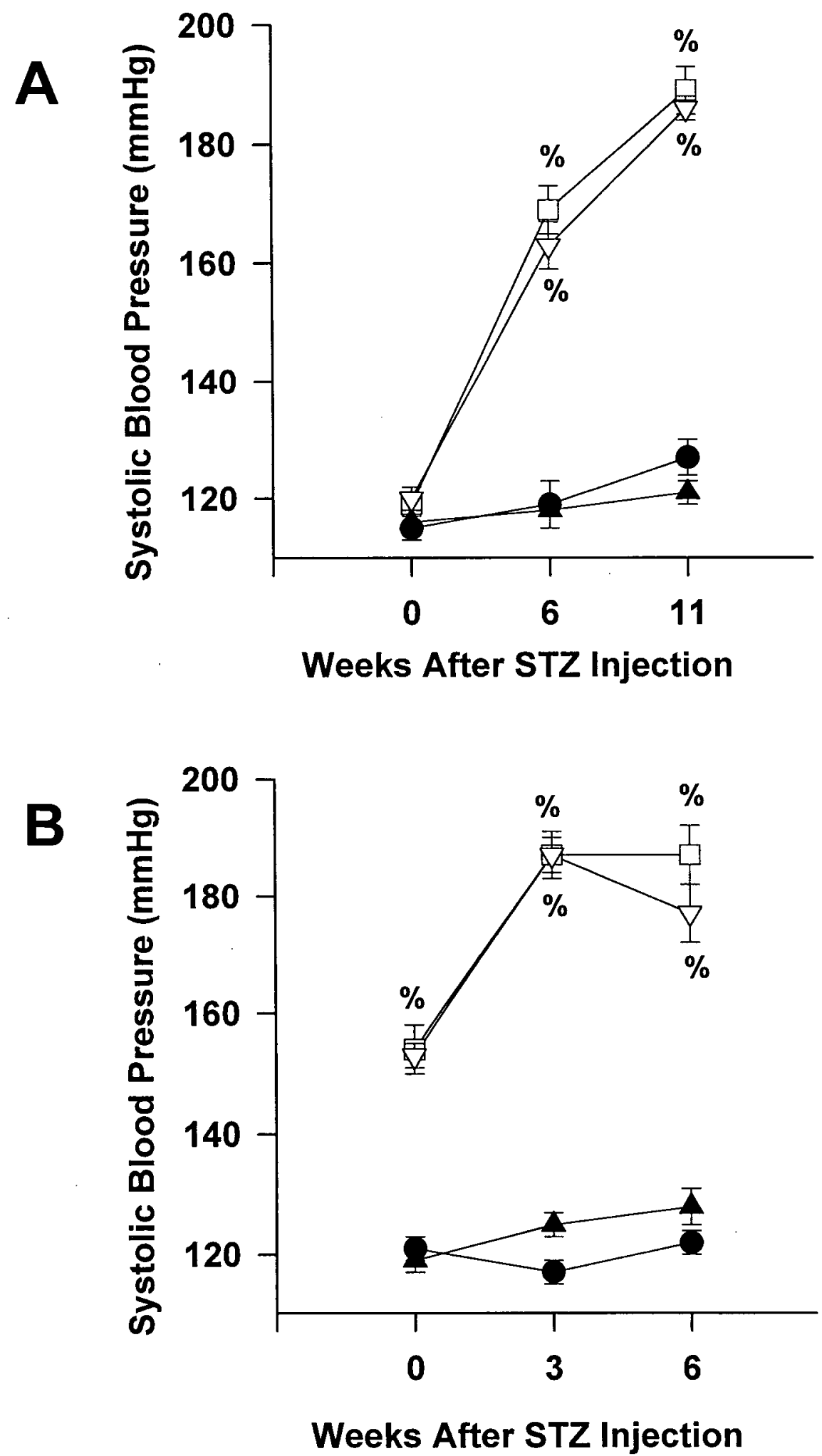

Figure 6. Systolic blood pressure of SHR and Wistar rats injected with STZ: A) before and $B$ ) after the development of hypertension. Blood pressure was measured using the indirect tail cuff method without external preheating.

Control $(n=10), \Delta \quad$ Wistar Diabetic $(n=9-11), \quad \nabla$ Wistar Control $(n=10)$, $\square$ SHR the number of rats in each group. Values are expressed as mean $+1-$ SEM. $\% P<0.05$ vs. both Wistar groups. 
Table 6. Comparison of Systolic Blood Pressure in SHR Using Direct Cannulation and Indirect Tail-Cuff Methods

\begin{tabular}{ccc}
\hline & $\begin{array}{c}\text { Direct } \\
\text { Cannulation } \\
(\mathrm{mmHg})\end{array}$ & $\begin{array}{c}\text { Indirect Tail-Cuff } \\
\text { (mmHg) }\end{array}$ \\
\hline SHR Control & 184 & 205 \\
$\# 1$ & 214 & 210 \\
\#2 & & 157 \\
Before Hypertension & 165 & 148 \\
After Hypertension & 146 & \\
\hline
\end{tabular}

Rats were Twenty-one Weeks of Age at Time of Blood Pressure Measurement 
A

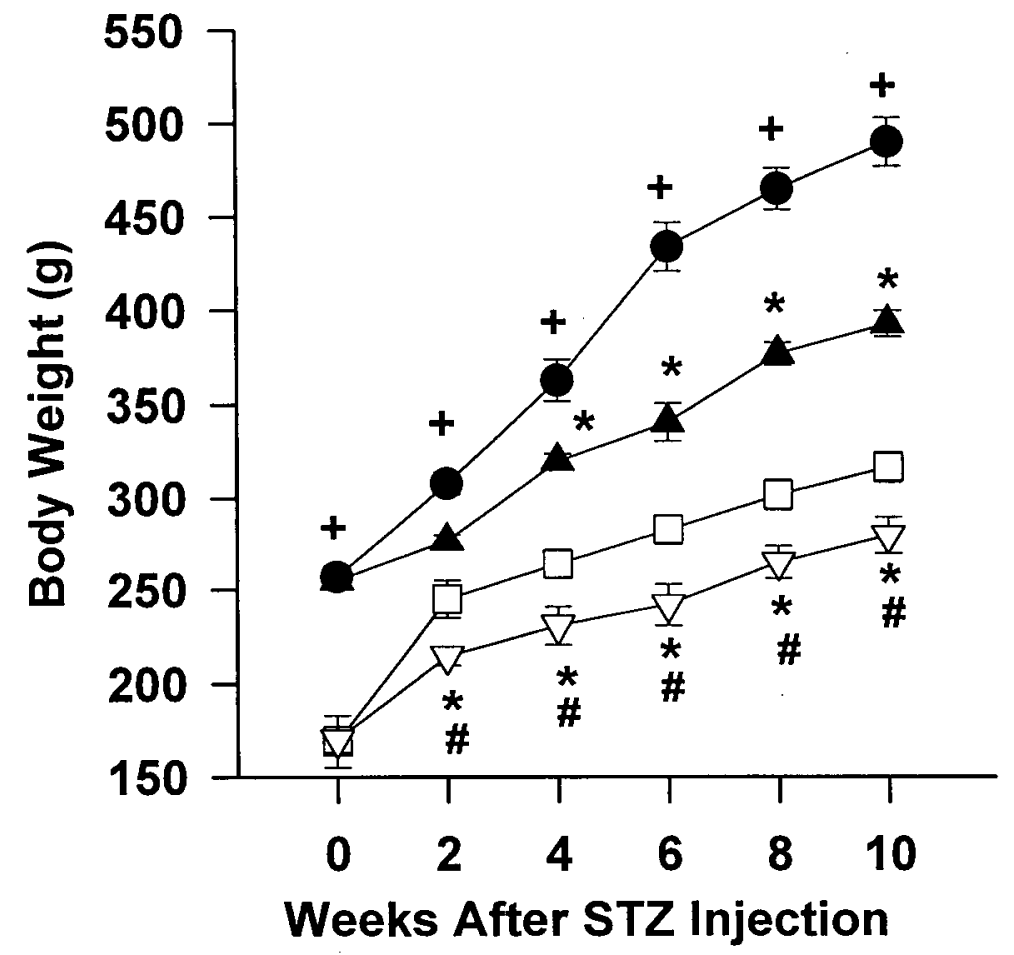

B

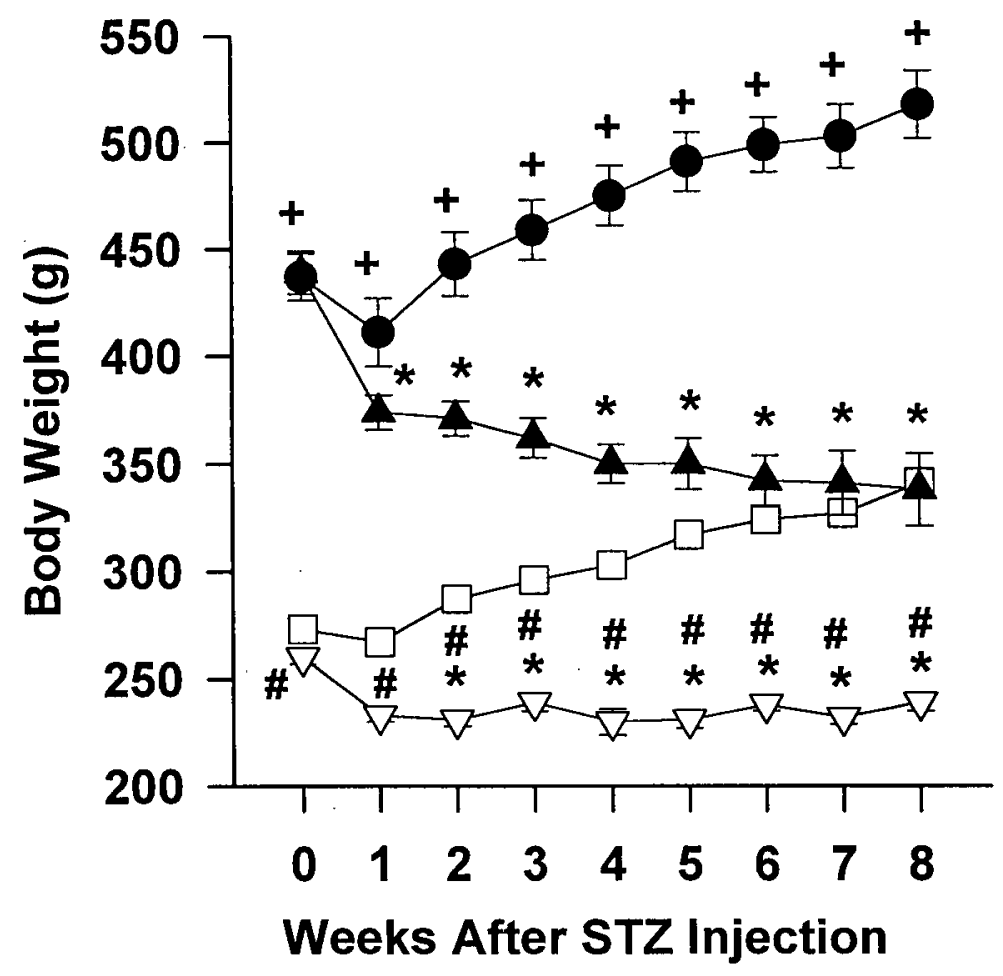

Figure 7. Body weight of SHR and Wistar rats injected with STZ at: A) eight weeks of age, and B) twelve weeks of age. Wistar Control $(n=10), \square$ SHR Control $(n=10)$, $\Delta$ Wistar Diabetic $(n=9-11), \nabla$ SHR Diabetic $(n=13)$. " $n$ " denotes the number of rats in each group. Values are expressed as mean $+/$ - SEM. ${ }^{*} P<0.05$ vs. same strain control. \# $P<0.05$ vs. WD group. + $P<0.05$ vs. SC group. 

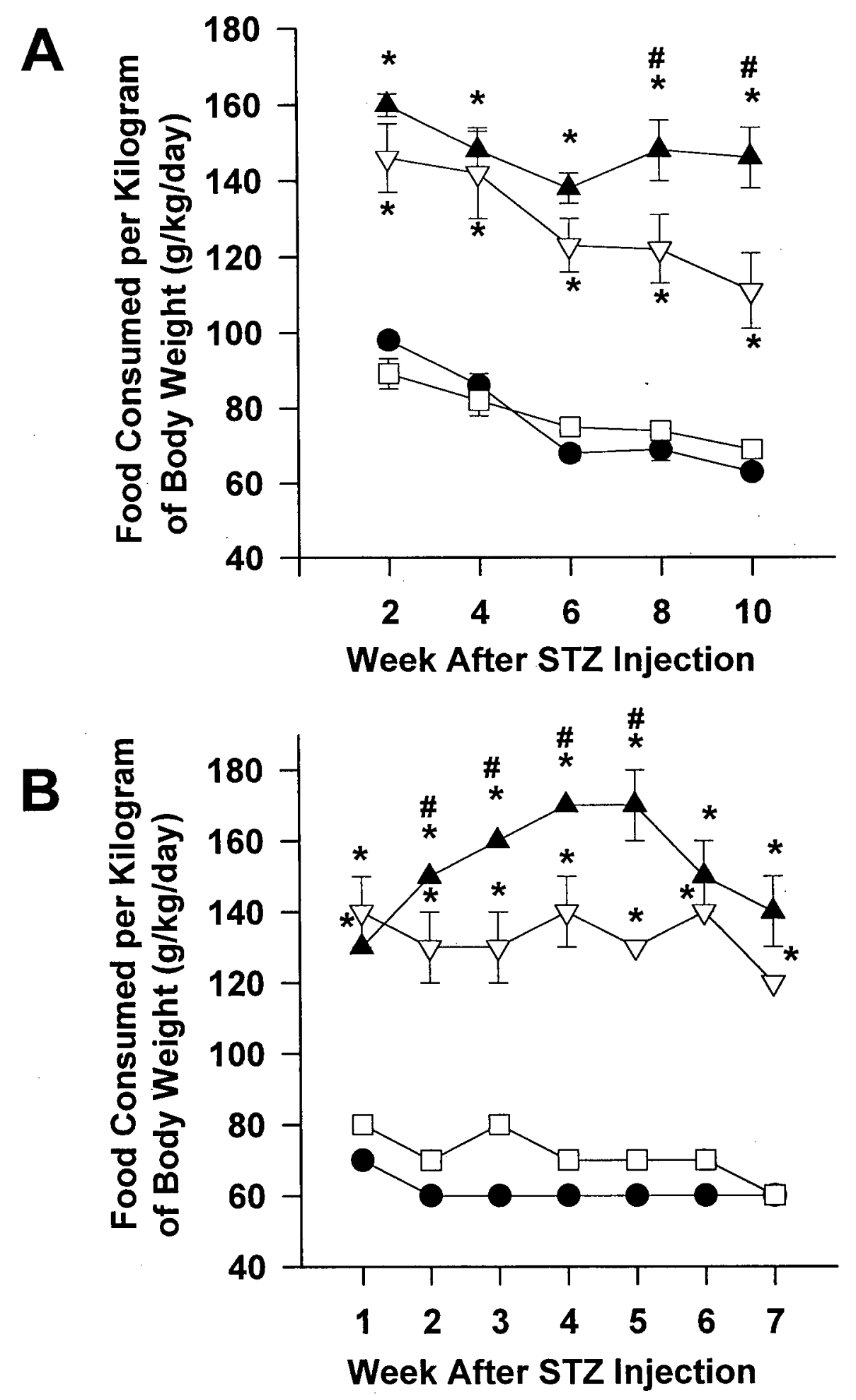

Figure 8. Food consumption per kilogram of body weight of SHR and Wistar rats injected with STZ at: A) eight weeks of age, and B) twelve weeks of age. Wistar Control $(n=10), \square$ SHR Control $(n=10), \quad \Delta$ Wistar Diabetic $(n=9-11), \nabla \quad$ SHR Diabetic $(n=13)$. " $n$ " denotes the umber of rats in each group. Values are expressed as mean $+/-$ SEM. ${ }^{*} P<0.05$ vs. same strain control. \# $P<0.05$ vs. WD group. 

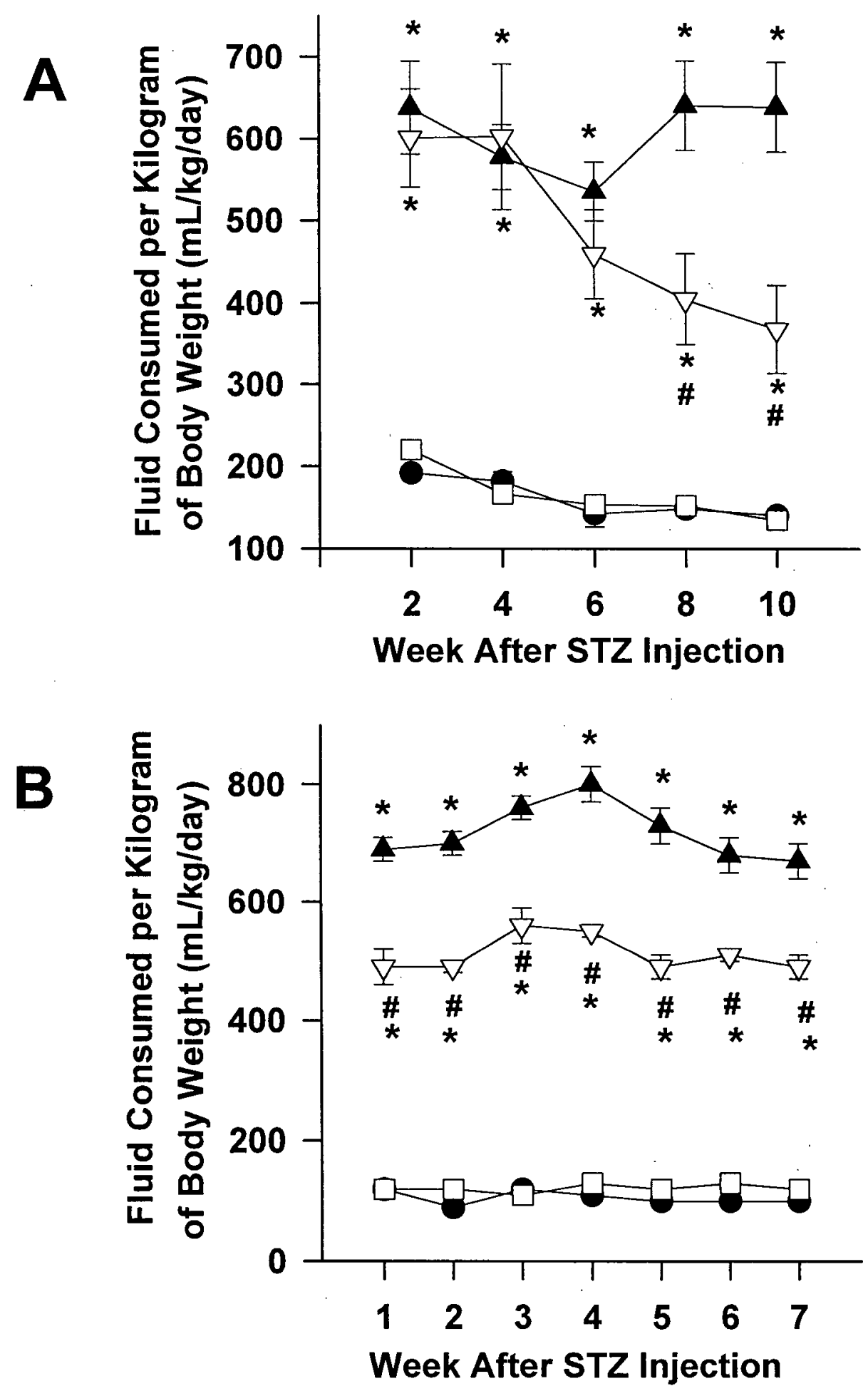

Figure 9. Fluid consumption per kilogram of body weight of SHR and Wistar rats injected with STZ at: A) eight weeks of age, and B) twelve weeks of age. Wistar Control $(n=10), \quad \square \quad$ SHR Control $(n=10), \quad \Delta \quad$ Wistar Diabetic $(n=9-11), \quad \nabla$ SHR Diabetic $(n=13)$. " $n$ " denotes the number of rats in each group. Values are expressed as mean $+/$ - SEM. ${ }^{*} P<0.05$ vs. same strain control. \# $P<0.05$ vs. WD group. 

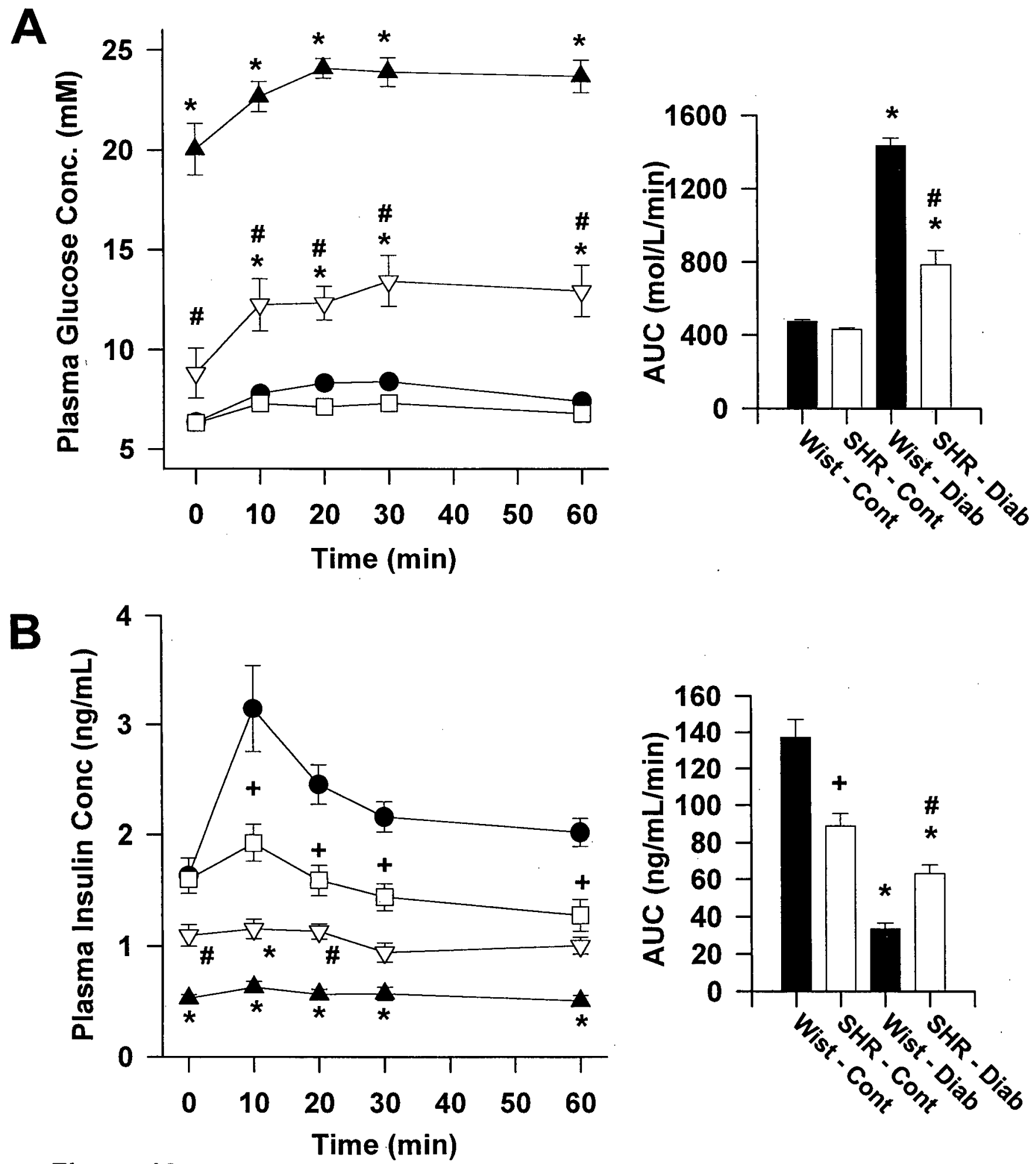

Figure 10. Plasma A) glucose and B) insulin levels of overnight-fasted SHR and Wistar rats injected with STZ at eight weeks of age. SHR received $45 \mathrm{mg} / \mathrm{kg} \mathrm{STZ}$

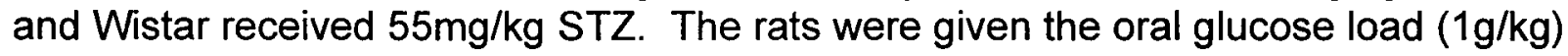
one week prior to termination (19 weeks of age). The figures represent the plasma profile over the time course of the OGTT as well as the integrated area under the curve (AUC) over 60 minutes. Wistar Control $(n=10), \quad \square$ SHR Control $(n=10), \quad \Delta$ Wistar Diabetic $(n=9), \quad \nabla$ SHR Diabetic $(n=13)$. " $n$ " denotes the number of rats in each group. Values expressed as mean $+/$ - SEM. ${ }^{*} P<0.05$ vs. same strain control. \# $P<0.05$ vs. WD group. $+\mathrm{P}<0.05$ vs. WC group. 

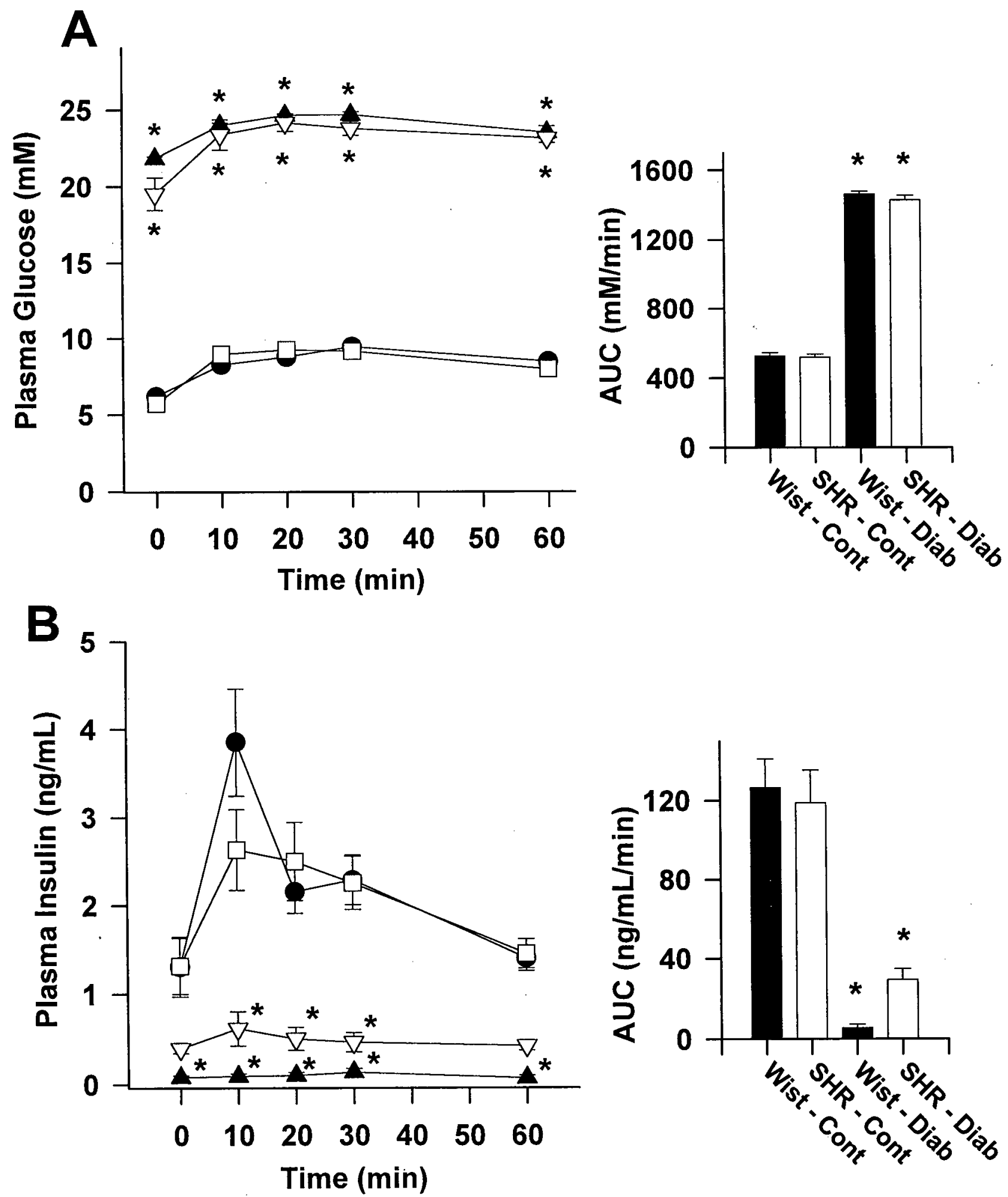

Figure 11. Plasma A) glucose and B) insulin levels of overnight-fasted SHR and Wistar rats injected with STZ at twelve weeks of age. SHR received $45 \mathrm{mg} / \mathrm{kg} \mathrm{STZ}$

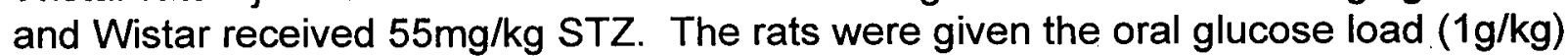
one week prior to termination (19 weeks of age). The figures represent the plasma profile over the time course of the OGTT as well as the integrated area under the curve (AUC) over 60 minutes.

Wistar Control $(n=6)$,

SHR Control $(n=6)$,

Wistar

Diabetic $(n=6), \nabla \quad$ SHR Diabetic $(n=6)$. " $n$ " denotes the number of rats in each group. Values expressed as mean $+/-\mathrm{SEM}$. ${ }^{*} \mathrm{P}<0.05$ vs. same strain control. 
Table 7. Percentage of SHR and Wistar Rats Remaining Diabetic At Termination

$\begin{array}{ccc}\text { Number } & \text { Number } & \text { Percentage } \\ \text { Injected } & \begin{array}{c}\text { Remaining } \\ \text { Diabetic }\end{array} & \text { Diabetic }\end{array}$

Eight Weeks of age

$\begin{array}{llll}\text { SHR Diabetic } & 13 & 9 & 69 \% \\ \text { Wistar Diabetic } & 10 & 9 & 90 \%\end{array}$

Twelve Weeks of age

$\begin{array}{llll}\text { SHR Diabetic } & 14 & 13 & 93 \% \\ \text { Wistar Diabetic } & 10 & 10 & 100 \%\end{array}$

SHR were injected with $45 \mathrm{mg} / \mathrm{kg} \mathrm{STZ}$ and Wistar rats received $55 \mathrm{mg} / \mathrm{kg}$ STZ. Rats injected at eight weeks of age correspond to SHR Study \#2, which were injected before hypertension. SHR Study \#3 corresponds to the rats injected at twelve weeks of age, after the development of hypertension in the SHR. 


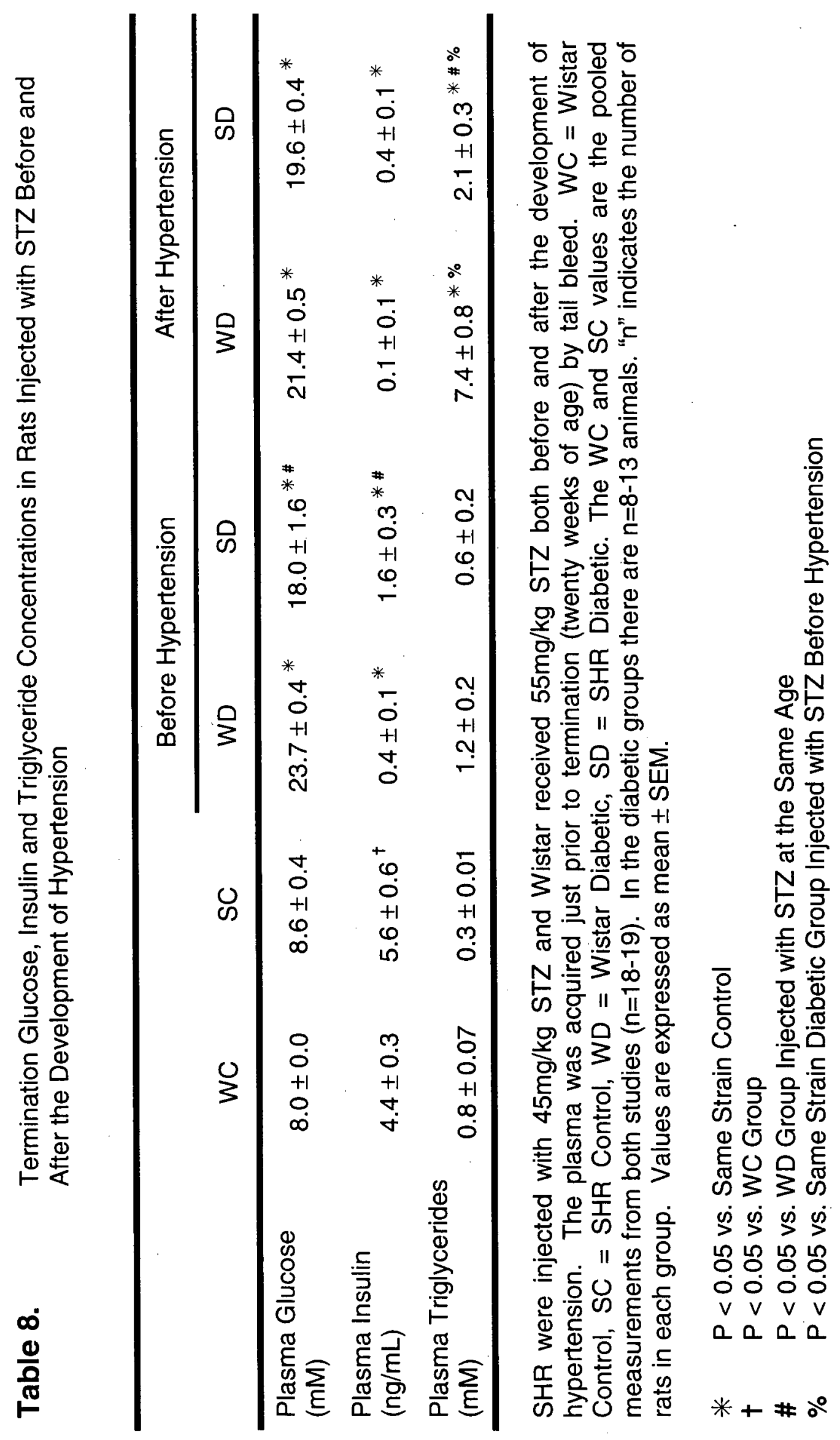




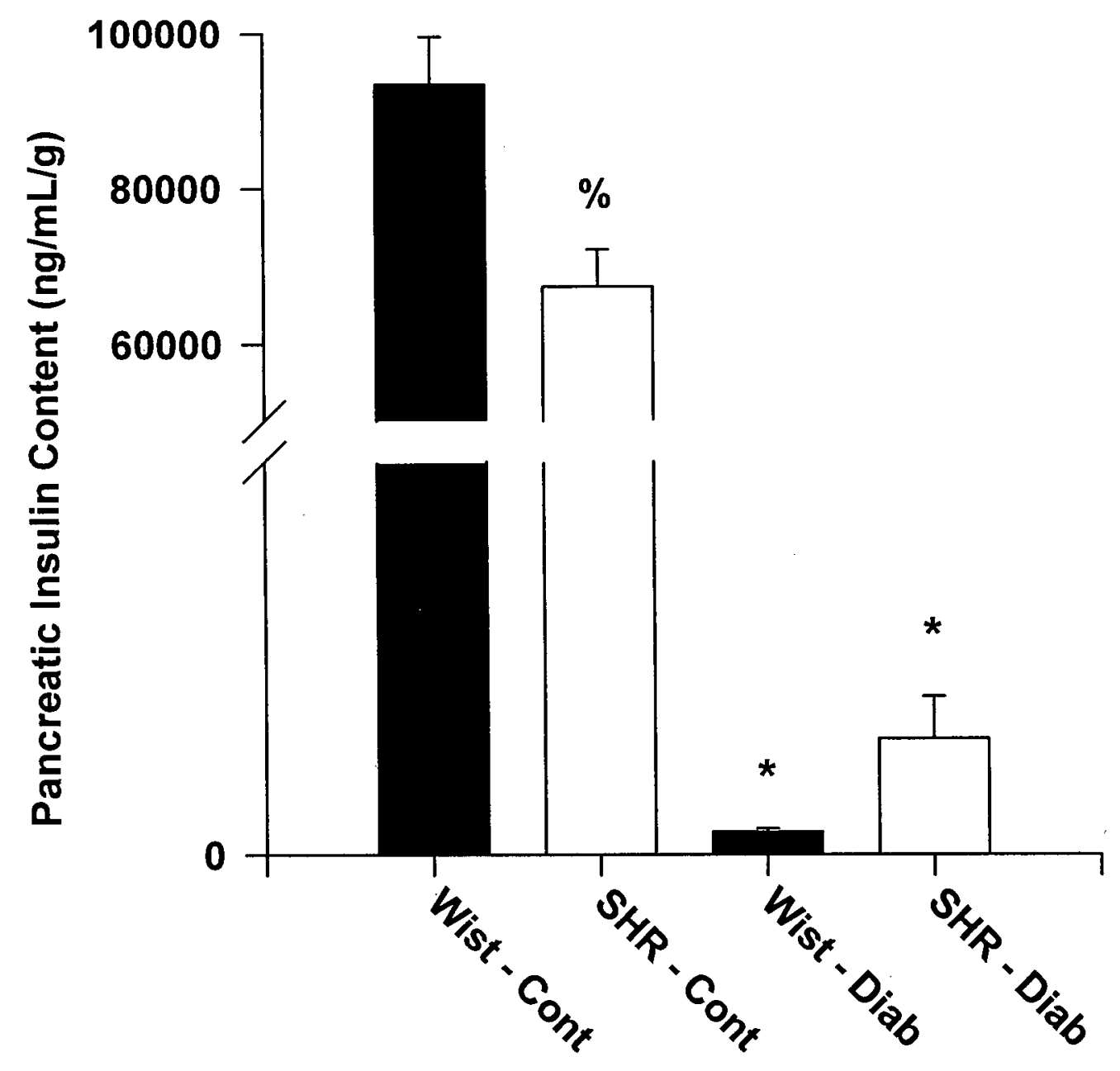

Figure 12. Pancreatic insulin content of diabetic and hypertensive rats injected with STZ before the development of hypertension. SHR received

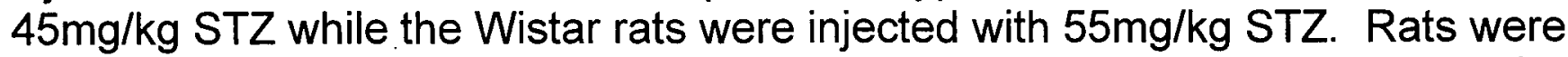
eight weeks of age at the time of injection. Values are expressed as mean +/SEM. ${ }^{*} \mathrm{P}<0.05$ vs. same strain control. \% $\mathrm{P}<0.05$ vs. WC group (by t-test). 


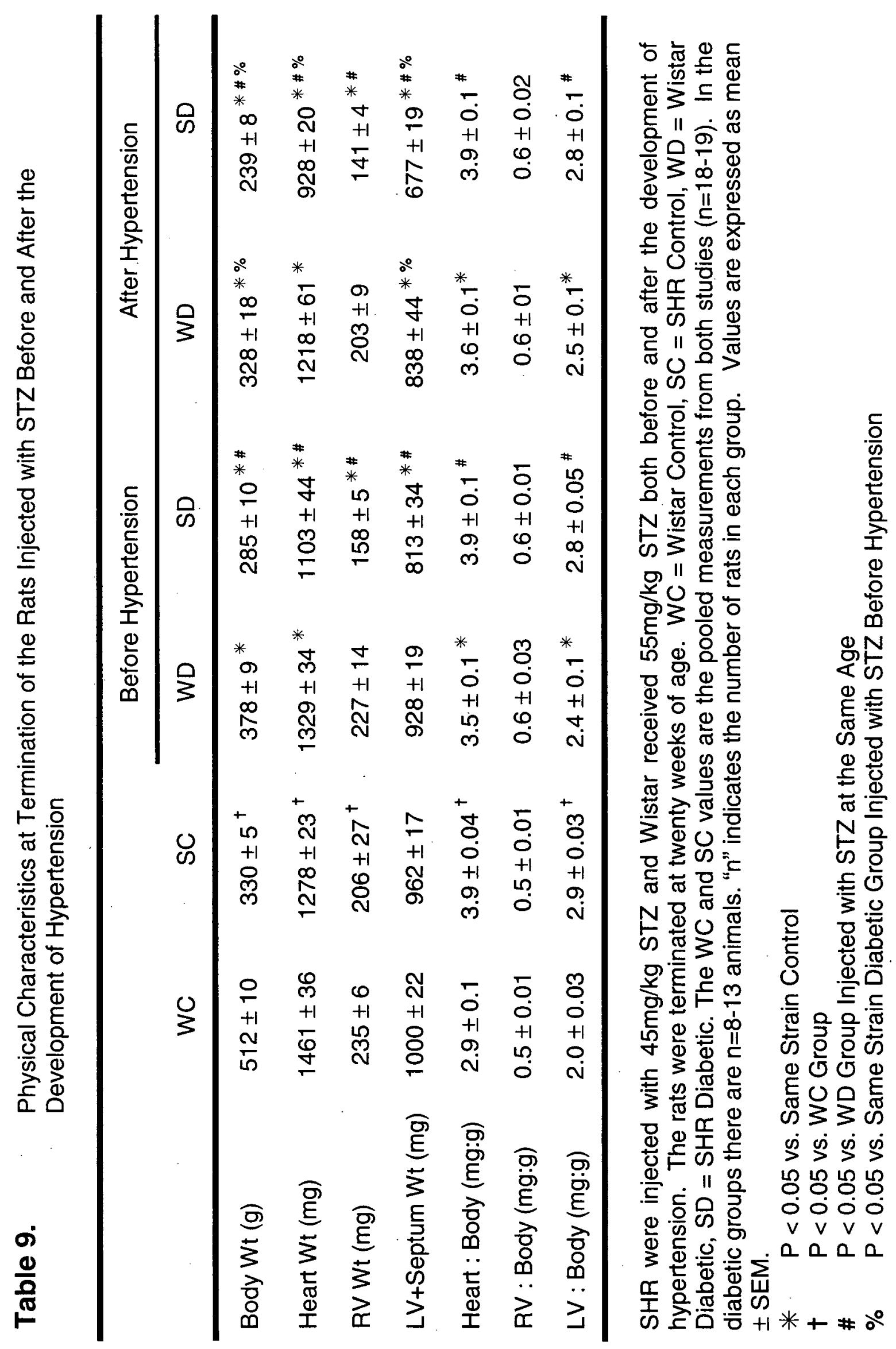



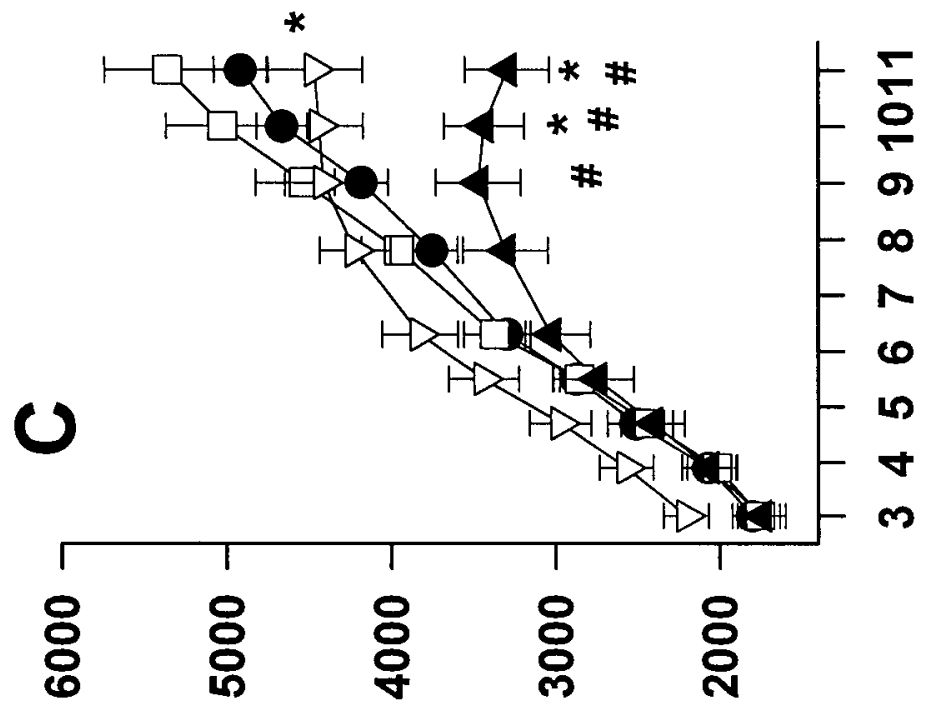

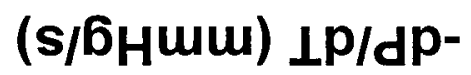
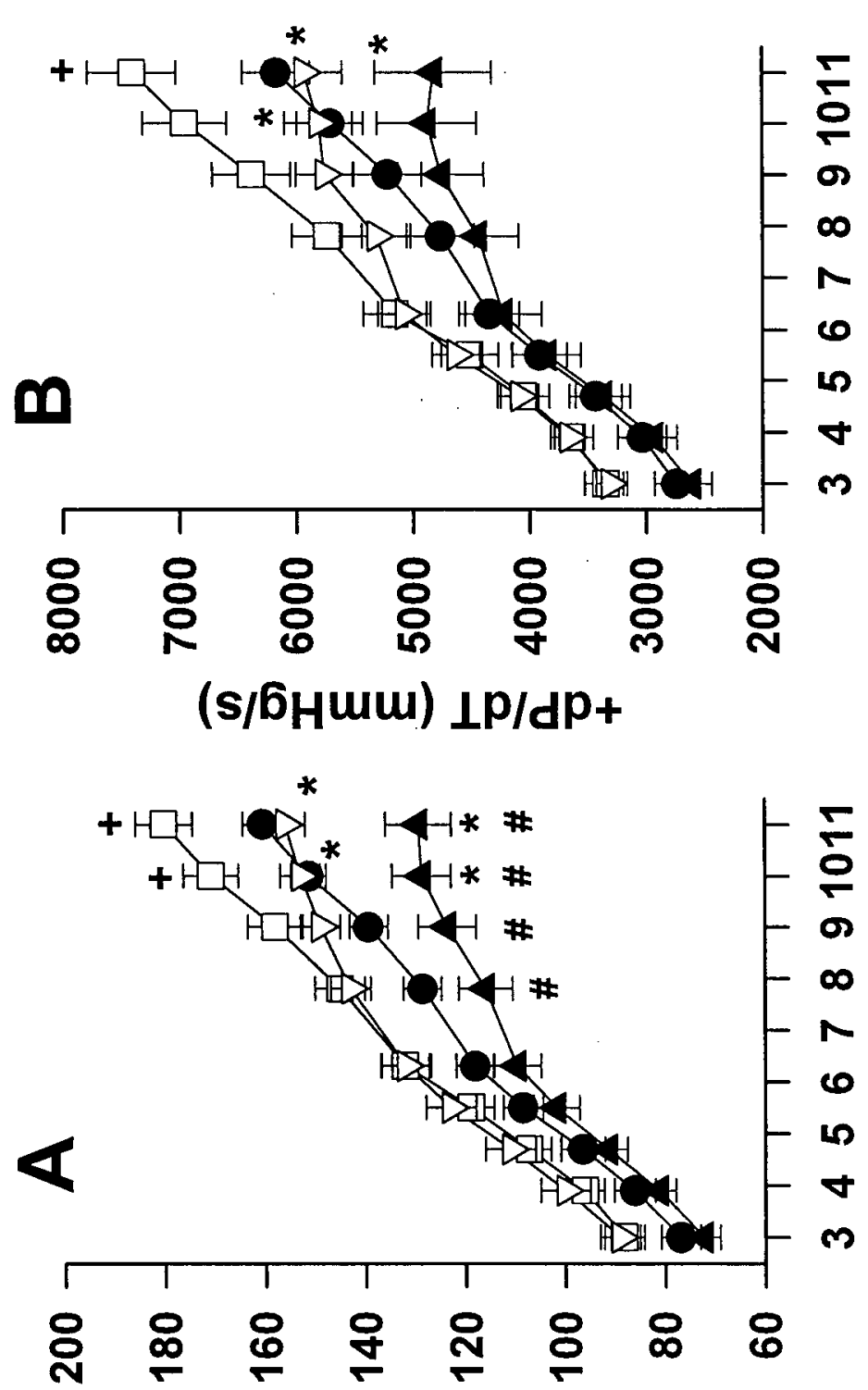

(6Hum) da^7

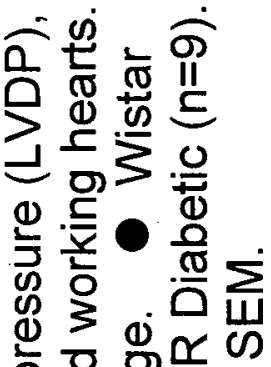

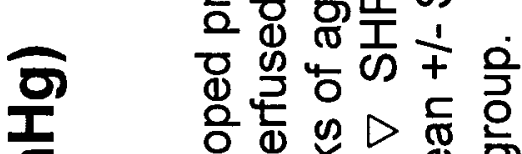

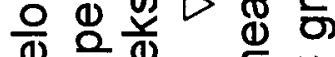

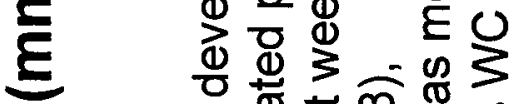

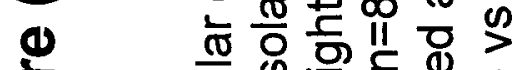

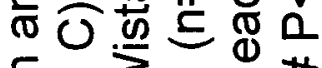

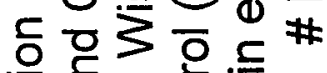

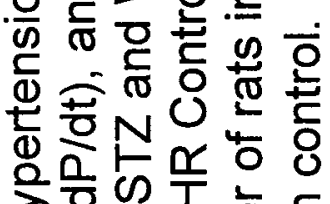

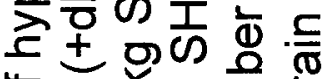

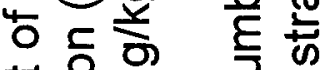

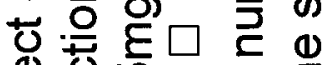
岁 山文 ค m Ф) $₫ \overline{0} 0$

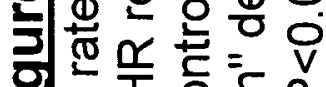

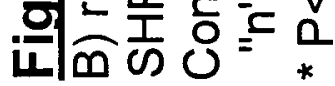




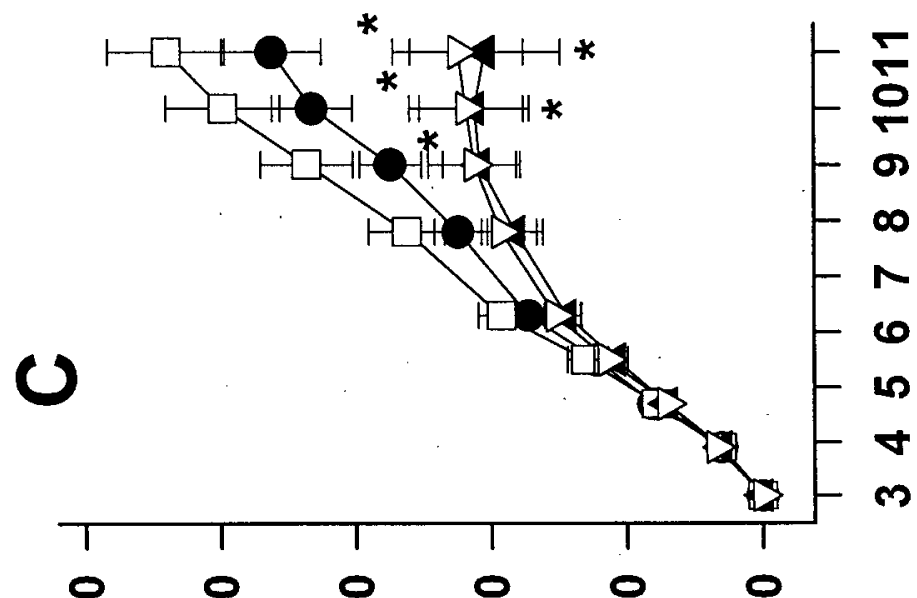

융 융유 융

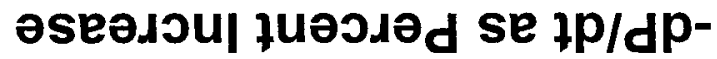

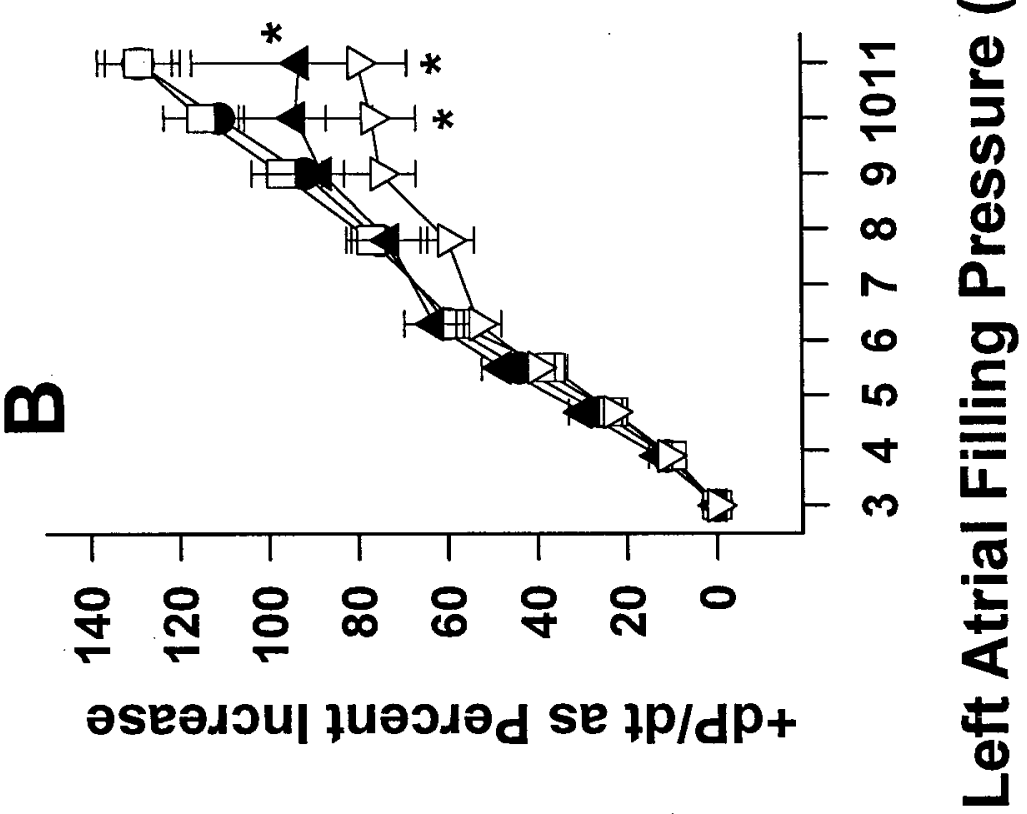

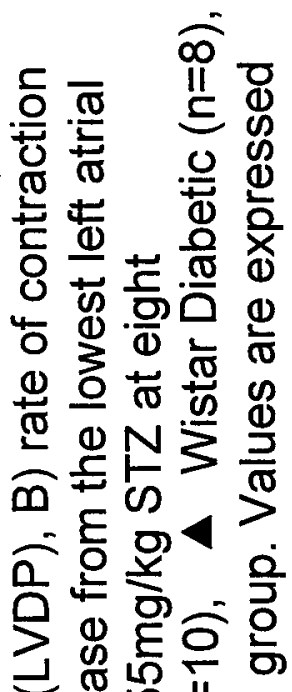

刃

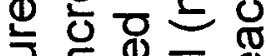

政

क्ष

क ष्ठ

은

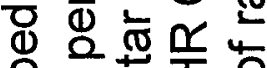

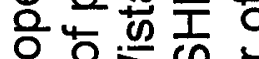

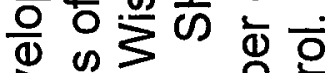

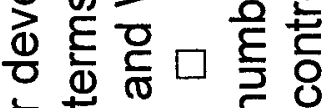

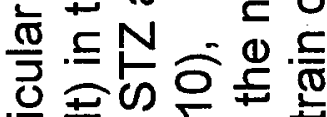

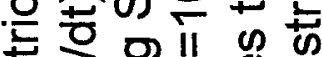

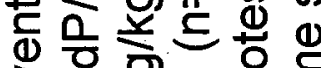

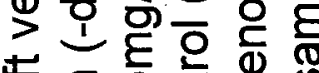

需 ᄃ

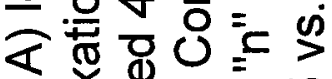

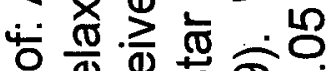

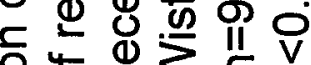

응

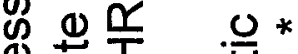

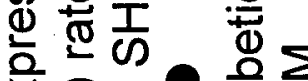

$x \widehat{0}$

i.

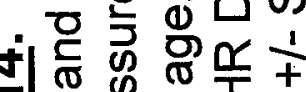

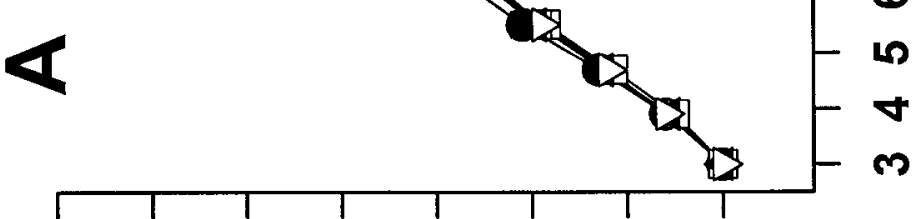

๑)

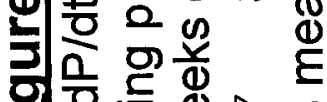

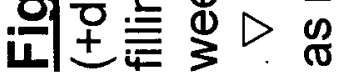




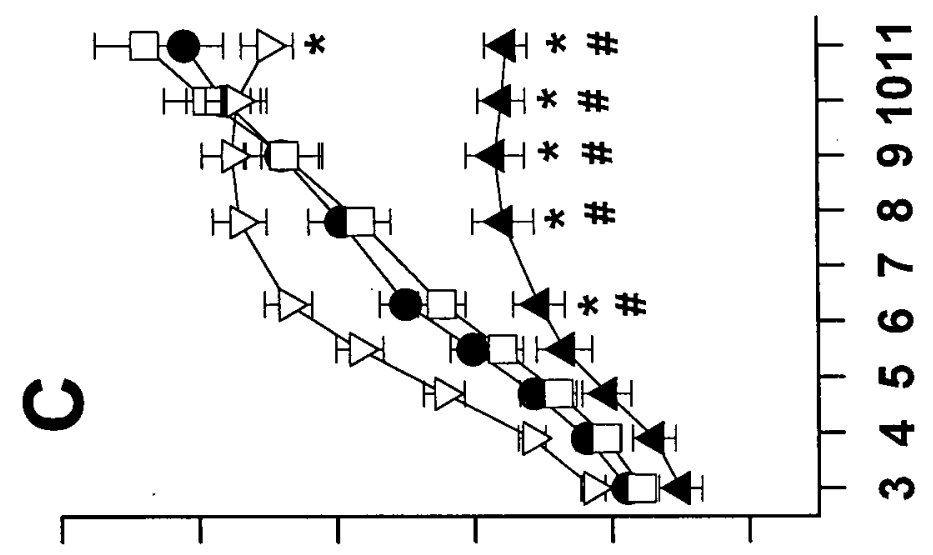

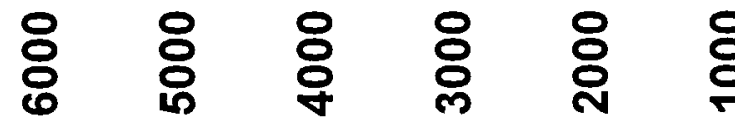 \\ (s/6Huw) Ip/dp-}
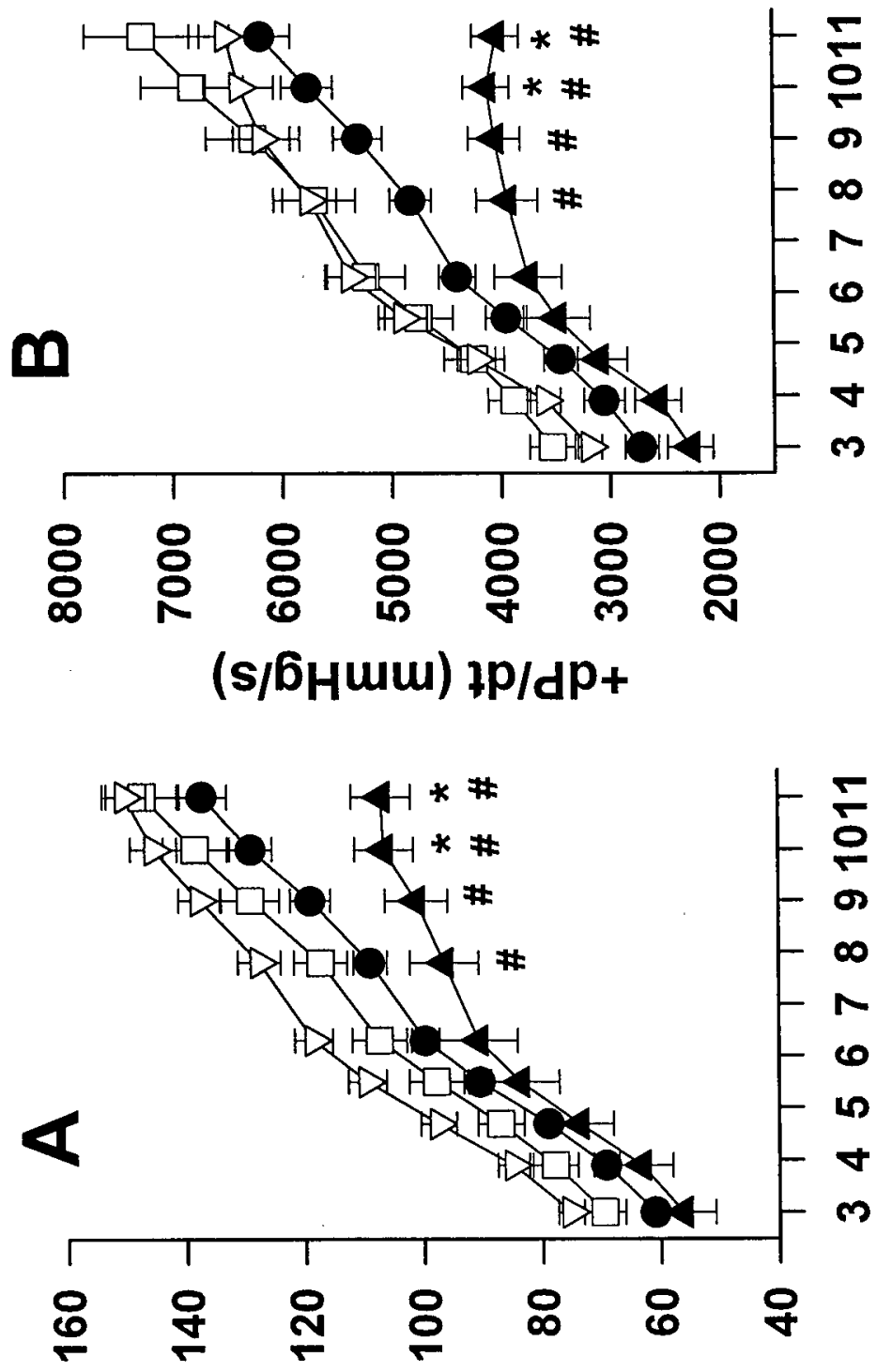

(Бнmس) da^า

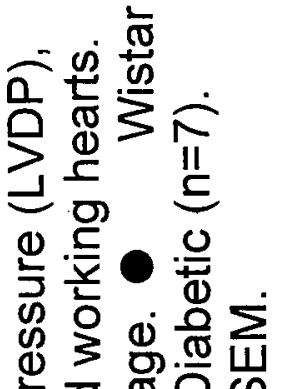

응 ฮั

엉

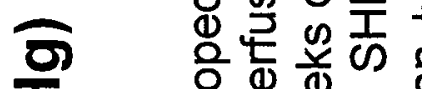

을 ฏ

४⿻

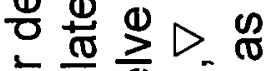

元 $\frac{0}{0} \approx 0$

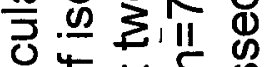

. 는

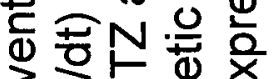

工的。

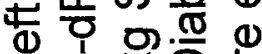

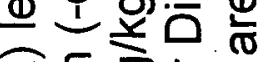

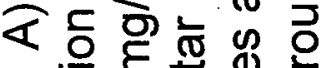

$\therefore$ 完

중ำ

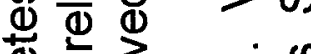

造这《只

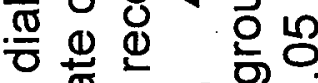

은

তั

등ํ요

음 它은 은 $\subseteq$ ㅎ

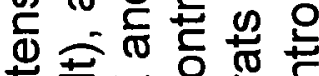

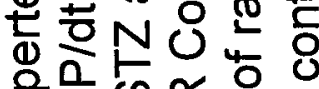

응웡엉

처웜

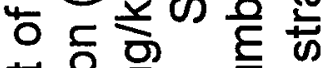

너을 을

出它守口它

山艺它市

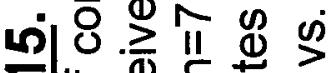

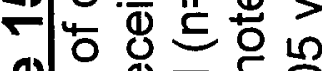

인

5 뜬

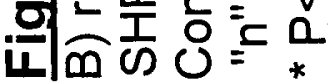



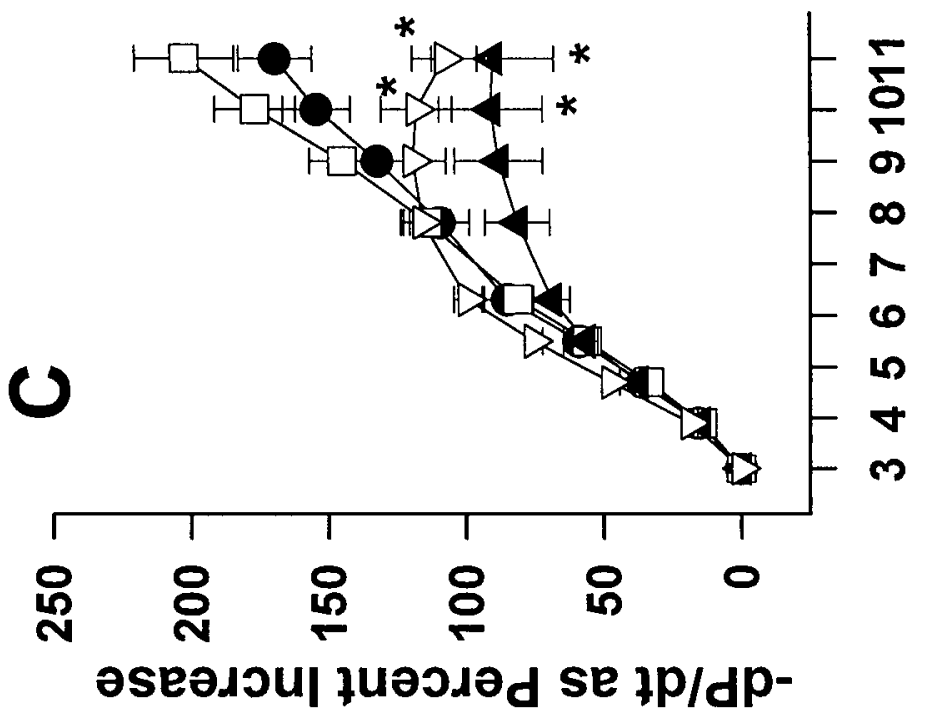

$\frac{\text { 욜 }}{\varepsilon}$
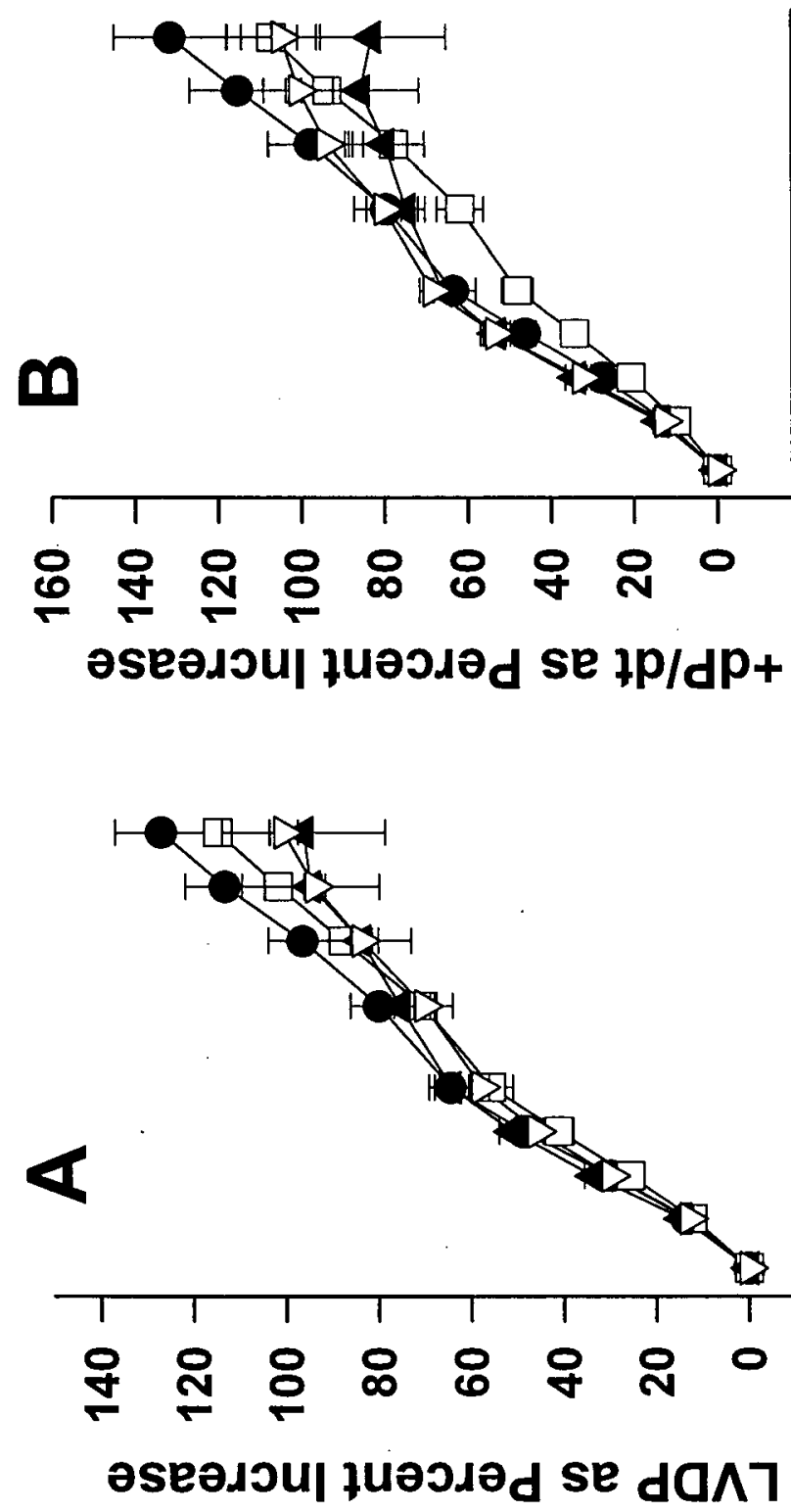

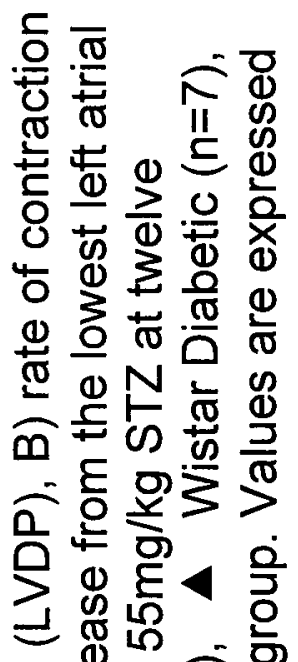
๒

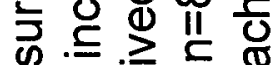
क

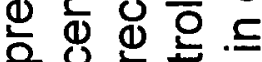
음 는 劳

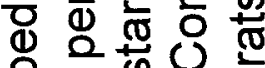
는 응 论号乐。 む) ญ 克. 它吾的会市

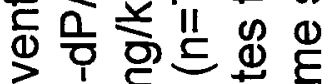

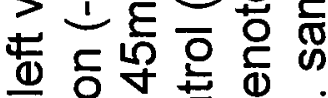
く苗

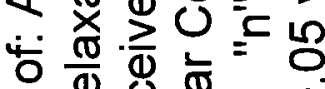

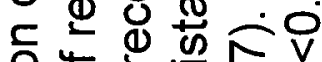

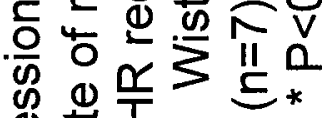
产的。施 யல凹.

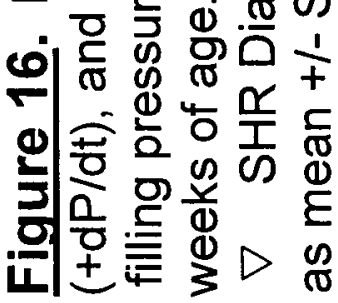




\section{DISCUSSION}

The objective of this thesis was to examine whether or not hypertension exacerbated the development of diabetic cardiomyopathy. Previous reports in the literature have suggested that this was likely the case, but the possibility existed that the increased dysfunction reported in the diabetic SHR was due to the increased susceptibility of this strain to STZ and not because of any additive or synergistic effect of the two disease states. To answer this question, diabetes was induced in the SHR using a dose of $45 \mathrm{mg} / \mathrm{kg} \mathrm{STZ}$ whereas the Wistar were given $55 \mathrm{mg} / \mathrm{kg}$ of the diabetogen. Because the doses were modified to produce a closer level of diabetes, the effect of hypertension on diabetic cardiomyopathy could be examined.

The spontaneously hypertensive rat (SHR) was used as the model of hypertension for a number of reasons (Doggrell and Brown, 1998). The first reason was the genetic composition of the SHR. Within each breeding colony, the SHR have a uniform genetic makeup, and it is this lack of inter-animal variation that makes this strain so appealing to researchers. The increase in blood pressure develops in $100 \%$ of the animals within two months of birth and continually rises to a plateau of about $200 \mathrm{mmHg}$. And because this is a genetic model of hypertension, there is no treatment required, either surgical or chemical, to induce the increase in blood pressure. This is an important advantage compared to models such as renovascular hypertension (RVH) which requires a surgical procedure to restrict renal blood flow. Another advantage of the SHR is that it follows the same progression of hypertension as the human condition, which includes prehypertensive, developmental and sustained hypertensive phases. One final advantage of 
the SHR is the fact that it is the most common model of hypertension and has been much more extensively studied than other genetic or experimental models.

Although the SHR has many advantages over other models of hypertension, there are a few drawbacks. One problem with the SHR is the lack of a normotensive control. The WKY strain was bred from the same colony of Wistar rats as the SHR but the large degree of genetic variation and resulting phenotypic differences limit their use for comparative studies (Kurtz and Morris, 1987; St. Lezin et al, 1992). Secondly, it is not known exactly which mechanisms are involved in the development of hypertension in the SHR. It has been estimated that up to six genes contribute to the elevation in blood pressure but they have not been positively identified at this time. Several quantitative trait loci have been identified for hypertension, but the actual genes involved and the role they play in the development of high blood pressure is not known (Kovacs et al, 1997; Kren et al, 1997). Thirdly, the lack of genetic variation between individual animals means that the SHR can be a model for only one of many possible causes of human hypertension.

\section{Insulin and Hypertension in the Spontaneously Hypertensive Rat}

An area that has garnered a lot of attention recently is the association between hyperinsulinemia, insulin resistance and hypertension. Patients with Type 2 diabetes and obesity show an increased risk of developing hypertension (Duston, 1985; Tarnow et al, 1994), whereas many patients with essential hypertension are hyperinsulinemic and insulin resistant (Ferrannini et al, 1987; Reaven, 1991). Insulin resistance and/or hyperinsulinemia have also been documented in several models of hypertension including the SHR (Mondon and Reaven, 1988), the Dahl rat (Kotchen et al, 1991) and the 
fructose-fed hypertensive rat (Hwang et al, 1987). Our results confirm that the SHR are hyperinsulinemic compared to the Wistar rats because, in both non-fasted and five-hour fasted states, plasma insulin levels were higher in the SHR compared to the Wistars (Tables 2 and 4). At the same time, plasma glucose levels were equivalent for both strains. Numerous other reports have documented the hyperinsulinemic state of SHR compared to both Wistar and WKY controls in fasted and non-fasted conditions (Bhanot and McNeill, 1994a; Dai et al, 1994; Verma et al, 1994a). These results suggest that the SHR require a greater plasma insulin concentration to maintain euglycemia than do the Wistars and are resistant to the glucose-disposing effects of insulin. However, there are conflicting reports in the literature as to whether or not the SHR exhibit impaired glucose tolerance. In euglycemic clamp studies performed during general anesthesia, the SHR demonstrated insulin resistance compared to WKY rats (Hulman et al, 1991). On the other hand, several other investigators have demonstrated that the SHR were not insulin resistant when the clamp study was performed in conscious, unstressed animals (Frontoni et al, 1992; Buchanan et al, 1992a; Bhanot et al, 1994c). SHR show a more enhanced response of the sympathetic nervous system (SNS) to stress than WKY which could lead to a greater impairment of glucose metabolism in the former strain when they are anesthetized or restrained (McMurtry and Wexler, 1981). Although the evidence indicates that the SHR are not insulin resistant compared to WKY rats, Buchanan and colleagues (1992b) showed that SHR had an exaggerated insulin response to a glucose challenge. The insulin response to a glucose load in SHR was 2-3 fold greater than in WKY animals and it was suggested that the reason for the greater insulin release was $\beta$ cell hyperfunction in the absence of insulin resistance. The lack of insulin resistance was further confirmed when the authors showed that the 3-O-methylglucose transport rates 
into isolated skeletal muscle were similar for both SHR and WKY rats (Buchanan et al, 1992b). In SHR Studies \#2 and \#3, an OGTT was performed one week before termination and the data support the argument that the SHR were not insulin resistant (Figures 10 and 11). In fact, the lower $\mathrm{AUC}_{\mathrm{i}}$ value of the $\mathrm{SC}$ group in Study \#2 suggest that SHR may be insulin sensitive compared to Wistar rats (Figure 10). Unlike the results from Buchanan and colleagues (1992b), who demonstrated postprandial hyperinsulinemia in SHR 2-3 fold greater than the WKY, our results showed that the insulin surge in SHR was lower than in the Wistar controls. These results are consistent with the belief that SHR were not insulin resistant because, if insulin resistance was present, a greater insulin concentration would be required to dispose of the glucose load and maintain euglycemia. A lower insulin surge in response to a glucose load has also been demonstrated by other authors who compared SHR to both WKY and Wistar control groups (Dai et al, 1994; Jian et al, 1996). Thus, SHR have fasted and non-fasted hyperinsulinemia but are not insulin resistant compared to their normotensive controls. Although the reason for the elevated plasma insulin concentration has not been identified, several investigators have demonstrated a reduced insulin clearance in the SHR (Mondon and Reaven, 1988; Mondon et al, 1989; Buchanan et al, 1992a) which may explain the hyperinsulinemia we and other investigators have reported.

A strong association between hyperinsulinemia and hypertension was shown in a series of experiments using compounds that decreased plasma insulin levels and improved glucose tolerance. The main concept behind these studies was that if hyperinsulinemia was involved in the development of hypertension, then compounds that improved insulin sensitivity and lowered plasma insulin levels would decrease the blood 
pressure. In both SHR and fructose-hypertensive rats, insulin sensitizers such as vanadyl sulphate and metformin decreased the plasma insulin concentration and lowered systolic blood pressure (Bhanot and McNeill, 1994a; Bhanot et al, 1994b; Verma et al, 1994a; Verma et al, 1994b). Adding further support for the link between hyperinsulinemia and blood pressure was the fact that, while maintaining treatment with the drug, restoring the plasma insulin level back to pre-treatment levels with exogenous insulin reversed the lowering of blood pressure. In addition, it has been shown that maintaining a chronic elevation of plasma insulin in the conscious rat caused an increase in systolic blood pressure (Brands et al, 1991). However, it is important to note that improving insulin sensitivity in the SHR did not decrease blood pressure completely down to normotensive levels, indicating that other mechanisms likely contribute to blood pressure elevation.

There are several possible mechanisms by which hyperinsulinemia may result in the development of high blood pressure, including SNS overactivity, vascular smooth muscle growth and proliferation, and renal sodium and water reabsorption (Bhanot and McNeill, 1996). It has been well documented that acute, short-term insulin infusion and carbohydrate consumption in both humans and animals stimulates sympathetic nerve activity (Rowe et al, 1981; Anderson et al, 1991; Berne et al, 1992; Lembo et al, 1992). More recently, Vollenweider and colleagues (1993) showed that sympathetic activation was the result of hyperinsulinemia per se and was not due to insulin-induced stimulation of carbohydrate metabolism. Confirmation that insulin's sympathoexcitatory action was due to central mechanisms occurred when local administration of insulin in the forearm failed to stimulate any NE release, thus indicting that local stimulation of the SNS was not involved (Lembo et al, 1992). The action of insulin on the SNS has been linked to the ventro-medial neurons of the hypothalamus (Landsberg and Young, 1985). In these 
neurons, insulin-mediated glucose uptake and metabolism results in the suppression of an inhibitory pathway acting on tonically active sympathetic neurons. The end result is an increase in sympathetic activity. Consequently, the development of hyperinsulinemia increases sympathetic activity and could contribute to hypertension by several mechanisms, such as increasing cardiac output, vasoconstriction and volume expansion.

The SNS has been shown to play an important role in the development of hypertension in the SHR. As mentioned in the introduction, resting sympathetic nerve activity has been reported to be elevated in the SHR, and SNS stimulation results in an augmented norepinephrine release (Judy et al, 1979; Ekas and Lokhandwala, 1981). Confirmation of the role of the SNS on the development of hypertension in the SHR was shown when neonatal sympathectomy prevented the blood pressure increase (Lee et al, 1987). Similar to these results, in fructose-hypertensive rats, chemical sympathectomy (via adrenal medullectomy, followed by weekly 6-hydroxy-dopamine injections) prevented the development of hypertension (Verma, 1997). In addition, there is evidence that insulin also causes an exaggerated sympathetic neural response in SHR (Morgan et al, 1990). Since the SHR has been shown to be hyperinsulinemic compared to WKY or Wistar rats, it is possible that the elevated plasma insulin levels increase SNS activity and increase systolic blood pressure through the actions on the heart, vasculature and kidney.

Even though there is ample evidence that insulin increases sympathetic nervous system activity and vasoconstriction, recent evidence indicates that insulin decreases vascular resistance and increases skeletal muscle blood flow. This notion was supported by studies in both humans and animals showing that euglycemic hyperinsulinemia at high physiological concentrations stimulated the SNS but also increased skeletal muscle bloodflow without any rise in blood pressure (Anderson et al, 1991; Lembo et al, 1992; 
Lembo et al, 1993a; Pitre et al, 1996). In the fructose-hypertensive rat, a model of insulin resistance, insulin's vasodilatory effects are blunted which may be important in the development of hypertension in this model (Verma et al, 1997). The vasorelaxant effect of insulin has been shown to be mediated through both a direct action on the vascular smooth muscle (Kahn et al, 1993) and an indirect endothelium-mediated (nitric oxide) effect (Steinberg et al, 1994). The mechanism by which insulin increases nitric oxide production in not known at this time, but may be related to increasing tetrahydrobiopterin $\left(\mathrm{BH}_{4}\right)$ availability (Verma et al, 1998). In the SHR, Lembo and colleagues (1995) demonstrated that insulin was unable to decrease norepinephrineinduced vasoconstriction in aortic rings. In addition, they also showed that the defect was present in the pre-hypertensive stage and thus was not acquired with the hypertensive condition. Resistance to insulin's vascular effect has been reported in several conditions such as Type 2 diabetes (Laakso et al, 1992), essential hypertension (Lembo et al, 1993b) and obesity (Laakso et al, 1990) and may be involved in the development of high blood pressure in these conditions. This has led to the concept that resistance to insulin's vasorelaxant effect may imbalance the regulation of vascular tone. The hyperinsulinemic state of the SHR would lead to elevated sympathetic activity and vascular tone, but the lack of insulin-induced vasorelaxation might likely result in an imbalance of vascular regulation and thereby increase blood pressure.

A second mechanism by which hyperinsulinemia could increase blood pressure is through its direct actions on the vasculature. In cultured vascular smooth muscle cells (VSMC) from both humans (Pfeifle and Ditschuneit, 1981) and rats (Pfeifle et al, 1980), the addition of physiological concentrations of insulin to the culture medium resulted in an increased rate of proliferation. Supporting the in vitro data were experiments in intact 
animals using a model of arterial injury induced by de-endothelialization with a balloon catheter. Using this model, Ridray (1995) showed that hyperinsulinemia of a short duration (2-4 days) did not increase smooth muscle proliferation, but that chronic hyperinsulinemia (30 days) increased the smooth muscle mitogenesis. The author found that aortic thickness was higher in the hyperinsulinemic group and that this increase was due to a greater number of smooth muscle cells within the intimal layer.

Because the SHR are hyperinsulinemic compared their normotensive controls, it is possible that the elevated insulin levels may increase the growth and proliferation of VSMC and increase vascular resistance. This notion is supported by studies demonstrating an elevated insulin effect on VSMC growth from SHR compared to WKY rats (Begum et al, 1998). In addition, cultured vascular smooth muscle cells from SHR have been shown to grow faster than those from WKY rats (Yamori et al, 1981).

The final mechanism by which insulin can influence blood pressure development is by its action on the kidney to increase sodium and water retention. In normal humans, it has been reported that insulin infusion during an euglycemic clamp decreased the rate of urinary sodium excretion (Gans et al, 1991). These results were later confirmed in hypertensive patients, where insulin infusion was shown to directly increase sodium reabsorption in the proximal and distal tubules (Endre et al, 1994). Sodium and water retention has been shown to be elevated in young SHR, but normalized during the development of hypertension (Beierwaltes et al, 1982). In addition, the authors showed that restricting sodium intake in SHR attenuated the rate of blood pressure development but ultimately did not prevent the hypertension. These results indicate, at least in the SHR, that sodium and water retention do not play an important role in the development of high blood pressure. 
In the literature, there are numerous reports documenting a hypertensive, hypotensive, or no effect of STZ on blood pressure when using the tail-cuff method (see Tomlinson et al, 1992 for a list). However, direct measurement of blood pressure using an inter-arterial catheter has consistently shown that STZ treatment causes a decrease in blood pressure (Hebden et al, 1987; Tomlinson et al, 1992). The hypotensive effect of STZ has been documented in SHR and shown to be dose-dependent (Somani et al, 1979; Davidoff and Rodgers, 1990b; Sato et al, 1991). In our results, measurement of systolic blood pressure using the indirect tail-cuff method demonstrated that the induction of diabetes in the SHR attenuated the blood pressure increase in one study (SHR Study \#1) but not in the other two (SHR Study \#2 and \#3) (Figures 1 and 6). The reason for this discrepancy is not known at this time. Comparing systolic blood pressure in the same rat using both indirect tail-cuff and direct cannulation showed that STZ-injected SHR had lower blood pressure than the SHR control rats. In addition, it also showed that the tailcuff method provided a close approximation of actual systolic blood pressure, with three of the four indirect measurements being within $10 \mathrm{mmHg}$ of the direct value (Table 6).

Following the injection of STZ, several hemodynamic alterations take place that could underlie the changes in blood pressure. These changes include a decrease in peripheral resistance, cardiac contractility and heart rate, along with an increase in blood volume and cardiac output (Carbonell et al, 1987). It has been suggested that the underlying cause of systolic hypotension in STZ-treated rats may be a reduction in sympathetic activity. This notion was supported by studies demonstrating that ganglion blockade in control rats decreased systolic blood pressure to a significantly greater extent than in STZ-diabetic rats, indicating that the SNS was less active in the diabetic animals (Hebden et al, 1987). In addition, a decrease in plasma insulin levels due to caloric 
restriction has been associated with low sympathetic activity and blood pressure (Young and Landsberg, 1977). Consequently, a lower sympathetic drive in the STZ-diabetic rat would result in decreased vascular tone and lower blood pressure.

\section{Sensitivity of the SHR to STZ}

The motive behind the experiments in this thesis was based on several recent studies using the STZ-injected SHR which demonstrated that the addition of hypertension exacerbated the development of diabetic cardiomyopathy and resulted in more severe cardiac dysfunction (Rodrigues and McNeill, 1986; Rodgers, 1986). However, recent evidence has shown the SHR to be more sensitive to the diabetogenic effects of STZ than different normotensive strains (Somani et al, 1979; Voss et al, 1989; Jian et al, 1996). Thus, it is possible that the increased cardiac dysfunction reported in the diabetic-SHR animals could be due to an increased severity of the diabetic condition and not to the additive effect of hypertension and diabetes. Confirmation that SHR were more susceptible to STZ was provided in Study \#1 when both SHR and Wistar rats were injected with the same dose $(45 \mathrm{mg} / \mathrm{kg})$ of STZ. At this dose, several indices used to demonstrate the development of diabetes, such as body weight, food and fluid consumption and plasma insulin concentration indicated that the SHR were more diabetic than the Wistar rats (Figures 1 and 2; Tables 2 and 3). Our results are in agreement with previous reports in the literature that have examined the sensitivity of SHR to STZinduced diabetes. Somani and colleagues (1979) injected three doses of STZ $(25,37.5$, and $50 \mathrm{mg} / \mathrm{kg}$ ) in SHR and WKY rats and showed that, at a given dose of STZ, the SHR had a greater degree of hypoinsulinemia along with a greater depletion of pancreatic insulin content. Other investigators have confirmed that STZ causes a greater depletion 
of pancreatic insulin content and destruction of pancreatic islets in the SHR compared to normotensive control strains (Voss et al, 1989; Jian et al, 1996). By titrating the dose of STZ, Jian and others (1996) showed that $45 \mathrm{mg} / \mathrm{kg} \mathrm{STZ}$ in the SHR produced a level of diabetes equivalent to $55 \mathrm{mg} / \mathrm{kg} \mathrm{STZ}$ in the Wistar. The increased sensitivity to STZ may be related to the lower number and smaller mass of islet tissue found in the pancreas of the SHR (Postnov et al, 1976). Since approximately $90 \%$ of the $\beta$-cells need to be destroyed before the characteristics of diabetes appear (Bonnevie-Nielsen et al, 1981), the dose necessary to produce diabetes in the SHR should be lower because of the lower islet number and mass in this strain. However, not all reports agree that $\beta$-cell mass in the SHR pancreas is lower than in other strains (Iwase et al, 1989). It has been suggested that the SHR have an impaired ability to regenerate pancreatic $\beta$-cells, and that this may be a cause for the increased sensitivity to STZ. Tanigawa and colleagues (1996) demonstrated in rats subjected to $90 \%$ pancreactectomy that SHR had an impaired ability to regenerate $\beta$-cells compared to WKY rats. Although this may be a factor in the continuance of long-term. diabetes, a more severe diabetic condition has been demonstrated in the SHR within days of STZ-injection (Reaven and Ho, 1991; Jian et al, 1996), which suggests that $\beta$-cell regeneration may not be the primary reason for the increased sensitivity.

In the final two experiments, $45 \mathrm{mg} / \mathrm{kg} \mathrm{STZ}$ was injected in SHR and $55 \mathrm{mg} / \mathrm{kg}$ STZ was given to Wistars, both before (eight weeks of age) and after (twelve weeks of age) the development of arterial hypertension in the SHR. In both studies, the induction of diabetes resulted in depressed weight gain and increased food and fluid consumption. These are common symptoms associated with the diabetic state and have been documented in numerous studies examining the complications of diabetes (Rodrigues and 
McNeill, 1986; Yu and McNeill, 1991; Jian et al, 1996). In both SHR and Wistar rats, the severity of the diabetic condition increased when the STZ injection was given at twelve weeks of age. This was demonstrated during the OGTT by the significantly lower insulin release in response to the glucose challenge (Figure 11). Furthermore, the lower insulin levels coincided with an elevation in the plasma triglyceride concentration (Table 8). Although the plasma triglyceride levels of the SD group were significantly lower than those in the corresponding WD animals, this was due to the fact that the SHR strain had lower triglyceride levels compared to the Wistar strain. The reason for the hypotriglyceridemia in the SHR is unclear but has been documented in other recent reports (Jian et al, 1996; Sambandam et al, 1997).

Our results are consistent with other studies demonstrating an increasing sensitivity to STZ as the rat ages (Masiello et al, 1979). It has been reported that as the rat ages the number and volume of islets increase less rapidly than body weight so that in older rats there is less islet tissue per unit of body weight (Hellman, 1959). Furthermore, the ability of residual $\beta$-cells to regenerate after STZ injection may be impaired in older rats (Masiello et al, 1979), which could result in a more severe diabetic condition when coupled with the overtaxing of the remaining $\beta$-cells.

\section{Diabetes, Hypertension, and Cardiac Dysfunction}

For all three studies in this thesis, cardiac performance of co ntrol, diabetic and hypertensive rats was evaluated using the isolated working heart technique at twenty weeks of age. The advantage of this technique was that left ventricular function could be studied under normal and stressful conditions simply by varying the filling pressure of the left atria. Furthermore, by analyzing heart function in vitro instead of in vivo using a 
whole body preparation, the influence of sympathetic, parasympathetic and hormonal activity on the heart could be avoided.

Several factors including the dose of STZ, age of the rat at the time of injection and the development of hypertension had effects on contractile function at the higher left atrial filling pressures. In the diabetic Wistar rats, injection of $55 \mathrm{mg} / \mathrm{kg} \mathrm{STZ}$ resulted in depressed cardiac function whereas the lower dose of $45 \mathrm{mg} / \mathrm{kg}$ STZ caused no significant depression (Figures 4 and 13). The lack of dysfunction at the lower dose of STZ was due to the fact that only $40 \%$ of the Wistar rats were diabetic and that, as a group, the plasma insulin concentration was not significantly lower than the Wistar controls (Table 2). The impaired cardiac function documented in the Wistar rats at 55 $\mathrm{mg} / \mathrm{kg} \mathrm{STZ}$ and the SHR at both 45 and $55 \mathrm{mg} / \mathrm{kg} \mathrm{STZ}$ was accompanied by a significant decrease in insulin in all cases. The biochemical alterations which caused the cardiac dysfunction developed because of the STZ-induced hypoinsulinemia and not because of a direct effect of STZ on the heart (Fein et al, 1981; Tahiliani et al, 1983).

The age at which the rats were injected with STZ had a significant effect on the contractile function of the heart. Using the same dose of STZ, Wistar rats injected at the older age (twelve weeks old) developed more severe cardiac problems compared to the Wistars injected at eight weeks of age (Figures 13 and 15). The increase in cardiac dysfunction was likely due to the more severe diabetic condition that developed when older rats were injected with STZ. A previous section has already discussed the increased sensitivity of older rats to the diabetogenic effects of STZ. Evidence that the older rats were more diabetic included significantly depressed weight gain, severe emaciation of skeletal muscle and adipose tissue, lower plasma insulin release during the OGTT, and increased plasma lipid levels (see pages 38-40 for more details). 
The effects of chronic diabetes on the myocardium are numerous and include micro- and macroangiopathy, increased fibrosis and collagen deposition, altered contractile, SR and sarcolemmal protein function, and changes in the intracellular enzyme function (Table 10). Although the prevention of these changes has been shown to improve cardiac function (Tahiliani et al, 1983; Heyliger et al, 1985; Verma and McNeill, 1994), the underlying causes of the changes are not entirely clear. In recent years, increasing evidence has suggested that changes in carbohydrate and lipid metabolism, brought about by the diabetic condition, may be the underlying factor responsible for the development of diabetic cardiomyopathy (Rodrigues et al, 1995). Under normal conditions, an estimated $60-70 \%$ of myocardial energy is derived from fatty acid metabolism, with the other $20-30 \%$ derived from carbohydrates (Neely and Morgan, 1974). However, during diabetes carbohydrate metabolism decreases to the point where the heart is almost exclusively dependent on fatty acid oxidation for ATP production (Wall and Lopaschuk, 1989). An increase in fatty acid metabolism could have a detrimental effect on myocardial function by several mechanisms. First of all, $\beta$ oxidation of fatty acids has a greater oxygen requirement per mole of ATP produced than does glucose oxidation. This could have a detrimental effect on the contractile function of the heart, especially in times of heavy exercise or stress when the oxygen requirements of the muscle are higher. Secondly, elevated fatty acid oxidation may result in the accumulation of metabolic intermediates such as long chain acyl-CoA and acylcarnitine that could disrupt cellular function (Rodrigues et al, 1995). Many of these alterations, such as disruption of the sarcolemmal and SR membranes, and inhibition of enzyme 


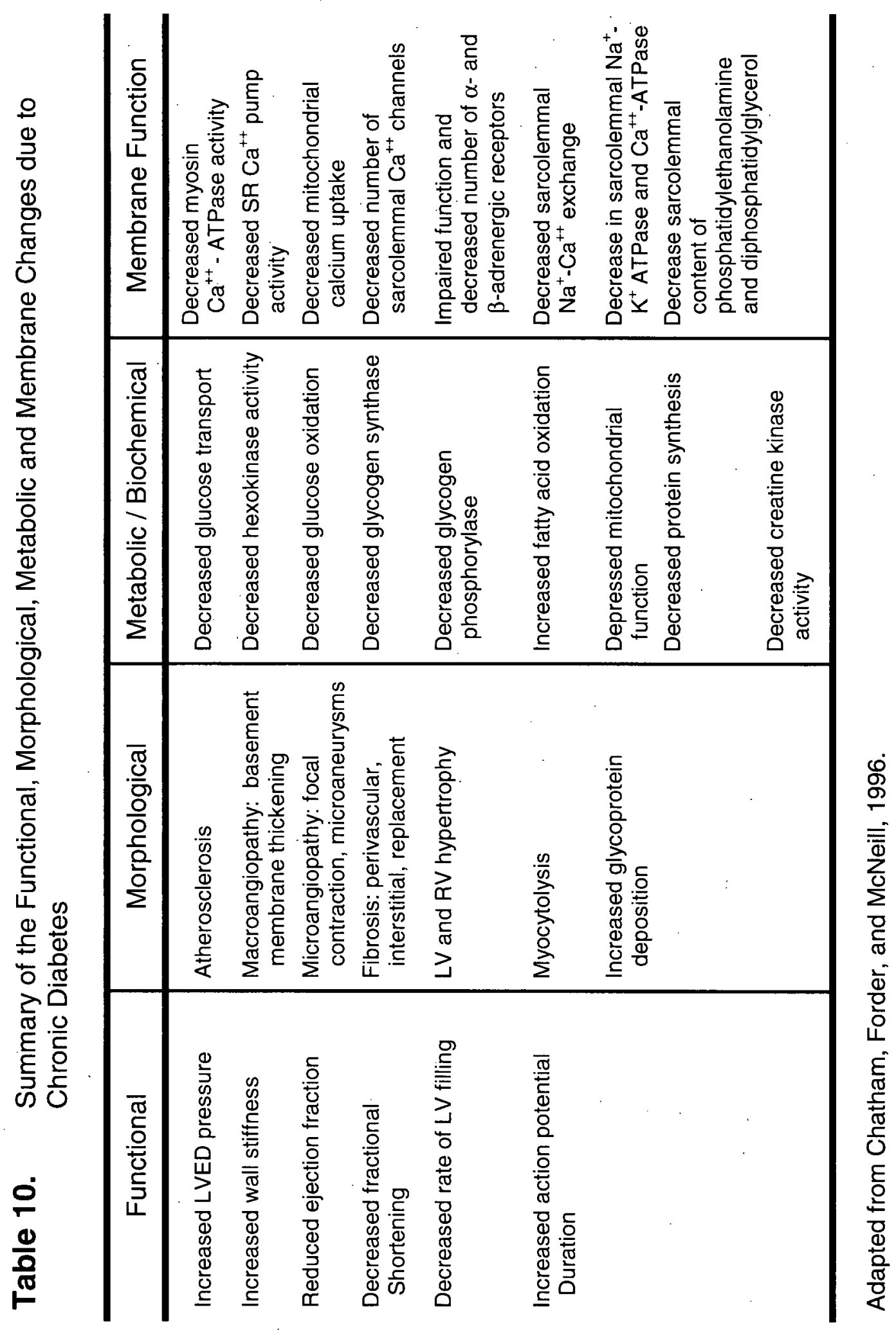

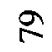


systems such as the $\mathrm{Ca}^{+}$-ATPase, $\mathrm{Na}^{+} / \mathrm{K}^{+}$-ATPase, $\mathrm{Na}^{+} / \mathrm{Ca}^{++}$- exchanger and $\mathrm{Ca}^{++}$pump ultimately affect intracellular calcium $\left[\mathrm{Ca}^{++}\right]_{\mathrm{i}}$ regulation (Rodrigues et al, 1995). Because the regulation of the $\left[\mathrm{Ca}^{++}\right]_{i}$ is important in the beat-to- beat control of contraction and relaxation, any disruption in the ability to release or sequester calcium would have an effect on cardiac function. The final mechanism by which fatty acid metabolism could impair cardiac function is through inhibition of glucose usage. Fatty acid oxidation can inhibit glucose metabolism by inhibiting both the pyruvate dehydrogenase (PDH) complex (involved in the mitochondrial oxidation of glucose) and phosphofructokinase, the rate-limiting step in glycolysis (Randle et al, 1963; Kerbey et al, 1985). Inhibition of $\mathrm{PDH}$ occurs due to an increase in the intramitochondrial acetyl CoA/CoA ratio, which activates pyruvate dehydrogenase kinase to phosphorylate and inhibit PDH (Kerbey et al, 1985). Phosphofructokinase activity is decreased due to elevated citrate levels. The fact that improving glucose oxidation improves diabetic heart function (Lopaschuk and Spafford, 1989; Nicholl et al, 1991), coupled with the fact that not all lipid lowering compounds correct the cardiac dysfunction (Rodrigues et al, 1994), suggests that the development of diabetic cardiomyopathy may be due to depressed glucose oxidation. Regardless of the actual mechanisms involved in the impairment of diabetic heart function, there is ample evidence showing that correction of substrate metabolism by either inhibiting fatty acid oxidation or stimulating glucose usage improves cardiac contractile function.

As discussed in the introduction, the majority of studies examining the combination of hypertension and diabetes have demonstrated increased cardiac dysfunction in the H-D group compared to control, diabetic or hypertensive animals. 
Isolated papillary muscle from H-D rats exhibit depressed rates of tension development and relaxation along with slower shortening and relaxation velocities (Fein et al, 1984; Siri et al, 1997). Analysis of heart function using the isolated working heart preparation shows depressed left ventricular developed pressure and rates of contraction and relaxation (Rodrigues and McNeill, 1986).

In SHR Study \#2, diabetes was induced using a dose of $45 \mathrm{mg} / \mathrm{kg} \mathrm{STZ}$ in SHR and $55 \mathrm{mg} / \mathrm{kg} \mathrm{STZ}$ in Wistar rats at eight weeks of age with the goal of producing an equivalent severity of diabetes in both strains of rat. In an acute study of two weeks duration, these doses have been previously reported to produce a similar level of diabetes in SHR and Wistar rats (Jian et al, 1996). However, in our study the OGTT performed after eleven weeks of diabetes indicated that the SD rats were less diabetic than the WD . group (Figure 10). This fact is important because it makes it more difficult to draw solid conclusions concerning the effect of hypertension on diabetic cardiomyopathy. In the study by Rodrigues and McNeill (1986), a dose of $55 \mathrm{mg} / \mathrm{kg} \mathrm{STZ} \mathrm{was} \mathrm{injected} \mathrm{into} \mathrm{both}$ strains of rats and caused more cardiac dysfunction in the SHR than Wistar rats. Because the SHR have been shown to be more sensitive to STZ, it was hypothesized the SD rats in that study were more diabetic than the corresponding WD animals. However, this could not be confirmed because there was no OGTT data assessing the diabetic state of the animals. Termination plasma glucose and insulin levels showed no significant difference between SD and WD groups (Rodrigues and McNeill, 1986) but these are not reliable indices to assess the severity of the diabetic condition. Our OGTT results showed that a dose of $45 \mathrm{mg} / \mathrm{kg} \mathrm{STZ}$ in the SHR, expected to induce a diabetic state equivalent to 55 $\mathrm{mg} / \mathrm{kg} \mathrm{STZ}$ in the Wistar, actually resulted in a less severe diabetic state. Therefore, it is possible that the SD animals in the study by Rodrigues and McNeill were not more 
diabetic than the WD rats. If that was the case, then the increased cardiac dysfunction in their SD animals was due to the interaction between hypertension and the diabetic condition and not to a more severe diabetic condition. Furthermore, since our SD group was less diabetic than the WD rats but had the same degree of cardiac dysfunction, the addition of hypertension may be further hindering cardiac performance.

To examine this possibility, both SHR and Wistar rats could be injected with a dose of $55 \mathrm{mg} / \mathrm{kg} \mathrm{STZ}$ and the diabetic state determined by OGTT prior to studying heart function. If our theory is correct, there will be no significant difference in the OGTT values between diabetic SHR and Wistar rats but cardiac dysfunction will be more pronounced in the SD group.

Both genetic and renovascular models of hypertension have demonstrated impaired cardiac performance when combined with diabetes (Rodrigues and McNeill, 1986, Rodgers, 1986; Rodgers et al, 1991) which suggests that depressed cardiac function in H-D rats is likely not a strain-related phenomena.

Although the interaction between hypertension and diabetes on the heart has been well documented, the underlying mechanisms are not clear. One possible mechanism is the alteration of cardiac substrate metabolism. As a strain, the SHR heart relies on glucose oxidation to a greater extent than do the hearts from normotensive strains such as Sprague-Dawley rats (Christe and Rodgers, 1994). It was suggested by the authors that the increased reliance on glucose use was an adaptation of the hypertrophic heart to maintain efficient energy production, because glucose oxidation requires less oxygen than do fatty acids (Christe and Rodgers, 1994). In the previous section, it was discussed how diabetes altered myocardial fuel consumption to an almost exclusive dependence on 
fatty acid metabolism, the opposite of the hypertensive heart. Thus, the induction of diabetes may disrupt the shift in substrate utilization necessary for efficient ATP production in the hypertensive heart and accelerate the development of heart failure (Christe and Rodgers, 1995).

Both diabetes and hypertension alter the lipid composition of the cellular membranes, which could disrupt the activity of membrane-bound enzyme systems that regulate intracellular ion concentrations (Petkov et al, 1988; Kuwahara et al, 1997). These changes could impair the regulation of intracellular $\mathrm{Ca}^{++}$and $\mathrm{pH}$ and therefore contribute to the contractile dysfunction reported in the diabetic-hypertensive heart.

Another possible way in which the combination of hypertension and diabetes could result in more severe cardiac dysfunction is through impairment of the blood supply to the myocardium. Both diabetes and hypertension are associated with decreased cardiac coronary flow reserve and patients with either condition are more susceptible to ischemic injury (Strauer, 1979; Strauer et al, 1997). The changes in coronary flow have been attributed to the coronary microvasculature and are likely the result of structural alterations that ultimately increase vascular resistance and perfusion pressure of the blood vessels. In a series of experiments examining the effect of hypertension and diabetes on the microvasculature, Factor and colleagues demonstrated an increased cardiac pathology in the hearts of H-D patients or. rats compared to hearts with either condition alone (Factor et al, 1981; Factor et al, 1983; Factor et al, 1984). Specifically, these alterations included areas of microvascular tortuosity, microaneurysms and focal areas of luminal narrowing believed to be microvessels in spasm (Factor et al, 1984). Based on these changes, the authors suggested that the microvascular spasms caused localized areas of ischemia and reperfusion that contributed to myocardial necrosis (Factor et al, 1984). In 
addition, H-D hearts exhibit greater vascular permeability than SHR control, diabetic and non-diabetic normotensive rats, which could be another cause of the cardiac pathology (Kubota et al, 1990). The cardiac pathology of H-D hearts has been well documented and includes cardiomegaly, extensive interstitial, replacement, and perivascular fibrosis and myocytolysis as well as ultrastructural changes to the myocardium (Factor et al, 1981; Factor et al, 1983).

In SHR Study \#3, injection of $45 \mathrm{mg} / \mathrm{kg} \mathrm{STZ}$ into the SHR after the development of hypertension (at 12 weeks of age) increased the severity of diabetes but did not depress cardiac function (Figures 15 and 16). These results do not agree with those of Rodgers (1986), who injected $50 \mathrm{mg} / \mathrm{kg} \mathrm{STZ}$ into 15 weeks old SHR and demonstrated impaired left ventricular pulse pressure compared to normotensive Sprague-Dawley and WKY rats. Possible reasons for the different results between our study and the study by Rodgers include the dose of STZ used and the age at time of injection. In the final study, we injected the SHR at twelve weeks of age whereas in the study by Rodgers, the SHR were injected at fifteen weeks of age. In addition, a dose of $50 \mathrm{mg} / \mathrm{kg} \mathrm{STZ} \mathrm{was} \mathrm{used} \mathrm{in}$ that study compared to a dose of $45 \mathrm{mg} / \mathrm{kg} \mathrm{STZ}$ for our study. Because the diabetogenic effects of STZ are age- and dose-dependent (Masiello et al, 1979), it is possible that the diabetic-SHR rats in the study by Rodgers were more severely diabetic than ours. The higher plasma glucose concentration, along with lower body and heart weights in the diabetic-SHR in his study, support this idea. Thus, it is possible that the cardiac dysfunction in the study by Rodgers may be due to a more severe diabetic condition.

The reason why cardiac performance was impaired in the H-D rats injected at the younger age but not at the older age is a matter of speculation. In the case of 
hypertension, sustained increases in systolic blood pressure cause the left ventricle to hypertrophy in an attempt to maintain adequate cardiac output in the face of increasing peripheral resistance. In the SHR, the development of LVH has been shown to parallel the increase in systolic blood pressure (Adams et al, 1989). Therefore, in the rats injected at twelve weeks of age the LV had already begun adapting to the elevated peripheral resistance by increasing myofibrillar growth. The increased LV strength at the time of STZ injection may have prevented or compensated for the damaging effects of diabetes on the myocardium, thereby enabling sufficient cardiac performance in light of the intracellular and ultrastructural changes to the myocardium. For the younger rats, the induction of diabetes at a time when myocardial growth would be just beginning may have hindered the heart's ability to adapt to the rise in peripheral resistance. However, this possibility cannot be confirmed because morphological and ultrastructural analysis of the myocardium was not performed. It is interesting to note that not all of the literature has documented increased cardiac dysfunction in the hypertensive-diabetic rat. Using a model of renovascular hypertension with STZ-induced diabetes, Fein and colleagues (1990) showed no additional dysfunction in the functional properties of isolated papillary muscles from H-D hearts. Additionally, Dai and McNeill (1992) demonstrated using the isolated working heart technique that the hearts of STZ-injected, DOCA-hypertensive rats had no cardiac dysfunction at the higher atrial filling pressures when compared to the hypertensive control group.

It is also important to note that for the rats injected with STZ after the development of hypertension (SHR Study \#3), diabetes was maintained for only eight weeks before cardiac performance was assessed. This is different than the rats injected before hypertension had developed because they were diabetic for twelve weeks (cardiac 
function was measured for all rats at twenty weeks of age). Since diabetic cardiomyopathy takes about six weeks to develop in the Wistar rat (Vadlamudi et al, 1982), it is possible that cardiac performance would deteriorate if the rats were maintained for twelve weeks of diabetes. The fact that ventricular relaxation was depressed at the highest filling pressure suggests that the other indices of heart function may have begun to deteriorate if the diabetic condition was maintained for a longer period of time.

The purpose of this project was to determine whether hypertension exacerbated the development of diabetic cardiomyopathy. The objective was to create a similar level of diabetes in both hypertensive and normotensive rats, and then determine if the addition of hypertension resulted in increased cardiac dysfunction. In the first study $45 \mathrm{mg} / \mathrm{kg}$ STZ was used in both SHR and Wistar rats to confirm that the SHR were more sensitive to STZ and ensure that çardiac dysfunction developed in the SHR at that dose. A greater percentage of SHR became diabetic and cardiac dysfunction was apparent at the higher atrial filling pressures. These results enabled the use of $45 \mathrm{mg} / \mathrm{kg} \mathrm{STZ}$ in the SHR and 55 $\mathrm{mg} / \mathrm{kg}$ in Wistar rats, doses previously shown to produce an equivalent level of diabetes one week after STZ administration (Jian et al, 1996). Inducing diabetes before the development of hypertension resulted in a similar degree of cardiac dysfunction in both SHR and Wistar rats. However, after twelve weeks of diabetes the SHR were not as diabetic as the Wistar (based on an OGTT), suggesting that hypertension was exacerbating the cardiomyopathy. Injecting the rats after hypertension had developed in the SHR magnified the diabetic state in these animals, but surprisingly, cardiac dysfunction did not develop. The development of left ventricular hypertrophy due to the 
increase in systolic blood pressure may have compensated for the development of contractile dysfunction in the diabetic heart. 


\section{CONCLUSIONS}

1. Injection of $45 \mathrm{mg} / \mathrm{kg} \mathrm{STZ}$ into the SHR resulted in sustained diabetes in over $70 \%$ of the animals whereas only $40 \%$ of the Wistar rat became diabetic at this dose, confirming that the SHR were more sensitive to the diabetogenic effects of STZ.

2. At $45 \mathrm{mg} / \mathrm{kg} \mathrm{STZ} \mathrm{cardiac} \mathrm{performance} \mathrm{was} \mathrm{impaired} \mathrm{in} \mathrm{the} \mathrm{SD} \mathrm{group} \mathrm{but} \mathrm{did} \mathrm{not}$ depress cardiac function in the WD rats.

3. Using a dose of $45 \mathrm{mg} / \mathrm{kg} \mathrm{STZ}$ in the SHR and $55 \mathrm{mg} / \mathrm{kg} \mathrm{STZ}$ in the Wistar, injection at eight weeks of age resulted in a diabetic state that was less severe in the SD than WD groups. The significantly greater AUCg and lower AUCi values of the WD group compared to the SD rats during the OGTT demonstrated this.

4. After twelve weeks of combined hypertension and diabetes, cardiac performance was equally depressed in both SD and WD groups.

5. Injecting the same doses of STZ into the rats at twelve weeks of age increased the severity of diabetes in both groups of animals.

6. At twenty weeks of age (eight weeks of diabetes) LVDP and rate of contraction was not impaired in the SD group but the rate of relaxation was depressed at the highest filling pressure. Heart function of the WD rats was depressed for all three parameters. 


\section{REFERENCES}

Adams, M.A., Bobik, A., Korner, P.I. Differential Development of Vascular and Cardiac Hypertrophy in Genetic Hypertension. Relation to Sympathetic Function. Hypertension 14: 191-202, 1989.

Ahmed, S.S., Jaferi, G.A., Narang, R.M., Regan, T.J. Preclinical Abnormality of Left Ventricular Function in Diabetes Mellitus. Am.Heart.J. 89: 153-158, 1975.

Akella, A.B., Ding, X-L., Cheng, R., Gulati, J. Diminished $\mathrm{Ca}^{++}$Sensitivity of Skinned Cardiac Muscle Contractility Coincident with Troponin T - Band Shifts in the Diabetic Rat. Circ.Res. 76: 600-606, 1995.

Anderson, E.A., Hoffman, R.P., Balon, T.W., Sinkey, C.A., Mark, A.L. Hyperinsulinemia Produces both Sympathetic Neural Activation and Vasodilation in Normal Humans. J.Clin.Invest. 87: 2246-2252, 1991.

Assmann, G., Schulte, H. The Prospective Cardiovascular Munster (PROCAM) Study: Prevalence of Hyperlipidemia in Persons with Hypertension and/or Diabetes Mellitus and the Relationship to Coronary Heart Disease. Am.Heart.J. 116: 1713-1724, 1988.

Baekkeskov, S., Aanstoot, H., Christgau, S., Reetz, A., Solimena, M., Cascalho, M., Folli, F., Richter-Olesen, H., Camilli, P-D. Identification of the 64K Autoantigen in Insulin-Dependent Diabetes as the GABA-Synthesizing Enzyme Glutamic Acid Decarboxylase. Nature 347: 151-156, 1990.

Banting, F.G., Best, C.H., Collip, J.B., Campbell, W.R., Fletcher, A.A. Pancreatic Extracts in the Treatment of Diabetes Mellitus. Can.Med.Assoc.J. 12: 141-146, 1922.

Begum, N., Song, Y., Rienzie, J., Ragolia, L. Vascular Smooth Muscle Cell Growth and Insulin Regulation of Mitogen-Activated Protein Kinase in Hypertension. Am.J.Physiol. 275: C42-C49, 1998.

Beierwaltes, W.H., Arendshorst, W.J., Klemmer, P.J. Electrolyte and Water Balance in Young Spontaneously Hypertensive Rats. Hypertension 4: 908-915, 1982.

Berne, C., Fagius, J., Pollare, T., Hjemdal, P. The Sympathetic Response to Euglycaemic Hyperinsulinaemia: Evidence from Microelectrode Nerve Recordings in Healthy Subjects. Diabetologia 35: 873-879, 1992.

Bhanot, S., McNeill, J.H. Vanadyl Sulfate Lowers Plasma Insulin and Blood Pressure in Spontaneously Hypertensive Rats. Hypertension 24: 625-632, 1994a. 
Bhanot, S., McNeill, J.H., Bryer-Ash, M. Vanadyl Sulfate Prevents Fructose-Induced Hyperinsulinemia and Hypertension. Hypertension 23: 308-312, 1994b.

Bhanot, S., Bryer-Ash, M., Cheung, A., McNeill, J.H. Bis(maltolato)oxovanadium(IV) Attenuates Hyperinsulinemia and Hypertension in Spontaneously Hypertensive Rats. Diabetes 43: 857-861, 1994c.

Bhanot, S., McNeill, J.H. Insulin and Hypertension: A Causal Relationship? Cardiovasc.Res. 31: 212-221, 1996.

Bhimji, S., Godin, D.V., McNeill, J.H. Biochemical and Functional Changes in Hearts from Rabbits with Diabetes. Diabetologia 18: 452-457, 1985.

Blumenthal, H.T., Alex, M., Goldenberg, S. A Study of Lesions of the Intramural Coronary Branches in Diabetes Mellitus. Arch.Pathol. 70: 27-42, 1960.

Bonnevie-Nielsen, V., Steffes, M.W., Lernmark, A. A Major Loss in Islet Mass and $\beta$ Cell Function Precedes Hyperglycemia in Mice Given Multiple Low Doses of Streptozotocin. Diabetes 30: 424-429, 1981.

Bottazzo, G.F., Gorsuch, A.N., Dean, B.M., Cudworth, A.G., Doniach, D. Complement Fixing Islet Cell Antibodies in Type 1 Diabetes: Possible Monitors of Active Beta Cell Damage. Lancet 1: 668-672, 1980.

Brands, M.W., Hildebrandt, D.A., Mizelle, H.L., Hall, J.E. Sustained Hyperinsulinemia Increases Arterial Pressure in Conscious Rats. Am.J.Physiol. 260: R764-R768, 1991.

Buchanan, T.A., Sipos, G.F., Madrilejo, N., Liu, C., Campese, V.M. Hypertension without Peripheral Insulin Resistance in Spontaneously Hypertensive Rats. Am.J.Physiol. 262: E14-E19, 1992a.

Buchanan, T.A.,Young, J.H., Campese, V.M., Sipos, G.F. Enhanced Glucose Tolerance in Spontaneously Hypertensive Rats. Pancreatic $\beta$-Cell Hyperfunction with Normal Insulin Sensitivity. Diabetes 41: 872-878, $1992 \mathrm{~b}$.

Bunag, R.D. Validation in Awake Rats of a Tail-Cuff Method for Measuring Systolic Pressure. J.App.Physiol 34: 279-282, 1973.

Bunag, R.D., Butterfield, J. Tail-cuff Blood Pressure Measurement Without External Preheating in Awake Rats. Hypertension 4: 898-903, 1982.

Carbonell, L.F., Salom, M.G., Garcia-Estan, J., Salazar, F.J., Ubeda, M., Quesada, T. Hemodynamic Alterations in Chronically Conscious Unrestrained Diabetic Rats. Am.J.Physiol. 252: H900-H905, 1987.

Cavan, D.A., Penny, M.A., Bain, S.C., Barnett, A.H. Molecular Genetics of Type 1 Diabetes Mellitus. In: International Textbook of Diabetes Mellitus, Second Edition. 
Edited by: Alberti, KGMM., Zimmet, P., DeFronzo, R.A., and Keen, H. John Wiley \& Sons Ltd., Toronto, 1997.

Chatham, J.C., Forder, J.R., McNeill, J.H. Conclusion. In: The Heart in Diabetes. Edited by: Chatham, J.C., Forder, J.R., McNeill, J.H. Kluwer Academic Publishers, Norwell, 1996.

Christe, M.E., Rodgers, R.L. Altered Glucose and Fatty Acid Oxidation in Hearts of the Spontaneously Hypertensive Rat. J.Mol.Cell.Cardiol. 26: 1371-1375, 1994.

Christe, M.E., Rodgers, R.L. Cardiac Glucose and Fatty Acid Oxidation in the Streptozotocin-Induced Diabetic Spontaneously Hypertensive Rat. Hypertension 25: 235$241,1995$.

Christlieb, A.R. The Hypertensions of Diabetes. Diabetes.Care. 5: 50-58, 1982.

Chukwuma, C., Tuomilehto, J. Diabetes and the Risk of Stroke. J.Diab.Comp. 7: 250$262,1993$.

Dai, S., McNeill, J.H. Myocardial Performance of STZ-Diabetic DOCA-Hypertensive Rats. Am.J.Physiol. 263: H1798-H1805, 1992.

Dai, S., Lee, S., Battell, M., McNeill, J.H. Cardiovascular and Metabolic Changes in Spontaneously Hypertensive Rats Following Streptozotocin Administration. Can.J.Cardiol. 10: 562-570, 1994.

Danielsen, R. Factors Contributing to Left Ventricular Diastolic Dysfunction in LongTerm type 1 Diabetic Subjects. Acta.Med.Scand. 224: 249-256, 1988.

Davidoff, A.J., Pinault, F.M., Rodgers, R.L. Ventricular Relaxation of Diabetic Spontaneously Hypertensive Rat. Hypertension 15: 643-651, 1990a.

Davidoff, A.J., Rodgers, R.L. Insulin, Thyroid Hormone, and Heart Function of Diabetic Spontaneously Hypertensive Rat. Hypertension 15: 633-642, $1990 \mathrm{~b}$.

DeFronzo, R.A., Bonadonna, R.C., Ferrannini, E. Pathogenesis of NIDDM. In: International Textbook of Diabetes Mellitus, Second Edition. Edited by: Alberti, KGMM., Zimmet, P., DeFronzo, R.A., and Keen, H. John Wiley \& Sons Ltd., Toronto, 1997.

DeFronzo, R.A. Classification and Diagnosis of Diabetes Mellitus. In: Current Therapy of Diabetes Mellitus. Edited by: DeFronzo, R.A. Mosby-Year Book, Inc., 1998.

Dhalla, N.S., Golfman, L.S., Elimban, V., Takeda, N. Remodelling of Subcellular Organelles During the Development of Diabetic Cardiomyopathy. In: The Heart in Diabetes. Edited by: Chatham, J.C., Forder, J.R., McNeill, J.H. Kluwer Academic Publishers, Norwell, 1996. 
Dietz, R., Schomig, A., Rascher, W. Pathophysiological Aspects of Genetically Determined Hypertension in Rats, with Special Emphasis on Stroke-Prone Spontaneously Hypertensive Rats. In: Handbook of Hypertension, Vol. 4: Experimental and Genetic Models of Hypertension. Edited by: de Jong, W. Elsevier Science Publishers B.V., New York, 1984.

Dillmann, W.H. Diabetes Mellitus Induces Changes in Cardiac Myosin in the Rat. Diabetes 29: 579-582, 1980.

Doggrell, S.A., Brown, L. Rat models of hypertension, cardiac hypertrophy, and failure. Cardiovasc.Res. 39: 89-105, 1998.

Dougherty, A., Maccarilli, G., Gray, E., Hicks, C., Goldstein, R. Congestive Heart Failure with Normal Systolic Function. Am.J.Cardiol. 54: 778-782, 1984.

Dunn, J.S., Sheehan, H.L., McLetchie, N.G.B. Necrosis of Islets of Langerhans Produced Experimentally. Lancet 1: 484-487, 1943.

Duston, H.P. Obesity and Hypertension. Ann.Intern.Med. 103: 1047-1051, 1985.

Ekas, R.D., Lokhandwala, M.F. Sympathetic Nerve Function and Vascular Reactivity in Spontaneously Hypertensive Rats. Am.J.Physiol. 241: R379-R384, 1981.

Endre, T., Mattiasson, I., Berglund, G., Hulthen, U.L. Insulin and Renal Sodium Retention in Hypertension-Prone Men. Hypertension 23: 313-319, 1994.

Factor, S.M., Okun, E.M., Minase, T. Capillary Microaneurysms in the Human Diabetic Heart. New.Engl.J.Med. 302: 384-388, 1980.

Factor, S.M., Minase, T., Sonnenblick, E.H. Clinical and Morphological Features of Human Hypertensive-Diabetic Cardiomyopathy. Am.Heart.J. 99: 446-458, 1980.

Factor, S.M., Bhan, R., Minase, T., Wolinsky, H., Sonnenblick, E.H. HypertensiveDiabetic Cardiomyopathy in the Rat. An Experimental Model of Human Disease. Am.J.Pathol. 102: 219-228, 1981.

Factor, S.M., Minase, T., Bhan, R., Wolinsky, H., Sonnenblick, E.H. Hypertensive Diabetic Cardiomyopathy in the Rat: Ultrastructural Features. Virchows.Arch. 398: 305$317,1983$.

Factor, S.M., Minase, T., Cho, S., Fein, F., Capasso, J.M., Sonnenblick, E.H. Coronary Microvascular Abnormalities in the Hypertensive-Diabetic Rat. A Primary Cause of Cardiomyopathy? Am.J.Pathol. 116: 9-20, 1984.

Factor, S.M., Borczuk, A., Charron, M.J., Fein, F.S., van Hoeven, K.H., Sonnenblick, E.H. Myocardial Alterations in Diabetes and Hypertension. Diab.Res.Clin.Practice. 31 (Suppl): S133-S142, 1996. 
Fein, F.S., Kornstein, L.B., Strobeck, J.E., Capasso, J.M., Sonnenblick, E.H. Altered Myocardial Mechanics in Diabetic Rats. Circ.Res. 47: 922-933, 1980.

Fein, F.S., Strobeck, J.E., Malhotra, A., Scheuer, J., Sonnenblick, E.H. Reversibility of Diabetic Cardiomyopathy with Insulin in Rats. Circ.Res. 49: 1251-1261, 1981.

Fein, F.S., Sonnenblick, E.H. Diabetic Cardiomyopathy. Prog.Cardiovasc.Dis. 27: 255$270,1985$.

Fein, F.S., Cho, S., Zola, B.E., Miller, B., Factor, S.M. Cardiac Pathology in the Hypertensive Diabetic Rat. Biventricular Damage with Right Ventricular Predominance. Am.J.Pathol. 134: 1159-1166, 1989.

Fein, R.S., Zola, B.E., Malhotra, A., Cho, S., Factor, S.M., Scheuer, J., Sonnenblick, E.H. Hypertensive-Diabetic Cardiomyopathy in Rats. Am.J.Physiol. 258:H793-H805, 1990.

Fein, F.S. Clinical Manifestations of Diabetic Cardiomyopathy. In: The Heart in Diabetes. Edited by: Chatham, J.C., Forder, J.R., McNeill, J.H. Kluwer Academic Publishers, Norwell, 1996.

Ferrannini, E., Buzzigoli, G., Bonadonna, R., Giorico, M.A., Oleggini, M., Graziadeli, L., Pedrinelli, R., Grandi, L., Bevilacqua, S. Insulin Resistance in Essential Hypertension. N.Engl.J.Med. 317: 350-357, 1987.

Ferrari, P., Bianchi, G. Lessons from Experimental Genetic Hypertension. In: Hypertension: Pathophysiology, Diagnosis, and Management, Second Edition. Edited by: Laragh, J.H., Brenner, B.M. Raven Press, Ltd., New York, 1995.

Fischer, V.W., Barner, H.B., Leskiw, M.L. Capillary Basal Laminar Thickness in Diabetic Human Myocardium. Diabetes 28: 713-719, 1979.

Foulis, A.K., Stewart, J.A., The Pancreas in Recent-Onset Type 1 (insulin-dependent) Diabetes Mellitus: Insulin Content of Islets, Insulitis, and Associated Changes in Exocrine Acinar Tissue. Diabetologia 26: 456-461, 1984.

Friedman, N.E., Levitsky, L.L., Edidin, D.V., Vitullo, D.A., Lacina, S.J., Chiemmongkoltip, P. Echocardiographic Evidence from Impaired Myocardial Performance in Children with Type 1 Diabetes Mellitus. Am.J.Med. 73: 846-850, 1982.

Frontoni, S., Ohman, L., Haywood, J.R., DeFronzo, R.A., Rossetti, L. In Vivo Insulin Action in Genetic Models of Hypertension. Am.J.Physiol. 262: E191-E196, 1992.

Fuller, J.H., Shipley, M.J., Rose, G., Jarrett, R.J., Keen, H. Coronary Heart Disease and Stroke Mortality by Degree of Glycaemia: the Whitehall Study. Br.Med.J. 287: 867-870, 1983. 
Fuller, J.H. Epidemiology of Hypertension Associated with Diabetes Mellitus. Hypertension 7(Suppl II): II3-II7, 1985.

Gans, R.O.B., Toorn, L., Bilo, H.J.G., Nauta, J.J.P., Heine, R.J., Donker, A.J.M. Renal and Cardiovascular Effects of Exogenous Insulin in Healthy Volunteers. Clin.Sci. 80: 219-225, 1991.

Gepts, W. Pathologic Anatomy of the Pancreas in Juvenile Diabetes Mellitus. Diabetes 14: 619-633, 1965.

Goyal, R.K., Satia, M.C., Bangaru, R.A., Gandhi, T.P. Effect of Long-Term Treatment with Enalapril in Streptozotocin Diabetic and DOCA Hypertensive Rats. J.Cardiovasc.Pharmacol. 32: 317-322, 1998.

Grossman, E., Shemesh, J., Shamiss, A., Thaler, M., Carroll, J., Rosenthal, T. Left Ventricular Mass in Diabetes-Hypertension. Arch.Intern.Med. 152: 1001-1004, 1992.

Guidelines Subcommittee of the WHO/ISH Mild Hypertension Liaison Committee. 1993 Guidelines for the Management of Mild Hypertension: Memorandum from a World Health Organization/International Society of Hypertension Meeting. Hypertension. 22: 392-403, 1993.

Guyton, A.C., Hall, J.E. Insulin, Glucagon, and Diabetes Mellitus. In: Textbook of Medical Physiology. W.B. Saunders Company, Toronto, 1996.

Haider, B., Yeh, C.K., Thomas, G. Influence of Diabetes on the Myocardium and Coronary Arteries of Rhesus Monkey Fed and Athrogenic Diet. Circ.Res. 49: 1278-1288, 1981.

Hamby, R.I., Zoneraich, S., Sherman, L. Diabetic Cardiomyopathy. JAMA 229: 17491754, 1974.

Hardin, N.J. The Myocardial and Vascular Pathology of Diabetic Cardiomyopathy. Coron.Artery.Dis. 7: 99-108, 1996.

Harris, M.I., Zimmet, P. Classification of Diabetes Mellitus and Other Categories of Glucose Intolerance. In: International Textbook of Diabetes Mellitus, Second Edition. Edited by: Alberti, KGMM., Zimmet, P., DeFronzo, R.A., and Keen, H. John Wiley \& Sons Ltd., Toronto, 1997.

Hebden, R.A., Bennett, T., Gardiner, S.M. Abnormal Blood Pressure Recovery During Ganglion Blockade in Diabetic Rats: Am.J.Physiol. 252: R102-R108, 1987.

Hellman, B. Effect of Ageing on the Total Volumes of the Alpha and Beta Cells in the Islets of Langerhans of the Rat. Acta.Endocrin.Copenh. 32: 92-112, 1959. 
Heyliger, C.E., Tahiliani, A.G., McNeill, J.H. Effect of Vanadate on Elevated Blood Glucose and Depressed Cardiac Performance of Diabetic Rats. Science 227: 1474-1477, 1985.

Heyliger, C.E., Prakash, A., McNeill, J.H. Alterations in Cardiac Sarcolemmal Ca ${ }^{++}$ Pump Activity During Diabetes Mellitus. Am.J.Physiol. 252: H540-H544, 1987.

Heyliger, C.E., Rodrigues, B., McNeill, J.H. Effect of Choline and Methionine Treatment on Cardiac Dysfunction of Diabetic Rats. Diabetes 35: 1152-1157, 1986.

Himsworth, H.P. Diabetes Mellitus: its Differentiation into Insulin-Sensitive and InsulinInsensitive Types. Lancet 1: 127-130, 1936.

Hofmann, P.A., Menon, V., Gannaway, K.F. Effects of Diabetes on Isometric Tension as a Function of $\left[\mathrm{Ca}^{+}\right]$and $\mathrm{pH}$ in Rat Skinned Cardiac Myocytes. Am.J.Physiol. 269: H1656-H1663, 1995.

Hoftiezer, V., Carpenter, A-M. Comparison of Streptozotocin and Alloxan-Induced Diabetes in the Rat, Including Volumetric Quantitation of the Pancreatic Islets. Diabetologia 9: 178-184, 1973.

Hoy, W., Light, A., Megill, D. Cardiovascular Disease in Navajo Indians with Type 2 Diabetes. Pub.Health.Rep. 110: 87-94, 1995.

Hulman, S., Falkner, B., Chen, Y.Q. Insulin Resistance in the Spontaneously Hypertensive Rat. Metabolsim 40: 359-361, 1991.

Hwang, I.S, Ho, H., Hoffman, B.B., Reaven, G.M. Fructose Induced Insulin Resistance and Hypertension in Rats. Hypertension 10: 512-516, 1987.

Hypertension in Diabetes Study Group. Hypertension in Diabetes Study (HDS): II. Increased Risk of Cardiovascular Complications in Hypertensive Type 2 Diabetic Patients. J.Hyperten. 11: 319-325, 1993.

Iwase, M., Nunoi, K., Kikuchi, M., Maki, Y., Kodama, T., Sadoshima, S., Fujishima, M. Morphometrical and Biochemical Differences of Endocrine Pancreata Between Spontaneously Hypertensive and Normotensive Rats with or without StreptozotocinInduced Diabetes. Lab.Invest. 60: 102-105, 1989.

Jian, K., Fok, E., Cam, M.C., Sambandam, N., Yao, J., Rodrigues, B. Susceptibility of Spontaneously Hypertensive Rats to the Diabetogenic Effects of Streptozotocin. Can.J.Physiol.Pharmacol. 74: 1215-1221, 1996.

Joint National Committee on Detection, Evaluation, and Treatment of High Blood Pressure. The Fifth Report of the Joint National Committee on Detection, Evaluation, and Treatment of High Blood Pressure (JNC-V). Arch.Intern.Med. 153: 154-183, 1993. 
Judy, W.V., Watanabe, A.M., Murphy, W.R., Aprison, B.S., Yu, P.I. Sympathetic Nerve Activity and Blood Pressure in Normotensive Back-Cross Rats Genetically Related to the Spontaneously Hypertensive Rat. Hypertension 1: 598-604, 1979.

Junod, A., Lambert, A.E., Stauffacher, W., Renold, A.E. Diabetogenic Action of Streptozotocin: Relationship of Dose to Metabolic Response. J.Clin.Invest. 48: 2129$2139,1969$.

Kahn, A.M., Seidel, C.L., Allen, J.C., O’Neil, R.G., Selat, H., Song, T. Insulin Reduces Contraction and Intracellular Calcium Concentration in Vascular Smooth Muscle. Circulation 22:735-742, 1993.

Kannel, W.B., Hjortland, M., Castelli, W.P. Role of Diabetes in Congestive Heart Failure: The Framingham Study. Am.J.Cardiol. 34:29-34, 1974.

Kannel, W.B., McGee, D.L. Diabetes and Cardiovascular Disease. The Framingham Study. JAMA 241: 2035-2038, 1979a.

Kannel, W.B., McGee, D.L. Diabetes and Cardiovascular Risk Factors. The Framingham Study. Circulation 59: 8-13, 1979 b.

Karvonen, M., Tuomilehto, J., Libman, I., LaPorte, R. A Review of the Recent Epidemiological Data on the Worldwide Incidence of Type 1 (insulin-dependent) Diabetes Mellitus. Diabetologia 36: 883-892, 1993.

Kerbey, A.K., Vary, T.C., Randle, P.J. Molecular Mechanisms Regulating Myocardial glucose Oxidation. Basic.Res.Cardiol. 80(suppl. 2): 93-96, 1985.

Klein, R., Klein, B.E.K. Diabetic Eye Disease. Lancet 350: 197-204, 1997.

Kloppel, G., In't Veld, P.A. Morphology of the Pancreas in Normal and Diabetic States. Cpt. 13. In: International Textbook of Diabetes Mellitus, Second Edition. Edited by: Alberti, KGMM., Zimmet, P., DeFronzo, R.A., and Keen, H. John Wiley \& Sons Ltd., Toronto, 1997.

Knowler, W.C., Bennett, P.H., Ballintine, E.J. Increased Incidence of Retinopathy in Diabetics with Elevated Blood Pressure. New.Engl.J.Med. 302: 645-650, 1980.

Kotchen, T.A., Zhang, H.Y., Covelli, M., Blehschmidt, N. Insulin Resistance and Blood Pressure in Dahl Rats and in One-Kidney, One-Clip Hypertensive Rats. Am.J.Physiol. 262:E692-E697, 1991.

Kovacs, P., Voight, B., Kloting, I. Novel Quantitative Trait Loci for Blood Pressure and Related Traits on Rat Chromosomes 1, 10, and 18. Biochem.Biophys.Res. Com. 235: 343348, 1997. 
Kren, V., Pravenec, M., Lu, S., Krenova, D., Wang, J-M., Wang, N., Merriouns, T., Wong, A., St.Lezin, E., Lau, D., Szpirer, C., Szpirer, J., Kurtz, T.W. Genetic Isolation of a Region of Chromosome 8 that Exerts Major Effects on Blood Pressure and Cardiac Mass in the Spontaneously Hypertensive Rat. J.Clin.Invest. 99: 577-581, 1997.

Krolewski, A.S., Canessa, M., Warram, J.H., Laffel, L.M.B., Christlieb, A.R., Knowler, W.C., Rand, L.I. Predisposition to Hypertension and Susceptibility to Renal Disease in Insulin-Dependent Diabetes Mellitus. New.Engl.J.Med. 318: 140-145, 1988.

Kubota, I., Fukuhara, T., Kinoshita, M. Permeability of Small Coronary Arteries and Myocardial Injury in Hypertensive Diabetic Rats. Internat.J.Cardiol. 29: 349-355, 1990.

Kurtz, T.W., Morris, R.C. Biological Variability in Wistar-Kyoto Rats: Implications for Research with the Spontaneously Hypertensive Rat. Hypertension 10: 127-131, 1987.

Kuwahara, Y., Yanagishita, T., Konno, N., Katagiri, T. Changes in Microsomal Membrane Phospholipids and Fatty Acids and in Activities of Membrane-Bound Enzyme in Diabetic Rat Heart. Bas.Res. Cardiol. 92: 214-222, 1997.

Laakso, M. Edelman, S.V., Brechtel, G., Baron, A.D. Impaired Insulin-Mediated Skeletal Muscle Blood Flow in Patients with NIDDM. Diabetes 41: 1076-1083, 1992.

Laakso, M. Edelman, S.V., Brechtel, G., Baron, A.D. Decreased Effect of Insulin to Stimulate Skeletal Muscle Blood Flow in Obese Man. J.Clin.Invest. 85: 1844-1852, 1990.

Lais, W.T., Brody, M.J. Vasoconstrictor Hyperresponsiveness: An Early Pathogenic Mechanism in the Spontaneously Hypertensive Rat. Eur.J.Pharmacol. 47: 177-189, 1978.

Landsberg, L., Young, J.B. Insulin-Mediated Glucose Metabolism in the Relationship Between Dietary Intake and Sympathetic Nervous System Activity. Internat.J.Obesity. 9(suppl 2): 63-68, 1985 .

LaPorte, R.E., Tajima, N., Akerblom, H.K. et al. Geographic Differences in the Risk of Insulin-Dependent Diabetes Mellitus: The Importance of Registries. Diabetes Care 8 (suppl. 1): 101-107, 1985.

Ledet, T., Neubauer, B., Christensen, N.J., Lundbaek, K. Diabetic Cardiopathy. Diabetologia 16: 207-209, 1979.

Lee, R.M.K.W., Triggle, C.R., Cheung, D.W.T., Coughlin, M.D. Structural and Functional Consequence of Neonatal Sympathectomy on the Blood Vessels of Spontaneously Hypertensive Rats. Hypertension 10: 328-338, 1987.

Lee, S.L., Ostadalova, I., Kolar, F., Dhalla, N.S. Alterations in $\mathrm{Ca}^{++}$-channels During the Development of Diabetic Cardiomyopathy. Mol.Cell.Biochem. 109: 173-179, 1992. 
Leitersdorf, E., Gottehrer, N., Fainaru, M., Friedlander, Y., Friedman, G., Tzivoni, D., Stein, Y. Analysis of Risk Factors in 532 Survivors "of First Myocardial Infarction Hospitalized in Jerusalem. Atherosclerosis 59: 75-93, 1986.

Lembo, G., Napoli, R., Capaldo, B., Rendina, V., Iaccarino, G., Volpe, M., Trimarco, B., Sacca, L. Abnormal Sympathetic Overactivity Evoked by Insulin in the Skeletal Muscle of Patients with Essential Hypertension. J.Clin.Invest. 90: 24-29, 1992.

Lembo, G., Rendina, V., Iaccarino, G., Lamenza, R., Volpe, M., Trimarco, B. Insulin Reduces Reflex Forearm Sympathetic Vasoconstriction in Healthy Humans. Hypertension 21: 1015-1019, 1993a.

Lembo, G., Rendina, V., Iaccarino, G., Lamenza, R., Volpe, M., Trimarco, B. Insulin does not Modulate Reflex Forearm Sympathetic Vasoconstriction in Patients with Essential Hypertension. J.Hyperten. 11 (suppl 5): S272-S273, 1993 b.

Lembo, G., Iaccarino, G., Vecchione, C., Rendina, V., Volpe, M., Trimarco, B. Insulin Modulation of Vascular Reactivity is Already Impaired in Prehypertensive Spontaneously Hypertensive Rats. Hypertension 26: 290-293, 1995.

Lopaschuk, G.D., Tahiliani, A.G., Vadlamudi, R.V.S.V., Katz, S., McNeill, J.H. Cardiac Sarcoplasmic Reticulum Function in Insulin or Carnitine-Treated Diabetic Rats. Am.J.Physiol. 245: H969-H976, 1983.

Lopaschuk, G.D., Spafford, M. Response of Isolated Working Hearts from Acutely and Chronically Diabetic Rats to Fatty Acids and Carnitine Palmitoyltransferase I Inhibition During Reduction of Coronary Flow. Circ.Res. 65: 378-387, 1989.

Lopaschuk, G.D. Abnormal Mechanical Function in Diabetes: Relationship to Altered Myocardial Carbohydrate/Lipid Metabolism. Coron.Art.Disease. 7: 116-123, 1996.

Mahler, R.J. Diabetes and Hypertension. Horm.Metab.Res. 22: 599-607, 1990.

Makino, N., Dhalla, K.S., Elimban, V., Dhalla, N.S. Sarcolemmal Ca ${ }^{++}$Transport in Streptozotocin-Induced Diabetic Cardiomyopathy in Rats. Am.J.Physiol. 253: E202E207, 1987.

Mall, G., Mann, J., Hasslacher, C., Mattfeldt, T., ritz, E., Onishi, S. Morphometric Study on the Rat Heart in Combined Revovascular Hypertension and Diabetes Mellitus: Evidence of Early Synergistic Effects on Myocytes. In: The Diabetic Heart. Edited by: Nagano, M., Dhalla, N.S. Raven Press. Ltd., New York, 1991.

Masiello, P., De Paoli, A.A., Bergamini, E. Influence of Age on the Sensitivity of the Rat to Streptozotocin. Hormone Res. 11: 262-274, 1979. 
Mayne, N. Neuropathy in the Diabetic and Non-Diabetic Populations. Lancet 2: 1313$1316,1965$.

McKee, P.A., Castelli, W.P., McNamara, P.M., Kannel, W.B. The Natural History of Congestive Heart Failure: the Framingham Study. N.Engl.J.Med. 285: 1441-1446, 1971.

McMurtry, J.P., Wexler, B.C. Hypersensitivity of Spontaneously Hypertensive Rats (SHR) to Heat, Ether, and Immobilization. Endocrinology 108: 1730-1736, 1981.

Mondon, C.E., Reaven, G.M. Evidence of Abnormalities of Insulin Metabolism in Rats with Spontaneous Hypertension. Metabolism 37: 303-305, 1988.

Mondon, C.E., Reaven, G.M., Azhar, S., Lee, C.M., Rabkin, R. Abnormal Insulin Metabolism by Specific Organs from Rats with Spontaneous Hypertension. Am.J.Physiol. 257: E491-E498, 1989.

Morgan, D.A., Balon, T.W., Mark, A.L. Hyperinsulinemia Produces Exaggerated Increases in Sympathoadrenal Activity in Spontaneously Hypertensive Rats. (Abstract). Hypertension 16: 339, 1990.

Nathan, D.M., Meigs, J., Singer, D.E. The Epidemiology of Cardiovascular Disease in Type 2 Diabetes Mellitus: How Sweet it is... or is it? Lancet 350 (Suppl 1): 4-9, 1997.

National Diabetes Data Group. Classification and Diagnosis of Diabetes Mellitus and Other Categories of Glucose Intolerance. Diabetes 28: 1039-1057, 1979.

Neely, J.R., Liebermeister, H., Battersby, E.J., Morgan, H.E. Effect of Pressure Development on Oxygen Consumption by Isolated Rat Heart. Am.J.Physiol. 212: 804$814,1967$.

Neely, J.R., Morgan, H.E. Relationship Between Carbohydrate Metabolism and Energy Balance of Heart Muscle. Ann.Rev.Physiol. 36: 413-459, 1974.

Neely, J.R., Rovetto, M.J. Techniques for Perfusing Isolated Rat Hearts. Cpt. 6. In: Methods in Enzymology, Volume XXXIX, Hormone Action. Edited by: Hardman, J.G., O'Malley, B.W. Academic Press, New York, 1975.

Nepom, G.T. A Unified Hypothesis for the Complex Genetics of HLA Associations with IDDM. Diabetes 39: 1153-1157, 1990.

Nerup, J., Platz, P., Andersen, O.O., Christy, M., Lyngsoe, J., Poulsen, J.E., Ryder, L.P., Thomsen, M., Nielsen, L.S., Svejgaard, A. HL-A Antigens and Diabetes Mellitus. Lancet 2: 864-866, 1974.

Nicholl, T.A., Lopaschuk, G.D., McNeill, J.H. Effects of Free Fatty Acids and Dichloroacetate on Isolated Working Diabetic Rat Heart. Am.J.Physiol. 261: H1053H1059, 1991. 
Oakley, W.G., Pyke, D.A., Tattersall, R.B., Watkins. P.J. Long-Term Diabetes. A Clinical Study of 92 Patients After 40 Years. Quart.J.Med. 43: 145-156, 1974.

Okamoto, H. Molecular Basis of Experimental Diabetes: Degeneration, Oncogenesis, and Regeneration of Pancreatic $\beta$-cells of Islets of Langerhans. Bioassays 2: 15-21, 1987.

Okamoto, K., Aoki, K. Development of a Strain of Spontaneously Hypertensive Rats. Jpn.Circ.J. 27: 202-293, 1963.

Opie, L.H. Effect of Fatty Acid on Contractility and Rhythm of the Heart. Nature (Lond) 227: 1055-1056, 1970.

Orrenius, S., McConkey, D.J., Bellomo, G., Nicotera, P. Role of $\mathrm{Ca}^{2+}$ in Toxic Cell Killing. TiPS 10: 281-285, 1989.

Paillole, C., Dahan, M., Paycha, F., Solal, A., Passa, P., Gourgon, R. Prevalence and Significance of Left Ventricular Filling Abnormalities Determined by Doppler Echocardiography in Young Type 1 (Insulin-Dependent) Diabetic Patients. Am.J.Cardiol. 64: 1010-1016, 1989.

Palmer, J.P., Asplin, C.M., Clemons, P., Lyne, K., Tatpati, O., Raghu, P.K., Paquette, T.L. Insulin Autoantibodies in Insulin-Dependent Diabetes Before Insulin Treatment. Science 222: 1337-1339, 1983.

Penpargkul, S., Schaible, T., Yipintsoi, T., Scheuer, J. The Effect of Diabetes on Performance and Metabolism of Rat Hearts. Circ.Res. 47: 911-921, 1980.

Penpargkul, S., Fein, F., Sonnenblick, E.H., Scheuer, J. Depressed Cardiac Sarcoplasmic Reticular Function from Diabetic Rats. J.Mol.Cell.Cardiol. 13: 303-309, 1981.

Petkov, O, Popova, N., Orbetsova, V., Kolarova, R., Dakovska, R. Changes in ECG, Plasma and Myocardial Lipids in Experimental Myocardial Hypertrophy in Rats. Basic.Res.Cardiol. 83: 296-305, 1988.

Pfeifle, B., Ditschuneit, H.H., Ditschuneit, H. Insulin as a Cellular Growth Regulator of Rat Arterial Smooth Muscle Cells In Vitro. Horm.Metab.Res. 12: 381-385, 1980.

Pfeifle, B., Ditschuneit, H. Effect of Insulin on Growth of Cultured Human Arterial Smooth Muscle Cells. Diabetologia 20: 155-158, 1981.

Pierce, G.N., Dhalla, N.S. Sarcolemmal $\mathrm{Na}^{+} / \mathrm{K}^{+}$-ATPase Activity in Diabetic Rat Heart. Am.J.Physiol. 252: H540-H544, 1987.

Pierce, G.N., Ramjiawan, B., Dhalla, N.S., Ferrari, R. $\mathrm{Na}^{+}-\mathrm{H}^{+}$Exchange in Cardiac Sarcolemmal Vesicles Isolated from Diabetic Rats. Am.J.Physiol. 258: H555-H561, 1990. 
Pierce, G.N., Russell, J.C. Regulation of Intracellular $\mathrm{Ca}^{++}$in the Heart During Diabetes. Cardiovasc.Res. 34: 41-47, 1997.

Pijl, A.J., van der Wal, A.C., Mathy, M-J., Kam, K.L., Hendriks, M.G.C., Pfaffendorf, M., van Zwieten, P.A. Streptozotocin-Induced Diabetes Mellitus in Spontaneously Hypertensive Rats: A Pathophysiological Model for the Combined Effects of Hypertension and Diabetes. J.Pharmacol.Toxicol.Methods. 32: 225-233, 1994.

Postnov, Y.V., Gorkova, S.I., Solovyova, L.P. Reduction of the $\beta$-Cell Component of Pancreatic Islets in Spontaneously Hypertensive Rats. Virch.Arch. 371: 79-87, 1976.

Pyke, D.A. Preamble: the History of Diabetes. In: International Textbook of Diabetes Mellitus, Second Edition. Edited by: Alberti, KGMM., Zimmet, P., DeFronzo, R.A., and Keen, H. John Wiley \& Sons Ltd., Toronto, 1997.

Randle, P.J., Hales, C.N., Garland, P.B., Newsholme, E.A. The Glucose Fatty Acid Cycle: Its Role in Insulin Sensitivity and the Metabolic Disturbances of Diabetes. Lancet 1: 785-789, 1963.

Reaven, G.M. Insulin Resistance, Hyperinsulinemia, and Hypertriglyceridemia in the Etiology and Clinical Course of Hypertension. Am.J.Med. 90(Suppl 2): 7-12, 1991.

Reaven, G.M., Ho, H. Low-Dose Streptozotocin-Induced Diabetes in the Spontaneously Hypertensive Rat. Metabolism 40: 335-337, 1991.

Regan, T.J., Ettinger, P.O., Kahn, M.I., Jesrani, M.U., Lyons, M.M., Oldewurtel, H.A., Weber, M. Altered Myocardial Function and Metabolism in Chronic Diabetes Mellitus Without Ischemia in Dogs. Circ.Res. 35: 222-237, 1974.

Regan, T.J., Lyons, M.M., Ahmed, S.S., Levinson, G.E., Oldewurtel, H.A., Ahmad, M.R., Haider, B. Evidence for Cardiomyopathy in Familial Diabetes Mellitus. J.Clin.Invest. 60: 885-899, 1977.

Ren, J., Davidoff, A.J. Diabetes Rapidly Induces Contractile Dysfunctions in Isolated Ventricular Myocytes. Am.J.Physiol. 41: H148-H158, 1997.

Ridray, S. Hyperinsulinemia and Smooth Muscle Cell Proliferation. Internat.J.Obesity. 19 (Suppl 1): S39-S51, 1995.

Rodgers, R.L. Depressor Effect of Diabetes in the Spontaneously Hypertensive Rat: Associated Changes in Heart Performance. Can.J.Physiol.Pharmacol. 64: 1177-1184, 1986.

Rodrigues, B., McNeill, J.H. Cardiac Function in Spontaneously Hypertensive Diabetic Rats. Am.J.Physiol. 251: H571-H580, 1986. 
Rodrigues, B., Goyal; R.K., McNeill, J.H. Effects of Hydralazine on StreptozotocinInduced Diabetic Rats: Prevention of Hyperlipidemia and Improvement in Cardiac Function. J.Pharm.Exp.Thera. 237: 292-299, 1986.

Rodrigues, B., Xiang, H., McNeill, J.H. Effect of L-Carnitine Treatment on Lipid Metabolism and Cardiac Performance in Chronically Diabetic Rats. Diabetes. 37: 13581364, 1988.

Rodrigues, B., McNeill, J.H. Cardiac Dysfunction in Isolated Perfused Hearts from Spontaneously Diabetic BB Rats. Can.J.Physiol.Pharmacol. 68: 514-518, 1990.

Rodrigues, B., Grassby, P.F., Battell, M.L., Lee, S.Y.N., McNeill, J.H. Hypertriglyceridemia in Experimental Diabetes: Relationship to Cardiac Dysfunction. Can.J.Physiol.Pharmacol. 72: 447-455, 1994.

Rodrigues, B., Cam, M.C., McNeill, J.H. Myocardial Substrate Metabolism: Implications for Diabetic Cardiomyopathy. J.Mol.Cell.Cardiol. 27: 169-179, 1995.

Rossing, P., Hougaard, P., Borch-Johnsen, K., Parving, H.H. Predictors of Mortality in Insulin Dependent Diabetes: 10 Year Observational Study. Br.Med.J. 313: 779-784, 1996.

Rowe, J.W., Young, J.B., Minaker, K.L., Stevens, A.L., Pallotta, J., Landsberg, L. Effect of Insulin and Glucose Infusions on Sympathetic Nervous System Activity in Normal Man. Diabetes 30: 219-225, 1981.

Rubler, S., Dlugash, J., Yuceoglu, Y.Z., Kumral, T., Branwood, A.W., Grishman, A. New Type of Cardiomyopathy Associated with Diabetic Glomerulosclerosis. Amer.J.Cardiol. 30: 595-602, 1972.

Sambandam, N., Chen, X., Cam. M.C., Rodrigues, B. Cardiac Lipoprotein Lipase in the Spontaneously Hypertensive Rat. Cardiovasc.Res. 33: 460-468, 1997.

Sato, T., Nara, Y., Kato, Y., Yamori, Y. Hypertensive Diabetic Rats: Different Effects of Streptozotocin Treatment on Blood Pressure in Adult SHR and in Neonatal SHR. Clin.Exper.Hyper.Theory.Pract. A13: 981-990, 1991.

Schnedl, W.J., Ferber, S., Johnson, J.H., Newgard, C.B. STZ Transport and Cytotoxicity, Specific Enhancement in Glut2-Expressing Cells. Diabetes 43: 1326-1332, 1994.

Sekikawa, A., LaPorte, R.E. Epidemiology of Insulin Dependent Diabetes Mellitus. In: International Textbook of Diabetes Mellitus, Second Edition. Edited by: Alberti, KGMM., Zimmet, P., DeFronzo, R.A., and Keen, H. John Wiley \& Sons Ltd., Toronto, 1997.

Sequist, E.R. Evidence for Genetic Susceptibility and Diabetic Nephropathy. N.Engl.J.Med. 320: 1161-1165, 1989. 
Shanmugam, M., Arroyo, L., Shehadeh, A., Regan, T.J. Alterations of Cardiac Function, Composition and Rhythm as a Consequence of Diabetes. In: The Heart in Diabetes. Edited by: Chatham, J.C., Forder, J.R., McNeill, J.H. Kluwer Academic Publishers, Norwell, 1996.

Shapiro, L.M., Leatherdale, B.A., Coyne, M.E., Fletcher, R.F., Mackinnon, J. Prospective Study of Heart Disease in Untreated Maturity Onset Diabetics. Br.Heart.J. 44: 342-348, 1980.

Shapiro, L.M., Howat, A.P., Calter, M.M. Left Ventricular Function in Diabetes Mellitus I: Methodology, and Prevalence and Spectrum of Abnormalities. Br.Heart.J. 45: 122128, 1981a.

Shapiro, L.M., Leatherdale, B.A., Coyne, M.E., Mackinnon, J., Fletcher, R.F. Left Ventricular Function in Diabetes Mellitus I: Relation Between Clinical Features and Left Ventricular Function, Br.Heart.J. 45: 129-132, 1981 b.

Siri, F.M., Malhotra, A., Factor, S.M., Sonnenblick, E.H., Fein, F.S. Prolonged Ejection Duration Helps to Maintain Pump Performance of the Renal-Hypertensive-Diabetic Rat Heart: Correlation Between Isolated Papillary Muscle Function and Ventricular Performance in Situ. Cardiovasc.Res. 34: 230-240, 1997.

Somani, P., Singh, H.P., Saini, K., Rabinovitch, A. Streptozotocin-Induced Diabetes in the Spontaneously Hypertensive Rat. Metabolism 28: 1075-1077, 1979.

Spiro, M.J., Crowley, T.J. Increased Rat Myocardial Type VI Collagen in Diabetes Mellitus and Hypertension. Diabetologia 36: 93-98, 1993.

Stamler, J., Vaccaro, O., Neaton, J.D. Wentworth, D. Diabetes, Other Risk Factors, and 12-yr Cardiovascular Mortality for Men Screened in the Multiple Risk Factor Intervention Trial. Diabetes Care 16: 434-444, 1993.

Steinberg, H.O., Brechtel, G., Johnson, A., Fineberg, N., Baron, A.D. Insulin-Mediated Skeletal Muscle Vasodilation is Nitric Oxide Dependent: a Novel Action of Insulin to Increase Nitric Oxide Release. J.Clin.Invest. 94: 1172-1179, 1994.

St. Lezin, E., Simonet, L., Pravenec, M., Kurtz, T.W. Hypertensive Strains and Normotensive "Control" Strains. How Closely are they Related? Hypertension 19: 419$424,1992$.

Strauer, B.E. Ventricular Function and Coronary Hemodynamics in Hypertensive Heart Disease. Am.J.Cardiol. 44: 999-1006, 1979.

Strauer, B.E., Motz, W., Vogt, M., Schwartzkopff, B. Impaired Coronary Flow Reserve in NIDDM: A Possible Role for Diabetic Cardiopathy in Humans. Diabetes 46 (Suppl. 2): S119-S124, 1997. 
Tahiliani, A.G., Vadlamudi, R.V.S.V., McNeill, J.H. Prevention and Reversal of Altered Myocardial Function in Diabetic Rats by Insulin Treatment. Can.J.Physiol.Pharmacol. 61: $516-523,1983$.

Takata, Y., Kato, H. Adrenoceptors in SHR: Alterations in Binding Characteristics and Intracellular Signal Transduction Pathways. Life.Sci. 58: 91-106, 1996.

Takenaka, K., Sakanioto, T., Amarro, K. Left Ventricular Filling Determined by Doppler Echocardiography in Diabetes Mellitus. Am.J.Cardiol. 61: 1140-1143, 1988.

Tanaka, Y., Shimizu, H., Sato, N., Mori, M., Shimomura, Y. Involvement of Spontaneous Nitric Oxide Production in the Diabetogenic Action of Streptozotocin. Pharmacology 50: 69-73, 1995.

Tanigawa, K., Xu, G., Nakamura, S., Kawaguchi, M., Kato, Y., Tamura, K. Impaired Compensatory Adaption to $\beta$-Cell Mass Reduction. Pancreas 12: 237-242, 1996.

Tarnow, L., Rossing, P., Gall, M-A., Nielsen, F.S., Parving, H-H. Prevalence of Arterial Hypertension in Diabetic Patients Before and After the JNC-V. Diabetes Care 17: 1247$1251,1994$.

Taylor, S.I., Accili, D., Imai, Y. Insulin Resistance or Insulin Deficiency. Which is the Primary Cause of NIDDM? Diabetes 43: 735-740, 1994.

Tischler, M.D. Clinical Abnormalities of Cardiac Function and Echocardiographic Tissue Characterization in Diabetes Mellitus. Coron.Artery.Dis. 7: 139-142, 1996.

Tomlinson, K.C., Gardiner, S.M., Hebden, R.A., Bennett, T. Functional Consequences of Streptozotocin-Induced Diabetes Mellitus, with Particular Reference to the Cardiovascular System. Pharmacol.Rev. 44: 104-150, 1992.

Uchigata, Y., Yamamoto, H., Kawamura, A., Okamoto, H. Protection by Superoxide Dismutase, Catalase, and Poly (ADP-ribose) Synthetase Inhibitors Against Alloxan- and Streptozotocin-induced Islet DNA Strand Breaks and Against the Inhibition of Proinsulin Synthesis. J.Biol.Chem. 257: 6084-6088, 1982.

Uusitupa, M.I.J., Niskanen, L.K., Siitonen, O., Voutilainen, E., Pyorala, K. 10-Year Cardiovascular Mortality in Relation to Risk Factors and Abnormalities in Lipoprotein Composition in Type-2 (Non-Insulin-Dependent) Diabetic and Non-Diabetic Subjects. Diabetologia 36: 1175-1184, 1993.

Uusitupa, M., Mustonen, J., Laakso, M., Vainio, P., Lansimies, E., Talwar, S., Pyorala, K. Impairment of Diastolic Function in Middle-Aged Type 1 (Insulin-Dependent) and Type 2 (Non-Insulin-Dependent) Diabetic Patients Free of Cardiovascular Disease. Diabetologia 31: 783-791, 1988. 
Vadlamudi, R.V.S.V., Rodgers, R.L., McNeill, J.H. The Effect of Chronic Alloxan- and. Streptozotocin-Induced Diabetes on Isolated Rat Heart Performance. Can.J.Physiol. Pharmacol. 60: 902-911, 1982.

Valle, T., Tuomilehto, J., Eriksson, J. Epidemiology of NIDDM in Europids. In: International Textbook of Diabetes Mellitus, Second Edition. Edited by: Alberti, KGMM., Zimmet, P., DeFronzo, R.A., and Keen, H. John Wiley \& Sons Ltd., Toronto, 1997.

van Hoeven, K.H., Factor, S.M. A Comparison of the Pathological Spectrum of Hypertensive, Diabetic, and Hypertensive-Diabetic Heart Disease. Circulation 82: 848$855,1990$.

van Zwieten, P.A., Kam, K.L., Pijl, A.J., Hendriks, M.G.C., Beenen, O.H.M., Pfaffendorf, M. Hypertensive Diabetic Rats in Pharmacological Studies. Pharmacol.Res. 33: $95-105,1996$.

Venco, A., Grandi, A., Barzizza, F., Finardi, G. Echocardiographic Features of Hypertensive-Diabetic Heart Muscle Disease. Cardiology 74: 28-34, 1987.

Verma, S., Bhanot, S., McNeill, J.H. Metformin Decreases Plasma Insulin Levels and Systolic Blood Pressure in Spontaneously Hypertensive Rats. Am.J.Physiol. 267: H1250H1253, 1994a.

Verma, S., Bhanot, S., McNeill, J.H. Antihypertensive Effects of Metformin in FructoseFed Hyperinsulinemic, Hypertensive Rats. J.Pharmacol.Exp.Therap. 271: 1334-1337, 1994b.

Verma, S., McNeill, J.H. Metformin Improves Cardiac Function in Isolated Streptozotocin-Diabetic Rat Hearts. Am.J.Physiol. 266: H714-H719, 1994.

Verma, S. Mechanisms of Hypertension in Hyperinsulinemic and Insulin Resistant Fructose Hypertensive Rats. Ph.D Thesis, 1997.

Verma, S., Bhanot, S., Yao, L., McNeill, J.H. Vascular Insulin Resistance in FructoseHypertensive Rats. Eur.J.Pharmacol. 322: R1-R2; 1997.

Verma, S., Arikawa, E., Yao, L., Laher, I., McNeill, J.H. Insulin-Induced Vasodilation is Dependent on Tetrahydrobiopterin Synthesis. Metabolism 47: 1037-1039, 1998.

Vollenweider, P., Tappy, L., Randin, D., Schneiter, P., Jequier, E., Nicod, P., Scherrer, U. Differential Effects of Hyperinsulinemia and Carbohydrate Metabolism on Sympathetic Nerve Activity and Muscle Blood Flow in Humans. J.Clin.Invest. 92: 147-154, 1993.

Von. Mering, J., Minkowski, O. Diabetes Mellitus nach Pankreasexextirpation. Arch.Exp.Pathol.Pharmakol. 26: 371-387, 1889. 
Voss, C., Moritz, V., Hartmann, K., Herrmann, I., von Dorsche, H.H., Zuhlke, H. Streptozotocin Diabetes in Spontaneously Hypertensive Rats. Exp.Clin.Endocrinol. 93: 231-240, 1989.

Wall, S.R., Lopaschuk, G.D. Glucose Oxidation Rates in Fatty Acid-Perfused Isolated Working Hearts from Diabetic Rats. Biochim.Biophys.Acta. 1006: 97-103, 1989.

Walters, D.P., Gatling, W., Mullee, M.A., Hill, R.D. The Prevalence, Detection, and Epidemiological Correlates of Peripheral Vascular Disease: A Comparison of Diabetic and Non-Diabetic Subjects in an English Community. Diabetic Med. 9: 710-715, 1992.

Yalow, R.S., Berson, S.A. Plasma Insulin Concentrations in Nondiabetic and Early Diabetic Subjects. Diabetes 9: 254-260, 1960 b.

Yamamoto, J., Nakai, M. Effects of Moderate Diabetes on Cardiac Performance in Spontaneously Hypertensive and Wistar-Kyoto Rats. Hypertension 11: 344-351, 1988.

Yamori, Y., Igawa, T., Kanabe, T., Kihara, M., Nara, Y., Horie, R. Mechanisms of Structural Vascular Changes in Genetic Hypertension: Analyses on Cultured Vascular Smooth Muscle Cells from Spontaneously Hypertensive Rats. Clin.Sci. 61 (Suppl 7): 121S-123S, 1981.

Yamori, Y. Physiopathology of the Various Strains of Spontaneously Hypertensive Rats. In: Hypertension, Physiopathology and Treatment. Edited by: Genest, J., Kuchel, O., Hamet, P., Cantin, M. McGraw-Hill Book Co., Montreal, 1983.

Yamori, Y. Development of the Spontaneously Hypertensive Rat (SHR) and of various Spontaneous Rat Models, and their Implications. In: Handbook of Hypertension, Vol. 4: Experimental and Genetic Models of Hypertension. Edited by: de Jong, W. Elsevier Science Publishers B.V., New York, 1984.

Young, J.B., Landsberg, L. Suppression of Sympathetic Nervous System During Fasting. Science 196: 1473-1475, 1977.

Yu, J.Z., Rodrigues, B., McNeill, J.H. Intracellular Calcium Levels are Unchanged in the Diabetic Heart. Cardiovasc.Res. 34: 91-98, 1997.

Zarich, S.W., Arbuckle, B.E., Cohen, L.R., Roberts, M., Nesto, R.W. Diastolic Abnormalities in Young Asymptomatic Diabetic Patients Assessed by Pulsed Doppler Echocardiography. J.Am.Coll.Cardiol. 12: 114-120, 1988.

Ziegler, A.G., Herskowitz, R.D., Jackson, R.A., Soeldner, J.S., Eisenbarth, G.S. Predicting Type 1 diabetes. Diabetes Care 13: 762-775, 1990. 